UNIVERSIDADE DE SÃO PAULO

FACULDADE DE MEDICINA DE RIBEIRÃO PRETO

DEPARTAMENTO DE BIOQUÍMICA E IMUNOLOGIA

LUMMY MARIA OLIVEIRA MONTEIRO

\title{
Deciphering the architecture/function relationship in complex bacterial promoters through Synthetic Biology approaches.
}


LUMMY MARIA OLIVEIRA MONTEIRO

Deciphering the architecture/function relationship in complex bacterial promoters through Synthetic Biology approaches.

Tese de Doutorado apresentada à Faculdade de Medicina de Ribeirão Preto da Universidade de São Paulo para obtenção do Título de Doutor em Ciências - Área de Concentração: Bioquímica.

Orientador: Prof. Dr. Rafael Silva Rocha.

RIBEIRÃO PRETO 
Autorizo a reprodução e divulgação total ou parcial deste trabalho, por qualquer meio convencional ou eletrônico, para fins de estudo e pesquisa, desde que citada a fonte.

Monteiro, Lummy Maria Oliveira

Desvendando as relações arquitetura/função de promotores bacterianos complexos utilizando abordagens de biologia sintética. Ribeirão Preto, 2020.

99 p.: il. ; $30 \mathrm{~cm}$

Tese de Doutorado, apresentada à Faculdade de Medicina de Ribeirão Preto/USP. Área de concentração: Bioquímica.

Orientador: Silva-Rocha, Rafael.

1. Regulação gênica; 2. Promotores Complexos; 3. Fatores de Transcrição; 4. Engenharia de Proteínas; 5 . Design de circuitos; 6 . Machine Learning 
Monteiro, L.M.O. Deciphering the architecture/function relationship in complex bacterial promoters through Synthetic Biology approaches. Tese apresentada à Faculdade de Medicina de Ribeirão Preto da Universidade de São Paulo para obtenção do Título de Doutor em Ciências - Área de Concentração: Bioquímica. Ribeirão Preto, 2020.

Aprovado em:

\section{Banca Examinadora}

Prof. Dr. Instituição:

Julgamento: Assinatura:

Prof. Dr. Instituição:

Julgamento: Assinatura:

Prof. Dr. Instituição:

Julgamento: Assinatura:

Prof. Dr. Instituição:

Julgamento: Assinatura: 


\section{AGRADECIMENTOS}

Na realização de um trabalho científico como este, se faz necessário a colaboração de pessoas e instituições para o bom desenvolvimento do mesmo, desde o projeto até 0 trabalho final. Assim como a participação ativa da família e amigos, que contribuem de forma essencial para seguir em frente e atingir com êxito aos objetivos estabelecidos. Dessa maneira, torna-se fundamental, agradecer a elas. Em especial, quero expressar meus sinceros agradecimentos:

Ao povo brasileiro, que com muita dificuldade financia a ciência em nosso país;

À minha família, Cassiana, Maria Helena, Ocacílio, Alessandro, Alexandre Filho (Fi), Felipinho e Alexandre, que mesmo de longe estão sempre ao meu lado me incentivando, acreditando no meu potencial, financiando meus sonhos e vibrando a cada conquista. Sem vocês, nada teria sido possível! O suporte de vocês foi essencial para que eu pudesse ir mais longe! Amo vocês;

Ao Jonathan, por todo amor e suporte, por apoiar todas as minhas decisões mesmo quando elas me levam para o outro lado do oceano. Obrigada por fazer toda distância parecer insignificante. "You are my lobster!". Por ter trazido com você uma segunda família para mim. Fran, Silvino e Bruna, muito obrigada por todo apoio, carinho e incentivo. Vocês são a minha família em $\mathrm{SP}$;

Ao meu orientador, Prof. Dr. Rafael Silva-Rocha, a quem eu sou muito grata por tudo 0 que aconteceu durante o Doutorado. Obrigada por ter acreditado em mim desde a nossa primeira conversa na FMRP, mesmo quando eu ainda não sabia quase nada de Biologia Sintética. Por todas as oportunidades e portas que você abriu para mim; se hoje defendo esse trabalho, foi porque tive seu apoio em todas as etapas;

Aos amigos do SSBLab: Léo, Greicy, Kauan, Luisa, Ananda, Juliana, Murilo, Bianca, Ninna e Felipe, agradeço por terem tornado melhor todos os dias de trabalho. Obrigada pelos ensinamentos e disponibilidade, por todas as nossas discussões produtivas, cafés e risadas! Aprendi muito com vocês! Um agradecimento bem especial à Claudinha, por todo carinho e amizade! Vou sentir saudades dos nossos cafezinhos pra começarmos bem o nosso dia de trabalho!

À Prof. Maria Eugenia Guazzaroni e aos amigos do Laboratório de Metagenômica Funcional, Luana, Guilherme, Gabriel, Tiago e Ítalo, por toda amizade e ensinamentos. Muito obrigada por toda orientação, sugestões de experimentos, colaborações em trabalhos e discussões científicas ao longo desses 4 anos. 
À Universidade de São Paulo, Faculdade de Medicina de Ribeirão Preto e ao Programa de pós-graduação em Bioquímica pelo ensino público de qualidade. À Ivone pela disponibilidade e atenção com todos nós!

To my supervisor in Germany, Dr. Ulisses Nunes da Rocha, for having welcomed me into his group for one year, for guiding me in the best way possible. For having believed in our project, many times even more than myself; for helping me in every detail. I grew up a lot in your group and I am extremely grateful for all the teachings I received. I learned to believe in my potential and to see science with more "Why? How? and What?".

Many thanks to Ulisses, João, Felipe, Rodolfo, Natascha, Junia, Havva, N'afiu, René, and Nicole for all assistance during 2019 at UFZ/UMB. I learned so much and I had a great time of my professional life with you. To all my amazing friends in Germany: Junia, Natascha, Felipe, Rodolfo, Mayara, Ruan, Juliana, Gabriela, Joyce, Laszlon, Bruna, Adriana, Canan, Peter, Amir, Krupa, Xin, Francesco, Fernando, Bijing, Swamini, Judith and Katharina. If my days in Germany were the best days of my life, it was because I had you guys participating of these incredible months;

To Helmholtz Centre for Environmental Research (UFZ), which received me as a guest scientist for one year and which during that time opened doors from all researchers and laboratories to me. It also showed me how productive it is to work at a research institute and that is possible to have a non-competitive work environment, with generosity and empathy.

Às minhas amigas Cataguasenses e aos amigos da BQI/UFV que longe ou perto estão sempre me apoiando e torcendo pelo meu sucesso.

À Fundação de Amparo à Pesquisa do Estado de São Paulo (FAPESP) (Processos: 2016/19179-9 e 2018/21133-2) pelo apoio financeiro no Brasil e no exterior. À Coordenação de Aperfeiçoamento de Pessoal de Nível Superior (CAPES), e ao Conselho Nacional de Desenvolvimento Científico e Tecnológico (CNPq), pelo apoio financeiro, imprescindível para a realização deste trabalho.

A todos que me inspiraram, incentivaram e auxiliaram, o meu muito obrigada por fazerem parte dos quatro anos mais importantes e incriveis da minha vida (até agora).

E que venham os novos desafios! 
"Around here, however, we don't look backwards for very long. We keep moving forward, opening up new doors and doing new things, because we're curious...and curiosity keeps leading us down new paths." 


\section{GENERAL INDEX}

RESUMO

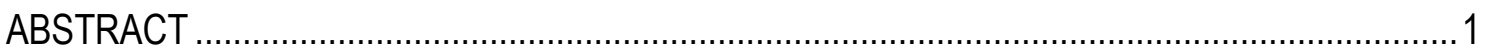

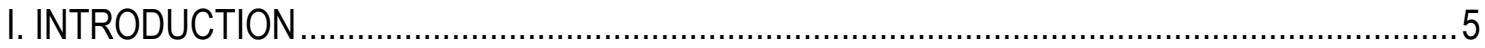

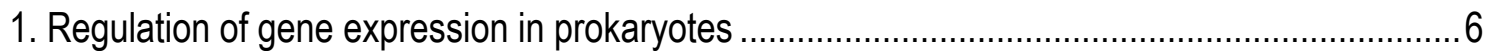

2. Transcription Factors and Signal Integration in Bacterial Promoters ....................................... 8

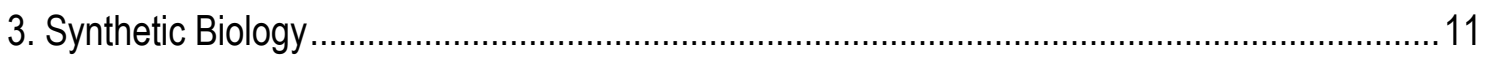

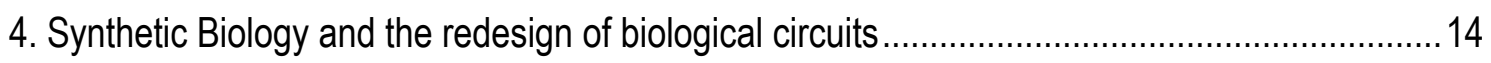

5. Synthetic biology and the development of bioinformatics tools to explore the microbial

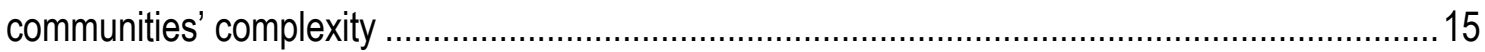

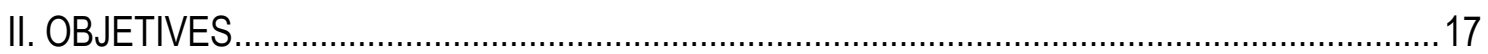

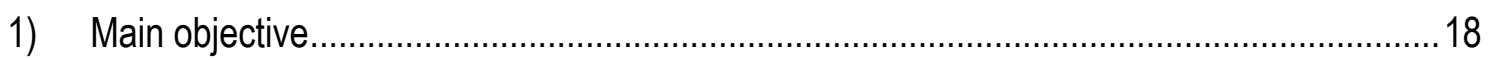

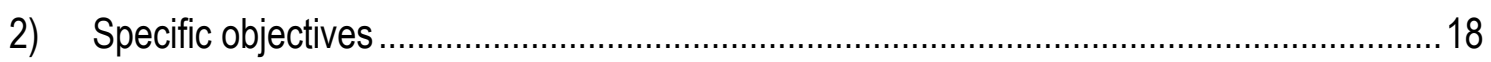

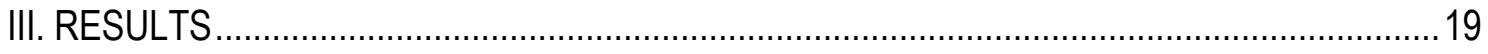

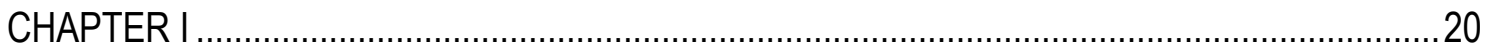

Emergent Properties in Complex Synthetic Bacterial Promoters ........................................20

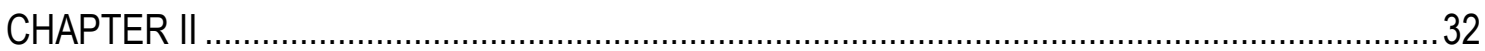

Unraveling the Complex Interplay of Fis and IHF Through Synthetic Promoter Engineering 32

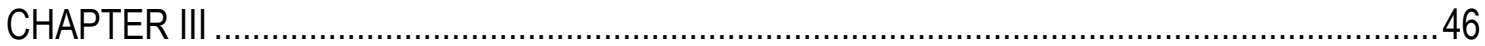

Reverse Engineering of an Aspirin-Responsive Transcriptional Regulator in Escherichia coli .46

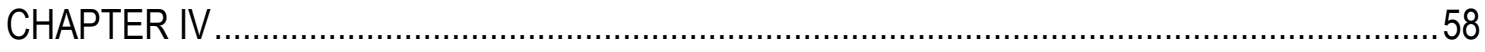

PredicTF: a tool to predict bacterial transcription factors in complex microbial communities 58

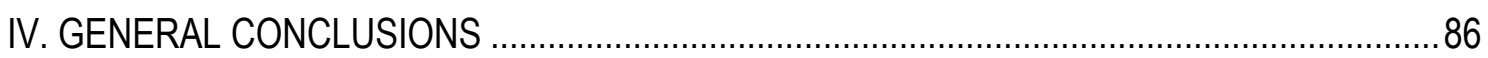

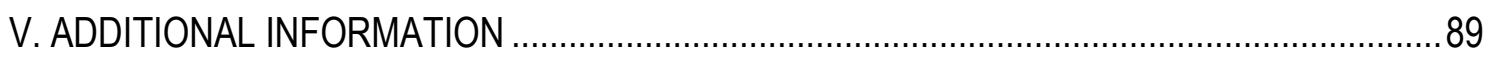

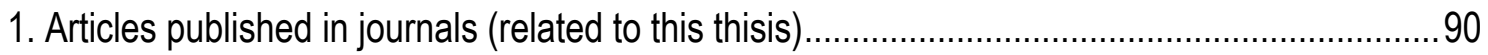

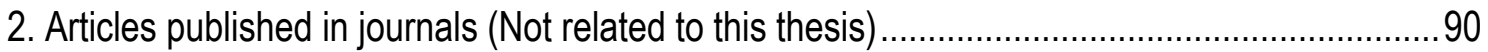

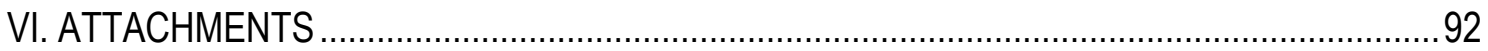

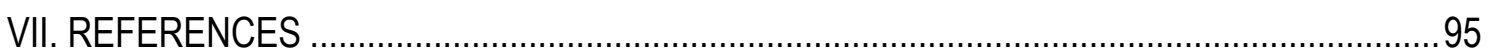


RESUMO 
Monteiro, L.M.O. Desvendando as relações arquitetura/função de promotores bacterianos complexos utilizando abordagens de biologia sintética. Tese de Doutorado. Faculdade de Medicina de Ribeirão Preto, Ribeirão Preto, 2020.

A regulação gênica tem sido estudada extensivamente, no entanto, a complexidade dos mecanismos regulatórios ainda permanece desconhecida. Entender os mecanismos da regulação gênica é importante não apenas para desvendar a complexidade de um organismo, mas para postular novas regras, caracterizar novas partes biológicas e então permitir novos designs de circuitos biológicos, por exemplo. Uma possível estratégia para desvendar os mecanismos de ação e complexidade dos promotores bacterianos seria combinar o conhecimento da regulação gênica com o uso de abordagens da biologia sintética e da bioinformática, que, por sua vez, permitem projetar e construir novas funções em sistemas biológicos. 0 progresso na biologia sintética é frequentemente possibilitado por poderosas ferramentas de bioinformática que permitem a integração das fases de design, construção e teste do ciclo de engenharia biológica. Consequentemente, o desenvolvimento de novas ferramentas de bioinformática é útil e importante para os cientistas que trabalham para estender ou modificar o comportamento dos organismos e projetá-los para realizar novas tarefas. Nesse contexto, a presente tese descreveu (i) a existência de propriedades emergentes em promotores sintéticos complexos em Escherichia coli, que poderiam ser extrapoladas para sistemas regulatórios de ocorrência natural e impactariam significativamente a engenharia de circuitos biológicos sintéticos em bactérias. Em resumo, esses dados demonstram como pequenas mudanças na arquitetura dos promotores bacterianos podem resultar em mudanças drásticas na lógica regulatória final do sistema, com implicações importantes na compreensão de promotores complexos naturais em bactérias e sua engenharia para novas aplicações; (ii) o mecanismo de reconhecimento do indutor de dois reguladores AraC/XylS de Pseudomonas putida (BenR e XylS) para a criação de um novo sistema de expressão responsivo ao ácido acetil salicílico (aspirina). Usando homologia de proteínas e docking molecular com o indutor benzoato e um conjunto de análogos químicos, identificamos 0 sítio de ligação conservado dessas duas proteínas. Como resultado, uma coleção de fatores de transcrição (TFs) engenheirados foram gerados com respostas aprimoradas a uma molécula bem caracterizada e amplamente inócua com um potencial para induzir a expressão heteróloga de genes bacterianos em animais; (iii) a complexidade dos fatores de transcrição em comunidades microbianas ambientais. Criamos um banco de dados de fatores de transcrição bacteriano (BacTFDB) que foi usado para treinar um modelo de Machine Learning para prever novos TFs e suas famílias em amostras metagenômicas e metranscriptômicas (PredicTF). PredicTF fornece a primeira ferramenta para traçar o perfil de TFs em bactérias ainda a serem cultivadas e abre 0 potencial para avaliar redes regulatórias em comunidades microbianas complexas. PredicTF é um pipeline de código aberto flexível capaz de prever e anotar TFs em genomas e metagenomas. PredicTF está disponível em https://github.com/mdsufz/PredicTF.

Palavras chaves: Regulação gênica, Promotores Complexos, Fatores de Transcrição, Engenharia de Proteínas, Design de circuitos, Machine Learning. 
ABSTRACT 
Monteiro, L.M.O. Deciphering the architecture/function relationship in complex bacterial promoters through Synthetic Biology approaches. Doctoral Thesis. Ribeirão Preto Medical School, Ribeirão Preto, 2020.

Gene regulation has been studied extensively, however the complexity of the regulatory mechanisms still remains unknown. Understanding how gene regulation occurs is important not only to better understand the complexity of an organism but to postulate new rules, characterize new biological parts and then allow new design of biological circuits, for example. A possible strategy to unravel the mechanisms of action and complexity of bacterial promoters would be to combine the knowledge of gene regulation with the use of approaches from synthetic biology and bioinformatics, which, in turn, allow to design and build new functions in biological systems. Progress in synthetic biology is often made possible by powerful bioinformatics tools that allow the integration of the design, construction and testing stages of the biological engineering cycle. Consequently, the development of new bioinformatics tools is useful and important for scientists working on the design, development and testing of parts to extend or modify the behavior of organisms and design them to perform new tasks. In this context, the present thesis described (i) the existence of emergent properties in complex synthetic promoters in Escherichia coli, which could be extrapolated to naturally occurring regulatory systems and would significantly impact the engineering of synthetic biological circuits in bacteria. Taken together, these data demonstrate how small changes in the architecture of bacterial promoters could result in drastic changes in the final regulatory logic of the system, with important implications for the understanding of natural complex promoters in bacteria and their engineering for novel applications; (ii) the inducer recognition mechanism of two AraC/XyIS regulators from Pseudomonas putida (BenR and XyIS) for creating a novel expression system responsive to acetyl salicylate (i.e. Aspirin). Using protein homology modeling and molecular docking with the cognate inducer benzoate and a suite of chemical analogues, we identified the conserved binding pocket of these two proteins. As a result, a collection of engineered transcription factors (TFs) was generated with enhanced response to a well characterized and largely innocuous molecule with a potential for eliciting heterologous expression of bacterial genes in animal carriers; (iii) the complexity of transcription factors in environmental communities. We created one bacterial transcription factor database (BacTFDB) that was used to train a deep learning model to predict novel TFs and their families in metagenomics and metranscriptomics samples (PredicTF). PredicTF provides the first tool to profile TFs in yet-to be cultured bacteria and it opens the potential to evaluate regulatory networks in complex microbial communities. PredicTF is a flexible, open source pipeline able to predict and annotate TFs in genomes and metagenomes. PredicTF is available at https://github.com/mdsufz/PredicTF.

Key words: Gene Regulation, Complex Promoters, Transcription Factors, Protein Engineering, Design of Circuits, Machine Learning. 
I. INTRODUCTION 


\section{Regulation of gene expression in prokaryotes}

Living organisms have mechanisms associated with the process of maintaining life. Considering the objectives of such processes, these could be basically grouped into two broad categories. The first would comprise processes of a structural nature, that is, related to the conversion of energy and raw material into new components necessary for the maintenance and growth of the cell. The second category would comprise processes of a regulatory nature, that is, those dedicated to the control of processes belonging to the first category. This second group has the function of coordinating the different cellular processes depending on factors present in the external and intracellular environment, necessary for the cell to maximize the use of the limited resources available in the environment. According to our current knowledge, the main mechanism for controlling cellular processes is obtained through the regulation of gene expression. The importance of adequate control of gene expression is so great that the greater the complexity of organisms, the greater the sophistication and the abundance of molecular mechanisms used for this purpose (Cases et al., 2003; Konstantinidis and Tiedje, 2004; Koonin and Wolf, 2008).

The regulation of gene expression can be defined as the regulation of information encoded in the gene to result in a gene product or function. It includes a wide variety of mechanisms that are used by cells to increase or decrease the production of specific gene products, such as proteins or RNA. Sophisticated gene expression programs can be observed in biology, for example, to trigger developmental pathways, respond to environmental stimuli or adapt to new food sources. Virtually any step of gene expression can be modulated, from initiation of transcription, processing of RNA, to post-translational modification of a protein. Often, one regulatory gene control another, and so on, in a transcriptional network. Gene regulation is therefore essential for all organisms, as it increases the versatility and adaptability of organisms, allowing the cell to express a protein when needed (Singleton, 2009). 
Prokaryotes, since they have a simpler genetic structure compared to eukaryotes (Lawrence, 1999), and as they have easy tools for efficient genetic manipulation (Sambrook et al., 1989), can be considered a good experimental model for the search and the study of mechanisms associated with the control of gene expression (Silva-Rocha and De Lorenzo, 2010; Gama-Castro et al., 2016). Bacteria use a variety of mechanisms to target RNA polymerase to specific promoters in order to activate transcription in response to growth signals or environmental stimuli. Activation can occur due to factors that somehow interact with specific promoters, increasing the transcription directed by these promoters. Alternatively, activation may be due to factors that interact with RNA polymerase, changing their preferences for target promoters (Browning and Busby, 2004).

Bacterial transcription occurs due to the action of the DNA-dependent multi-subunit RNA polymerase enzyme, which is able to synthesize RNA, but is unable to locate promoters. A sigma subunit is necessary for bacterial RNA polymerase to recognize a promoter. The promoters, therefore, control the transcription of all genes, since the initiation of transcription requires the interaction of the promoter with RNA polymerase forming an open complex. The key step in the initiation of transcription is the recognition of the promoter by RNA polymerase, and different elements of DNA sequence responsible for this have been studied (Browning and Busby, 2004).

Both the recognition of the promoter by RNA polymerase and its activity are regulated by a series of transcriptional factors (TFs) that join areas adjacent to the union region of this enzyme (Browning and Busby, 2004). These TFs can modulate the activity of target promoters in a positive (in the case of activators) or negative (repressive) ways through a variety of mechanisms (Browning and Busby, 2004). In turn, TFs modulate gene expression, through different mechanisms, such as the DNA binding affinity for TFs, which can be modulated by small ligands or by covalent modifications, and, in addition, changes in cell concentration of TFs can control promoter activity. Finally, TF can be sequestered by a regulatory protein which binds to it and consequently 
modulates its activity (Browning and Busby, 2016). The main TFs in Eschericha coli, as well as the mechanisms of gene regulation, will be better described in the following topics.

\section{Transcription Factors and Signal Integration in Bacterial Promoters}

The Escherichia coli genome has more than 300 genes that encode proteins that are able to bind to promoters, regulating transcription in a positive or negative way. Most of these proteins are specific DNA-binding molecules and this ensures that their actions are targeted at specific promoters. Many of these proteins control a vast number of genes, while others control only few genes (Martínez-Antonio et al., 2003; Browning and Busby, 2004). It is estimated that the seven transcription factors CRP, FNR, IHF, Fis, ArcA, NarL and Lrp, are capable of controlling $50 \%$ of all E. coli genes, while another 60 transcription factors are capable of controlling only one sole promoter (Martínez-Antonio et al., 2003). In this sense, TFs with a larger repertoire of targets are known as global regulators and coordinate the expression of the various genes according to priority stimuli, such as carbon source, oxygen concentration, physiological state of the cell, etc (MartínezAntonio et al., 2003; Browning and Busby, 2004).

In the context of gene expression modulation, repressors bind to DNA targets that overlap essential elements at their target promoters, thereby occluding access of RNA polymerase (Figure 1A) (Bintu et al., 2005b, 2005a). In many cases, repression is enhanced by multiple binding of repressor molecules, which at some promoters bind distally to each other and interact with each other via DNA loops (Figure 1B). At other promoters, RNA polymerase is able to engage but is blocked at the promoter by the repressor (Figure 1C). Most bacterial transcription factors that function as activators bind to DNA targets located just upstream of the essential elements at their target promoters (Lee et al., 2012). Such factors often interact with RNA polymerase, and this results in its recruitment to the target promoter, thereby increasing transcript initiation (Figure 2D) (Busby and Ebright, 1994). The activation surface on the factor, known as the Activating Region, 
is usually composed of a small cluster of amino acid sidechains that make direct contact with a cognate surface somewhere on RNA polymerase, usually on Domain 4 of the RNA polymerase sigma subunit or the C-terminal domain of the RNA polymerase alpha subunit. Other activators induce conformation changes in promoter DNA that result in adjustment in the spacing between different essential elements such that they can be served by RNA polymerase (Figure 2E) (Brown et al., 2003). For the majority of activators that function at promoters served by RNA polymerase carrying the "housekeeping" sigma factor (or one related to the housekeeping sigma), transcript activation occurs without any major conformation change in the RNA polymerase. However, for RNA polymerase carrying a sigma factor related to Sigma- 54 , this is not the case, as major conformation changes are required for transcript initiation (Yang et al., 2015). These conformation changes are driven by activator- RNA polymerase interactions energized by ATP hydrolysis by a special class of activators known as enhancer-binding proteins (Huo et al., 2009).

Molecular analysis of the regulatory regions of many bacterial transcription units has shown that they are often not simple, with the involvement of many different transcription factors (Barnard et al., 2004). Since the activity of most bacterial transcription factors is regulated by just one signal, we can regard bacterial promoters as integration devices converting messages from the different factors into a single output. Hence, here, we consider three classes of promoters: those controlled by both an activator and a repressor, those controlled just by repressors, and those controlled by two activators. 
(a) Repression by Steric Hindrance.

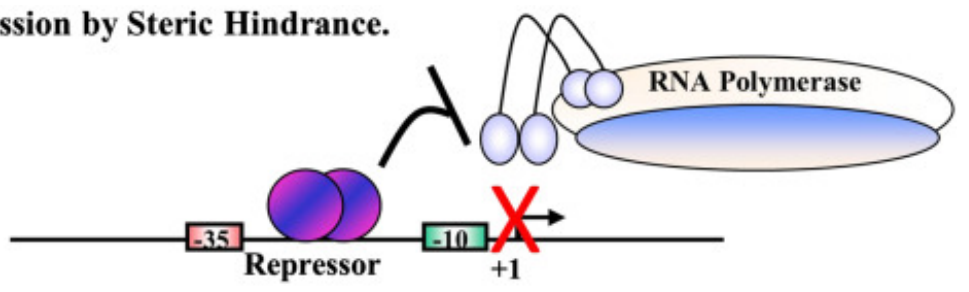

(b) Repression by Looping.

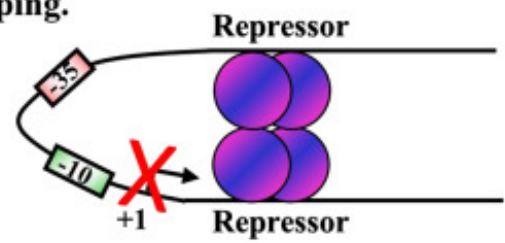

(c) Repression by Locking RNA Polymerase at a Promoter.

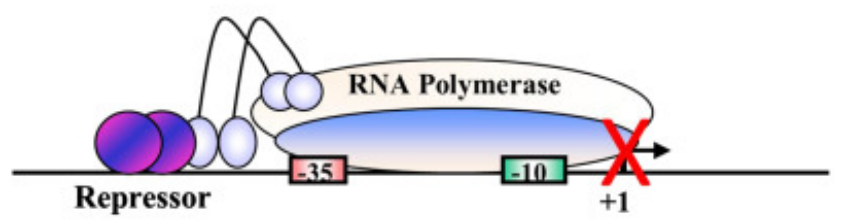

(d) Simple Activation.

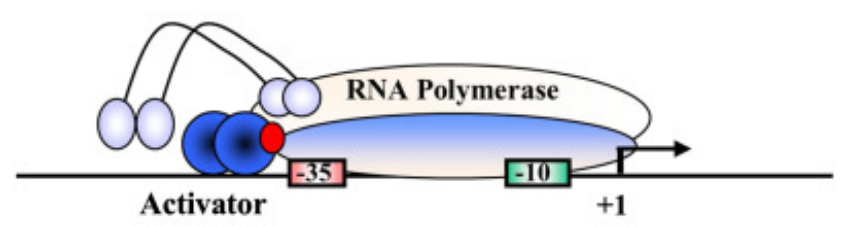

(e) Activation by Conformation Change.

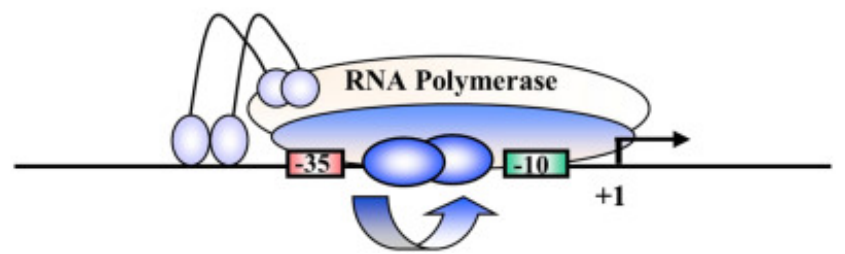

Figure 1. Mechanisms of repression and activation by transcription factors at bacterial promoters. In each panel, the target promoter region is shown as a line with different promoter elements shown by rectangles, and the transcript start, marked +1 , indicated with a bent arrow that shows the direction of transcription. Transcription factors are shown as circular or oval dimers. The multisubunit RNA polymerase is sketched, as in Fig. 1, with the two catalytic subunits, $\beta$ and $\beta$ ', drawn as a larger oval, the sigma subunit drawn as a smaller darker-shaded oval, and each of the two a subunits drawn as a dumbbell with a curved line to illustrate the flexible linker between the $\mathrm{N}$ - and C-terminal domains (illustrated by the two lobes of each dumbbell). (a) A repressor binds adjacent to key promoter elements and prevents RNA polymerase engagement. (b) Repressor dimers bind at some distance from promoter elements but interact, thereby preventing RNA polymerase access to the promoter. (c) RNA polymerase binds to the promoter but is jammed by repressor binding. (d) Activator provides direct contact (small circle) with RNA polymerase, thereby recruiting RNA polymerase to the promoter and facilitating transcript initiation. (e) Activator alters the juxtaposition of essential promoter elements so as to enable RNA polymerase binding and subsequent transcript initiation. Figure taken from Busby, 2019 (Browning et al., 2019). 


\section{Synthetic Biology}

Synthetic biology is a young discipline that seeks to design and construct new biological entities such as enzymes, genetic circuits, and cells or the redesign of existing biological systems. The goal of synthetic biology is to extend or modify the behavior of organisms and engineer them to perform new tasks. One useful analogy to conceptualize both the goal and methods of synthetic biology is the computer engineering hierarchy (Figure 2) (Andrianantoandro et al., 2006). Within the hierarchy, every constituent part is embedded in a more complex system that provides its context. Design of new behavior occurs with the top of the hierarchy in mind but is implemented bottom-up (Andrianantoandro et al., 2006). At the bottom of the hierarchy are, for example, DNA, RNA, proteins, and metabolites (including lipids and carbohydrates, amino acids, and nucleotides), analogous to the physical layer of transistors, capacitors, and resistors in computer engineering. At the next layer, are biochemical reactions that regulate the flow of information responsible for physical processes, equivalent to engineered logic gates that perform computations in a computer. At the module layer, the synthetic biologist uses a diverse library of biological devices to assemble complex pathways that function like integrated circuits. The connection of these modules to each other and their integration into host cells allows the synthetic biologist to extend or modify the behavior of cells (Andrianantoandro et al., 2006). 

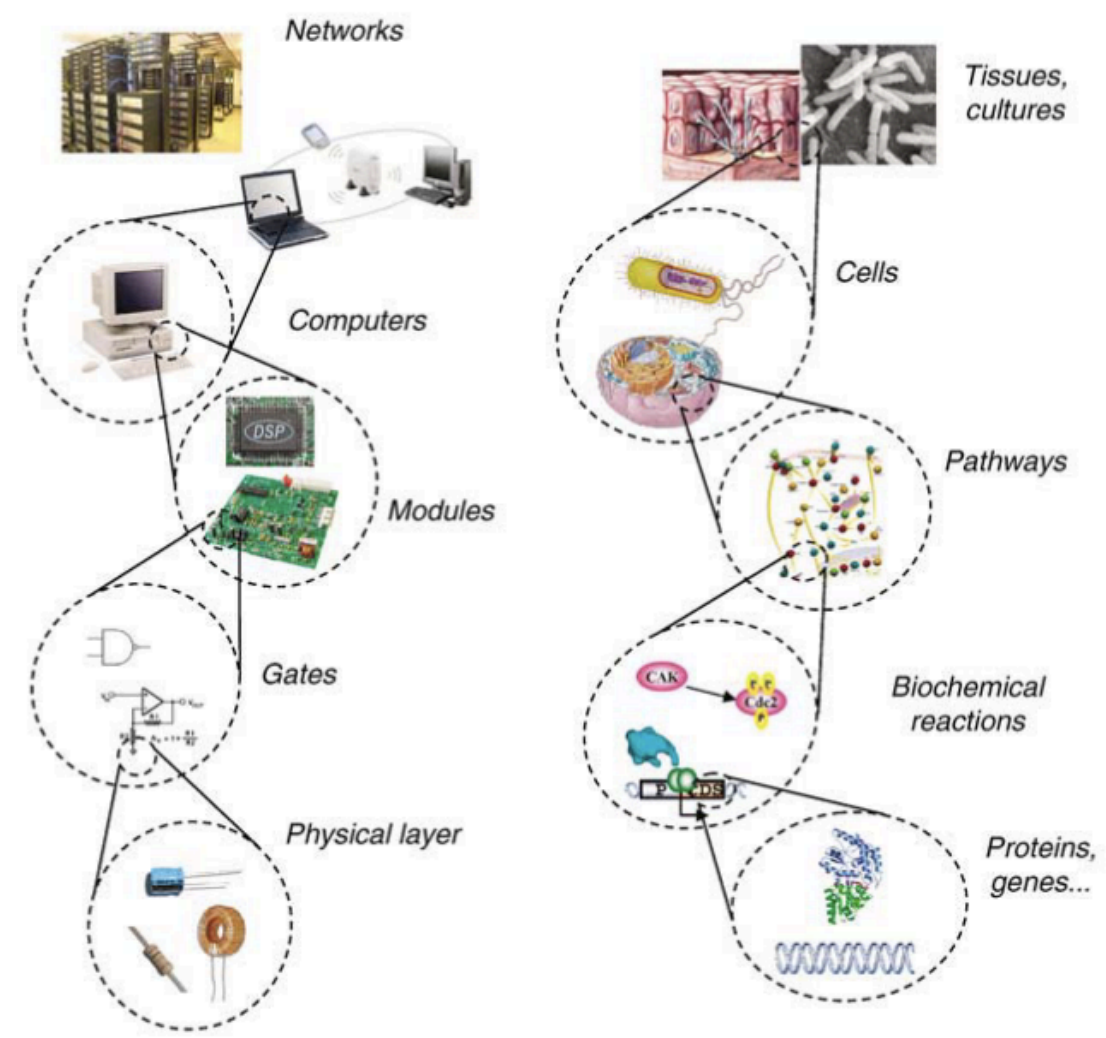

Figure 2. A possible hierarchy for synthetic biology is inspired by computer engineering. Figure taken from Andrianantoandro, 2006 (Andrianantoandro et al., 2006).

The Synthetic biology fundaments goes through the designing of a new biological entity using bioinformatics or modelling approaches, the building of an entity by DNA design and synthesis, the testing or validation of the project using, for example, automated genomes or plasmid engineering and finally, the learning by assessment and enrichment of engineering biological parts (Figure 3). Thus, synthetic biologists have several objectives to be achieved as design and build engineered biological systems. Synthetic biology includes several working to develop like: 1) Standardized biological parts - identify and catalog the standardized genomic parts that can be used (and quickly synthesized) to build new biological systems (Elowitz and Lim, 2010; Way et al., 2014; Sanches-Medeiros et al., 2018); 2) Applied protein design - redesigning the existing biological parts and expanding the set of functions of the natural protein to new processes (Hyeon et al., 2016a; Liu and Chen, 2016; Wang et al., 2018); 3) Natural product synthesis - design microbes to produce all the enzymes and biological functions needed to perform complex multi- 
stage production of natural products (Hyeon et al., 2016b; Noda et al., 2016; Siu et al., 2017); and

4) Synthetic genomics - design and build a "simple" genome for a natural bacterium (Zhang and Voytas, 2018; Zhang et al., 2020).

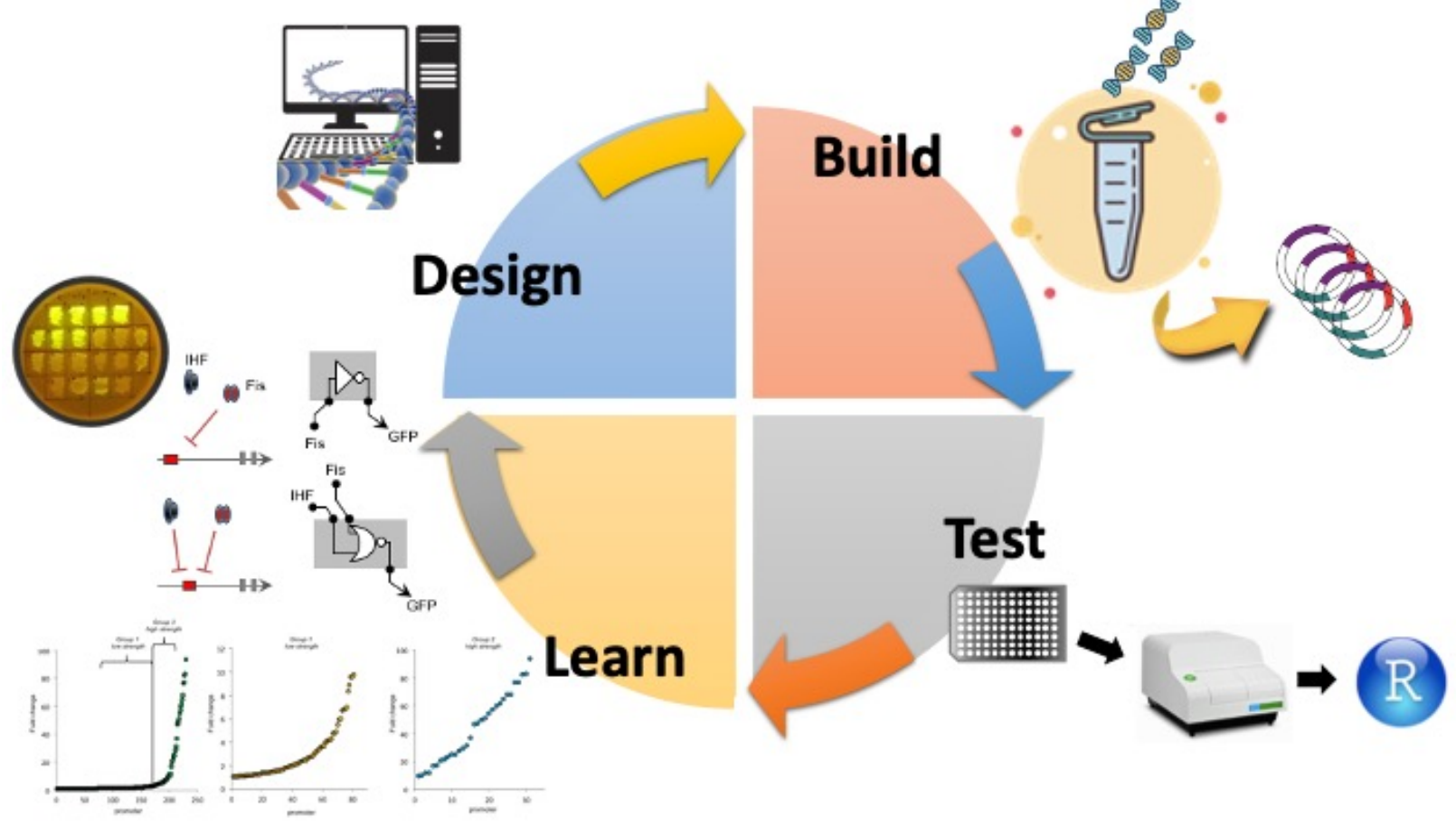

Figure 3. Synthetic biology fundaments. Desing, Build, Test, Learning.

The element that distinguishes synthetic biology from traditional molecular and cellular biology is the focus on the design and construction of core components (parts of enzymes, genetic circuits, metabolic pathways, etc.) that can be modeled, understood, and tuned to meet specific performance criteria, and the assembly of these smaller parts and devices into larger integrated systems to solve specific problems (Khalil and Collins, 2010; Deplazes-Zemp, 2012). Unlike many other areas of engineering, biology is incredibly non-linear and less predictable, and there is less knowledge of the parts and how they interact. Hence, the overwhelming physical details of natural biology (gene sequences, protein properties, biological systems) must be organized and recast via a set of design rules that hide information and manage complexity, thereby enabling the 
engineering of many-component integrated biological systems. It is only when this is accomplished that designs of significant scale will be possible (Benner and Sismour, 2005; Cameron et al., 2014).

\section{Synthetic Biology and the redesign of biological circuits}

The use of logical models for the analysis of regulatory networks, as well as the implementation of new "logic gates" in biological networks through the engineering of regulatory elements, belong to the field of Synthetic Biology (Cameron et al., 2014). Synthetic Biology seeks to reprogram biological circuits in order to modify living systems, generating new behaviors of interest in fields such as biotechnology (Cameron et al., 2014). An advantage of this approach is that the process of reissuing the regulatory network also allows unveiling unknown properties of these systems, which could not be found through classical strategies. Thus, Synthetic Biology allows to explore these properties of the regulatory networks in addition to generating practical knowledge about the study systems, considering that the ultimate goal of this field is to generate a biological system with new properties (Andrianantoandro et al., 2006).

Two main approaches have been used for the redesign of logical behavior in biological systems. The first is to use pre-existing regulatory elements, such as TFs and promoters and reconnect them, following a specific design to obtain the desired behavior (Silva-Rocha and De Lorenzo, 2011; Tamsir et al., 2011). The second is to re-edit the regulatory elements to modify their intrinsic properties and thus generate new logical behaviors. In this sense, it has been demonstrated that, in fact, the modification of cis-regulatory elements at target promoters is sufficient to modify the logic of their signal integration (Hunziker et al., 2010).

As Boolean logic gates are widely used in electronic circuits to build digital devices, logic operations are encoded in gene regulatory networks that cells use to integrate multiple environmental and cellular signals to respond accordingly (Wang et al., 2011). The combination of logic gates together with new experimental designs has enabled important advances in 
understanding the relationship between the architecture of regulatory elements (mainly promoters) and the final response generated as a result of the signal integration process (Tamsir et al., 2011). However, our knowledge of the relationship between the promoters' architecture and the resulting logic is still quite limited. For example, while deciphering the logic of promoters of low complexity (that is, with few operator sequences) is a relatively easy task, the same cannot be said for promoters formed by numerous regulatory sequences (Ishihama, 2010). In addition, recent progress in the massive identification of operator sequences on a genomic scale (for example, through chromatin immunoprecipitation experiments and computational tools) has shown that the integration of multiple operators into bacterial promoters is more frequent than previously imagined (Shimada et al., 2011a, 2011b; Chen et al., 2018; Barne et al., 2019).

\section{Synthetic biology and the development of bioinformatics tools to explore the microbial communities' complexity}

Progress in synthetic biology is enabled by powerful bioinformatics tools allowing the integration of the design, build and test stages of the biological engineering cycle. The development of new bioinformatics tools is helpful and important for scientists working on design, build and test parts to extend or modify the behavior of organisms and engineer them to perform new tasks. Bioinformatics tools for the DESIGN and BUILD stages include tools for the selection, synthesis, assembly and optimization of parts (enzymes and regulatory elements), devices (pathways) and systems (chassis). TEST tools include those for screening, identification and quantification of metabolites for rapid prototyping (Carbonell et al., 2016).

The functional potential of microbial communities can be determined by the genetic content of its constituent members. However, genetic content alone does not guarantee that a given function or enzymatic reaction will be performed as predicted (Liu et al., 2019). In this scenario, Transcription Factor proteins (TFs) play a central and critical role in gene regulation. Since TFs 
may determine when and which genes are expressed, profiling TFs can help understand the regulation of gene expression and to build regulatory networks in complex microbial communities. Further, defining which factors control gene expression may offer insights into the mechanisms controlling ecosystem processes and even interactions between species of a microbial community.

One of the major goals in the manipulation of microbiomes for ecological and biotechnological applications is to control the outcome of their functions (Widder et al., 2016). As TFs are key to potentially control which genes are expressed, one of the best ways to study and understand gene regulation in a microbiome may be to profile its TFs. Unfortunately, to date, no platform supports prediction and classification of novel bacterial TF from 'omics data recovered from microbial communities.

Although the regulation of gene expression in prokaryotes has been studied extensively, there is still a void regarding the effects that different regulatory elements would have on the final system logic. Unraveling these rules would help to create a predictive system able to decipher the logic of natural transcription factors and promoters. These rules would allow a significant advance in the understanding of the combinatorial mechanisms of control of gene expression in bacteria, with the potential impact on biotechnological applications on the re-engineering of biological circuits. The results of this endeavor contribute not only to a fundamental understanding of the signal integration mechanisms for bacteria and microbial communities but also produce new rules and methods for the design and build of standardized, integrated biological systems to accomplish many tasks of biotechnological interest. 
II. OBJETIVES 


\section{1) Main objective}

Unraveling rules is fundamental for the understanding of the signal integration mechanisms for bacteria and microbial communities. Decipher the logic of natural transcription factors and promoters is a start point to create a predictive system with potential impact on biotechnological applications on the re-engineering of biological circuits. In this way, the general objective of this thesis was to engineer biological systems at the level of regulators and promoters through synthetic biology approaches and, in addition, to use a systemic approach to decipher the complexity of microbial communities through the mining of regulatory elements in massive data.

\section{2) Specific objectives}

- Decipher the logic of integrating signals in complex promoters, seeking to characterize biological parts and understand the relationship between the architecture of complex promoters and the logic of gene regulation dependent on global regulators in bacteria.

- Engineer a set of bacterial transcription factors from Pseudomonas putida with enhanced response to a well characterized and largely innocuous molecule with a potential for eliciting heterologous expression of bacterial genes in animal carriers.

- Decode the complexity of transcription factors in environmental communities by mapping the complex regulatory profile of (meta)genomes of interest by searching for know and novel transcription factors through bioinformatics tools. 
RESULTS - CHAPTER I

III. RESULTS 


\section{CHAPTER I}

\section{Emergent Properties in Complex Synthetic Bacterial Promoters}

This chapter was published as:

(Monteiro et al., 2018) MONTEIRO, Lummy Maria Oliveira; ARRUDA, Leticia Magalhaes; SILVAROCHA, Rafael. Emergent properties in complex synthetic bacterial promoters. ACS synthetic biology, v. 7, n. 2, p. 602-612, 2018. 


\title{
Emergent Properties in Complex Synthetic Bacterial Promoters
}

\author{
Lummy Maria Oliveira Monteiro, ${ }^{\dagger}$ Letícia Magalhães Arruda, ${ }^{\dagger}$ and Rafael Silva-Rocha*0 \\ Systems and Synthetic Biology Lab, Ribeirao Preto Medical School, University of São Paulo, Ribeirão Preto, São Paulo, Brazil
}

ABSTRACT: Regulation of gene expression in bacteria results from the interplay between hundreds of transcriptional factors (TFs) at target promoters. However, how the arrangement of binding sites for TFs generates the regulatory logic of promoters is not well-known. Here, we generated and fully characterized a library of synthetic complex promoters for the global regulators, CRP and IHF, in Escherichia coli, which are formed by a weak $-35 /-10$ consensus sequence preceded by four combinatorial binding sites for these two TFs. Using this approach, we found that while cis-elements for CRP
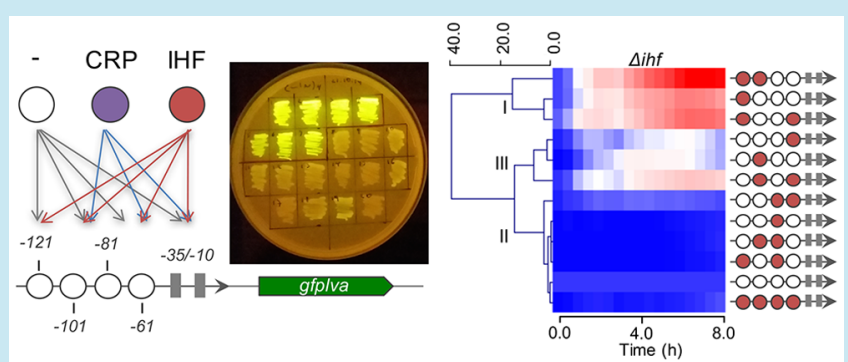

preferentially activate promoters when located immediately upstream of the promoter consensus, binding sites for IHF mainly function as "UP" elements and stimulate transcription in several different architectures in the absence of this protein. However, the combination of CRP- and IHF-binding sites resulted in emergent properties in these complex promoters, where the activity of combinatorial promoters cannot be predicted from the individual behavior of its components. Taken together, the results presented here add to the information on architecture-logic of complex promoters in bacteria.

KEYWORDS: emergent properties, global regulators, promoter architecture, regulatory networks, synthetic biology

$\mathrm{T}$ he experience of the past decade has greatly increased our knowledge of how cells coordinate gene expression in response to changing environmental and physiological conditions. Since the seminal description of the first gene regulatory mechanism by Jacob and Monod in the 60s, thousands of molecular studies have described the different mechanisms by which transcriptional factors (TFs) coordinate gene expression in bacteria. In particular, the model organism Escherichia coli has been used for decades to investigate the different ways in which TFs activate or repress gene expression, and a number of mechanisms have been elucidated in this and other bacteria. ${ }^{1-8}$ With an increase in our knowledge of these mechanisms, it was soon evident that bacterial promoters are usually regulated by several TFs that bind to specific cisregulatory elements located in close proximity to the promoter site and interact with one another in different ways. In this sense, the existence of synergy or competition between TFs for binding sites in the DNA will ultimately determine the level and timing of expression for each particular gene depending on the combination of specific molecular signals available to the bacteria. $^{9,10}$ Additionally, compilation of the regulatory interactions known for $E$. coli resulted in the classification of TFs as global and local regulators, where the first group is composed of TFs capable of controlling a large number of target genes, whereas the second group has a more limited regulatory scope. ${ }^{11,12}$ This analysis also showed that some environmental and physiological signals that control global regulators are higher in the regulatory hierarchy since their presence will lead to major regulatory effects in the organisms compared to the presence of signals for local regulators. For instance, the CRP global regulator controls the expression of a large number of genes in E. coli in response to changes in cAMP levels, which in turn is modulated by glucose. ${ }^{13,14}$ Although it is well established that cAMP synthesis is modulated by glucose, it is noteworthy that several sugars independent of phosphotransferase system can also reduce cAMP levels. ${ }^{15}$ In another case, the nucleoid associated protein IHF has an important role in DNA organization in response to bacterial growth and can modulate the expression of a number of genes. ${ }^{16,17}$ Furthermore, many global regulators are known to co-occur frequently at target promoters, ${ }^{5,11}$ and this co-occurrence could indicate the existence of some interaction mechanisms between these pairs of regulators. $^{18,19}$

With the advent of synthetic biology, using the current knowledge on gene regulatory mechanisms in bacteria to reprogram these organisms for novel applications has been of special interest. ${ }^{20-22}$ In order to accomplish this task, many studies have addressed the modification of native promoters to construct synthetic regulatory systems with enhanced and/or modified performance. ${ }^{23-26}$ Moreover, some initial studies have focused on the shuffling of cis-regulatory elements to reconstruct complex promoters in bacteria; ${ }^{27-30}$ this approach could not only provide novel regulatory systems but also reveal some of the hidden roles regarding the interaction of multiple TFs in target promoters. Though these approaches have resulted in significant progress such as the knowledge that promoter arrangement indeed determines the final regulatory logic of systems, these studies have mainly used local regulators and it is not yet known whether global regulators would follow the same rules. Moreover, the standard model for gene regulation in bacteria states that we could anticipate the

Received: September 27, 2017

Published: November 1, 2017 
regulatory behavior of complex promoters by analyzing the individual contributions of each TF and its respective ciselements, as evidenced by the widely used mathematical frameworks available to model gene regulation. ${ }^{31,32}$ However, in an alternative scenario, the combination of several cisregulatory elements for specific TFs (mainly for global regulators that naturally act together) could result in promoters with emergent properties, where the final response of the system would not be anticipated based on known individual contributions. This hypothesis is also motivated by the fact that many biological systems have been shown to display emergent properties. $^{33}$

In order to get insights into the regulatory mechanisms of combinatorial bacterial promoters, we investigated here the relationship between promoter architecture and gene expression regulation. These insights are relevant since promoters in their natural form are known to co-occur frequently at target promoters. $^{18,19}$ This study is important, since many E. coli genes can be regulated by CRP, IHF or for both at the same time. This is the case of $g c d$ gene that is regulated by one CRP (repressor) and one IHF (activator). This gene encodes for quinoprotein glucose dehydrogenase. ${ }^{34}$ Another natural example is the hpt gene that is regulate by one CRP (activator) and one IHF (repressor). This gene encodes for hypoxanthine phosphoribosyltransferase. This protein is involved in step 1 of the subpathway that synthesizes IMP (Inosine monophosphate) from hypoxanthine. ${ }^{35}$ And finally, the acs gene that is regulate by at least two CRP (activator) and three IHF (repressor). This gene encodes for acetyl-CoA synthetase. Acetyl-CoA synthetase is an enzyme involved in metabolism of acetate. There are many other known genes that are regulated by CRP and IHF at the same time. In addition, possibly many other genes have not yet been studied. ${ }^{36}$ For this, we constructed and characterized a library of synthetic promoters containing an array of cis-elements for CRP and IHF, two global regulators of $E$. coli, using a GFP(LVA) reporter assay. Our data clearly indicated that though CRP and IHF have very different regulatory effects, many binding site combinations for both TFs resulted in novel regulatory activities that were not anticipated by the analysis of individual elements when their sites were placed in different positions and arrangements. These results demonstrate the existence of emergent properties in complex synthetic promoters in E. coli, which could be extrapolated to naturally occurring regulatory systems and would significantly impact the engineering of synthetic biological circuits in bacteria.

\section{RESULTS}

CRP Strongly Activates Synthetic Promoters with cisElements Immediately Upstream of a Core Promoter. In order to investigate the architecture-logic relationship in synthetic bacterial promoters, we employed a minimal design as presented in Figure 1. First, we designed a promoter composed of a weak core element (comprising the -35 and -10 boxes of Plac) preceded by $20 \mathrm{bp}$ sequences that could be occupied by cis-elements for the target TFs (Figure 1A). In this design, the cis-elements can be centered at regions $-61,-81$, -101 , and -121 related to the transcriptional start site (TSS) of the promoter. By fixing these positions, we would expect the effect of TF to be stimulatory at the resultant promoter, based on previous systematic inspections on the effect of cis-element localization on gene regulation. ${ }^{5,37}$ For each of the four potential positions, we designed double stranded DNA
A

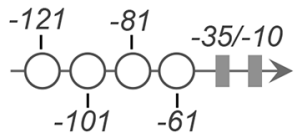

$\mathrm{B}$

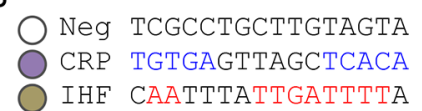

C

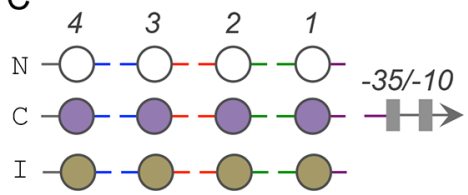

Figure 1. Construction of the complex promoter library. (A) Schematic representation of the promoter library, showing the positions $-121,-101,-81$, and -61 (white circles) at which ciselements were inserted. The -35 and -10 boxes (gray rectangles) correspond to the core promoter. (B) Nucleotide sequences for Neutral (N), CRP (C), IHF (I) cis-elements. (C) Simplified scaffold scheme for the minimal synthetic promoter library. Motifs positions are identified as $4,3,2$, and 1 respective to the core promoter, and colored lines represent the cohesive sequences for DNA ligation. (D) E. coli library transformants showing different promoter strengths.

oligonucleotides with a consensus sequence for CRP, IHF, and a control sequence (called "Neg", Figure 1B) that does not display any stimulatory effect in vivo. ${ }^{18}$ In this sense, each double stranded DNA fragment has $3^{\prime}$ overhang elements with four nucleotides that specify each position where the fragment can be ligated (Figure 1C). In this manner, we used a portfolio of 12 different fragments that could be used to construct up to $81\left(3^{4}\right)$ different combinatorial promoters. Using this setup, we constructed a library of synthetic promoters by ligating these cis-elements and the core promoter into a GFP(LVA) reporter vector, allowing the measurement of promoter activities in vivo to determine the effect of promoter architecture in the final output of promoters (exemplified by the different clones represented in Figure 1D).

In order to determine the effect of different arrangements of cis-elements for CRP, we analyzed the promoter activity of 10 synthetic promoters in the wild type strain growing in minimal media for a period of $8 \mathrm{~h}$. As shown in Figure 2, clustering of promoter activities reveals the existence of two clear groups, one (marked as I in the figure) composed of six promoters with activities similar to the reference promoter (the one in the top with four Neg sites) and another group (marked as II) composed of four promoters with a high level of activity (about 80 times the level of the reference promoter). By analyzing the architecture of each promoter, it is easily notable that all members of the highly active group have a cis-element for CRP at position 1 (equivalent to the -61 relative to the TSS), which is in accordance to previous reports on this TF. ${ }^{19,37,38}$ Moreover, the addition of another CRP cis-element at positions 2 , 3, and 4 (boxes $-81,-101$, and -121 ) only marginally affects the activity of a promoter harboring a cis-element at position 1. In summary, this result demonstrates the potential of our approach to investigate the effect of cis-element arrangement on promoter activity, as the resulting synthetic promoters reproduced the expected behavior for CRP.

cis-Element for IHF Enhances Promoter Activity in the Complex Promoters in the Absence of This TF. In order to investigate the effect of cis-elements for IHF in our complex 


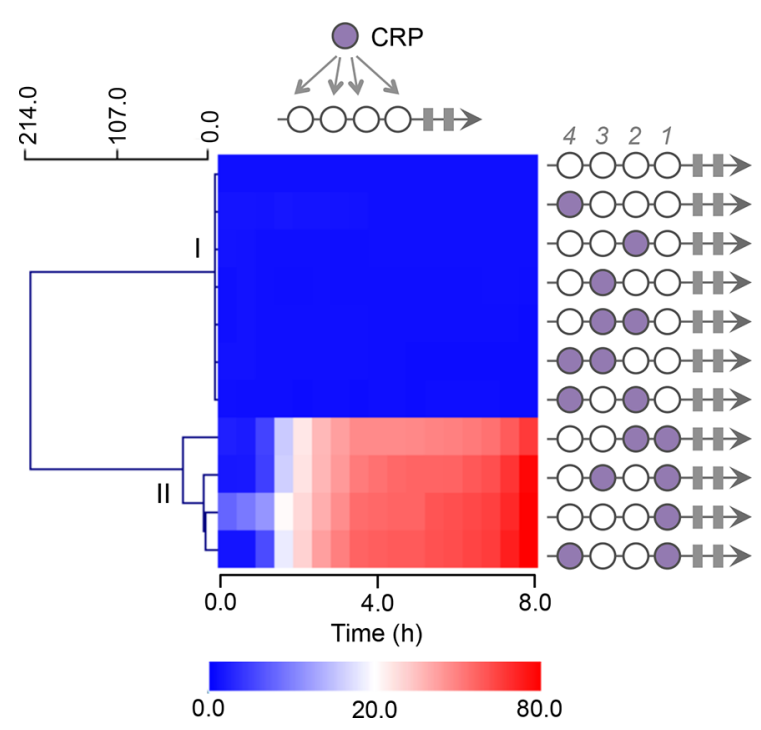

Figure 2. CRP motif at position 1 is fundamental for high promoter activity. A subset of 11 synthetic promoters containing shuffled CRP and Neutral cis-elements displaying two clear activity patterns (groups I and II). In group I are promoters that do not present promoter activity while group II includes promoters with high transcription rates. Circles in magenta represent the positions of CRP sites. Relative promoter activity was measured for $8 \mathrm{~h}$, calculated based on the Neutral full promoter, and displayed on an intensity scale from 0.0 to 80.0. Plots were calculated based on the average of three independent experiments.

promoter design, we analyzed 11 synthetic promoters harboring combinations of one or two IHF binding site and Neg sequences in addition to the full IHF $P_{\text {IIII }}$ promoter (Figure 3). The experiments were performed similarly as before but both in the wild type and $\Delta i h f$ mutant strains of E. coli. Promoter activity analysis allowed clustering of the data into three major groups as shown in Figure 3A for the wild type strain. In this sense, group I (high activity) was formed of two promoters with maximal activity not higher than 8 times that observed for the reference promoter, whereas group II (Medium activity) (5 promoters) displayed activities comparable to those of the reference, and group III (Low activity) (4 promoters) showed intermediate activity. When the same set of promoters was assayed in $\Delta i h f$ mutant strains of $E$. coli, we observed two major features (Figure 3B). First, a generalized increase in promoter activity was observed for groups I and III, where the former was still formed of promoters with stronger activity. Second, the composition of the groups was almost unchanged, with the exception of one promoter (with two IHF cis-elements at positions 4 and 3) that displayed no activity in the wild type but showed the highest activity of the group in the mutant, and another promoter (composed of four IHF binding sites) that did not gain activity in the mutant, were clustered into group II in the mutant. These expression profiles clearly indicate that the cis-elements for IHF could stimulate promoter activity mainly in the absence of this global regulator. In addition, groups I and III which display significant promoter activity in mutant strain, they have IHF cis-elements at all positions except 2 (equivalent to the -81 region), whereas promoters with position 2 occupied displayed very low activity regardless of occupancy at other sites (group II). These results suggest that cis-elements for IHF could operate as an RNAP transcriptional activity enhancer, probably as a UP element-like motif as described previously ${ }^{39,40}$ although it have not been described UP-element at position -60 to -120 yet. Our hypothesis is that the IHF cis-element would be acting recruiting the RNAP to the promoter; however, experiments proving this hypothesis are still necessary. Thus, when IHF binds to its cognate cis-element, it blocks RNAP contact with the UP element-like sequence, thus preventing transcriptional stimulation of the promoter. However, the reason why the

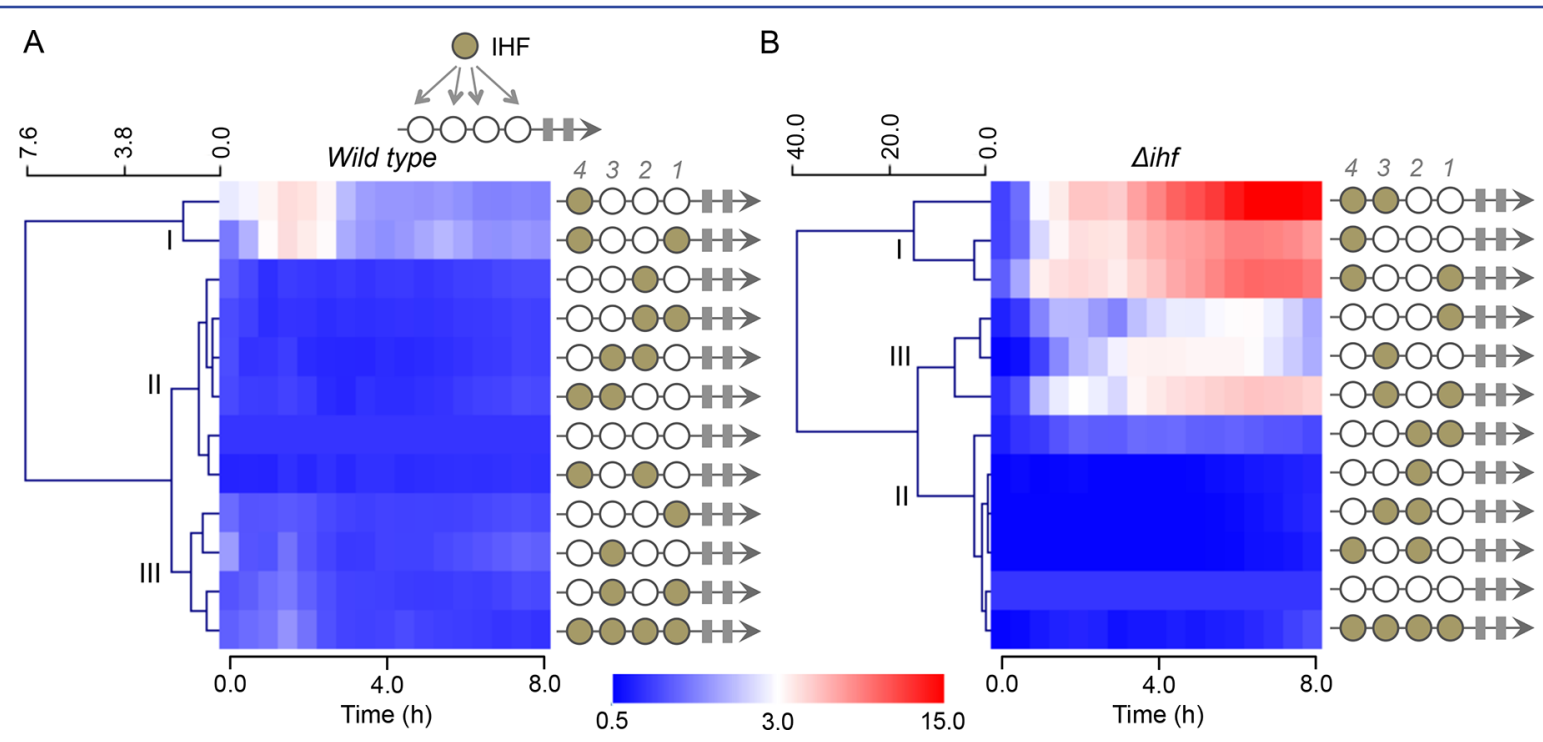

Figure 3. IHF motif enhanced promoter activity in E. coli $\Delta i h f$ strain. A subset of shuffled IHF and Neutral motif promoters were assayed in the wild type and $\Delta i h f$ mutant strains and grouped according to their relative activity. Circles in beige represent the positions of IHF sites. (A) IHF vs Neutral motifs assayed in the wild type strain. Synthetic promoters that showed higher promoter activities are clustered in group I, group II is formed of promoters with low activity, whereas group III is formed of promoters with intermediate promoter activity. (B) The same set of promoters were assayed in the E. coli $\Delta i h f$ mutant strain, highlighting that in the absence of IHF transcription factor, promoter activity was generally improved for the groups I and III. Relative promoter activity was measured for $8 \mathrm{~h}$, calculated based on the Neutral full promoter, and displayed on an intensity scale from 0.0 to 15.0. Plots were calculated based on the average of three independent experiments. 
existence of a cis-element for IHF at position 2 renders the promoters inactive regardless of the identity of other positions is unknown and may be related to some intrinsic property of the DNA sequence itself.

Rise of Emergent Properties in Complex Promoters with CRP and IHF cis-Elements. Once we determined that the CRP and IHF cis-elements have distinct effects on promoter activity, we wondered what would happen if the CRP and IHF binding sequences were combined, as occurs in the natural promoters of E. coli. In this sense, would the resulting promoter represent the sum of each contribution of the isolated ciselements, or would it display a novel regulatory logic? To address these questions, we used as the start point, two architectures containing cis-elements for IHF that displayed activity both in the wild type and $\Delta$ ihf mutant strains as represented by the members of group I in Figure 3A. These two promoters possess either one position (position 4) or two (positions 4 and 1) occupied by the IHF cis-element. Using these two basic architectures, we introduced cis-elements for CRP at either position 3, 2, or both, and assayed the resulting promoter activity (Figure 4). In this data set, we did not test

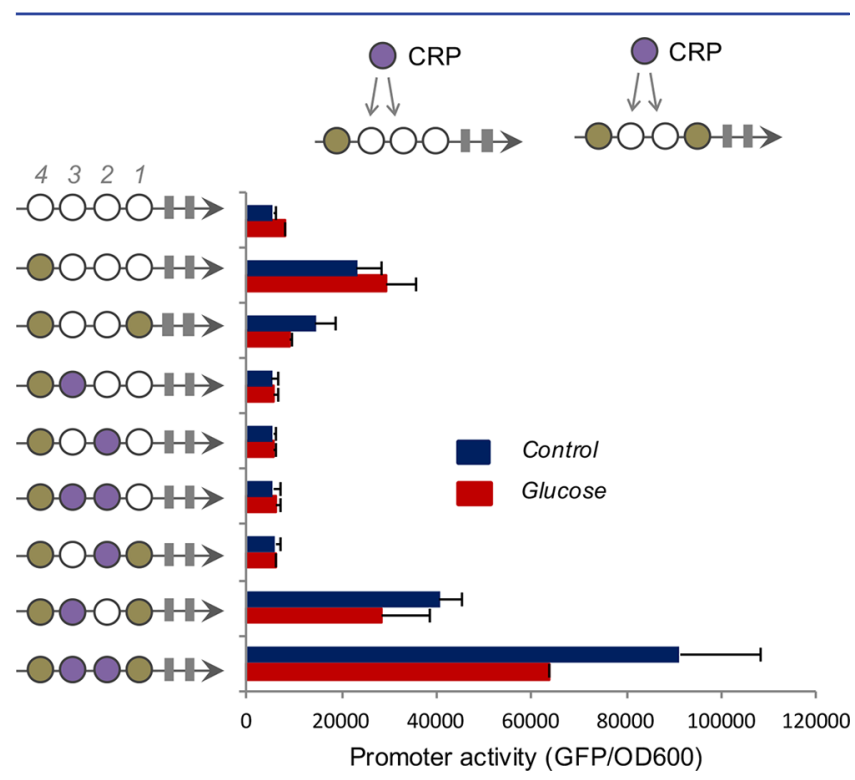

Figure 4. Emergence in combinatorial promoters based on CRP and IHF cis-elements. Complex promoters were constructed based on two promoters shown in Figure 3 and were assayed in the E. coli wild type strain, in the absence (blue) or presence (red) of $0.4 \%$ glucose. The promoters were constructed by fixing the IHF cis-element at position 4 and at positions 4 and 1 and by shuffling the CRP motifs at positions 2 and 3. Relative promoter activity was measured after $4 \mathrm{~h}$ of incubation. Plots were calculated based on the average of three independent experiments.

position 1 since CRP at this position has a strong stimulatory effect regardless of other upstream elements (as already presented in Figure 2). Notably, when positions 3 and 2 where occupied by CRP cis-elements (either in isolation or simultaneously), no significant promoter activity was detected (Figure 2). When we assayed combinatorial promoters based on single IHF cis-elements in the wild type strain, we observed that the introduction of single or double cis-elements for CRP resulted in complete abolishment of promoter activity. When these promoters were evaluated in the presence of $0.4 \%$ glucose (which in our tested condition, is sufficient to block CRP activity ${ }^{41}$ ), we did not recover the original promoter activity, suggesting that this effect was not dependent on CRP binding but rather on the combination of the DNA elements itself. When we performed a similar analysis on the variants of the promoters harboring the two IHF cis-elements (at positions 4 and 1), we observed a remarkably different behavior. When single CRP cis-elements were placed individually at positions 3 or $2\left(P_{I C N I}\right.$ and $\left.P_{I N C I}\right)$, we observed the same promoter blocking effect as described previously, and this effect was not alleviated in the presence of glucose (Figure 4). However, when both positions, 3 and $2\left(P_{I C C I}\right)$, where occupied by cis-elements for CRP resulting in a synthetic promoter with two IHF sites flanking two CRP sites, we observed a strong increase in promoter activity compared to that of the original promoter. It is striking to note that the presence of two CRP sites at positions 2 and 3 provides an expressive promoter activity and that withdrawal of only one CRP binding site at position 2 or 3 significantly impairs the promoter force. It is very clear the requirement for the double CRP site when comparing PICCI with PICNI and PINCI promoters. Interestingly, the addition of glucose resulted in complete abolishment of promoter activity, indicating that the strong enhancement of promoter activity was indeed dependent on CRP activity. These data strongly support the notion that the combination of ciselements for global regulators such as CRP and IHF leads to the appearance of emergent properties, since the final regulatory behavior of the complex promoter does not represent the sum of the behavior of the original architectures (i.e., the promoter harboring two IHF sites at positions 4 and 1 and the promoter harboring two CRP sites at positions 3 and 2).

In order to further evaluate the promoter architecture effect, we expanded the number of architectures assayed and performed experiments in the absence of IHF and by modulating CRP activity (i.e., in the presence or absence of glucose). For a better presentation of the results, the experiment was divided into three subgroups. Figure 5A shows constructs that have one IHF cis-element fixed at position 4 ( -121 region) and different combinations of CRP cis-element at positions 2 and 3 ( -81 and -101 regions). As shown in the figure, a promoter containing a single IHF site at position 4 displays strong activity in the $\Delta i h f$ mutant strain that was insensitive to glucose presence. Moreover, addition of single or double CRP cis-elements at positions 3 and 2 completely abolishes promoter activity, and this could not be reverted by the addition of glucose to the media. These results agree with the previous analysis and indicate that addition of CRP cis-elements blocks the activity of the original promoter independently of CRP activity. Next, we investigated the effect of the presence of CRP binding sites at different positions in promoters with a single IHF cis-element fixed at position 1 (Figure 5B). In this condition, though the initial promoter displayed detectable activity with a fold-change about three times that of the reference promoter, addition of a single CRP cis-element immediately upstream of the IHF site (position 2) completely abolished the promoter activity. Interestingly, moving the CRP site far from the IHF site (for instance, from position 2 to position 3 ) generates a marginally detectable activity, whereas placing the site in the farthest position (i.e., at position 4) generates a combinatorial promoter with activity similar to that of the original harboring a single IHF site at position 1 (Figure 5B). These results indicate a position dependent effect of CRP cis-elements, which was not related to 


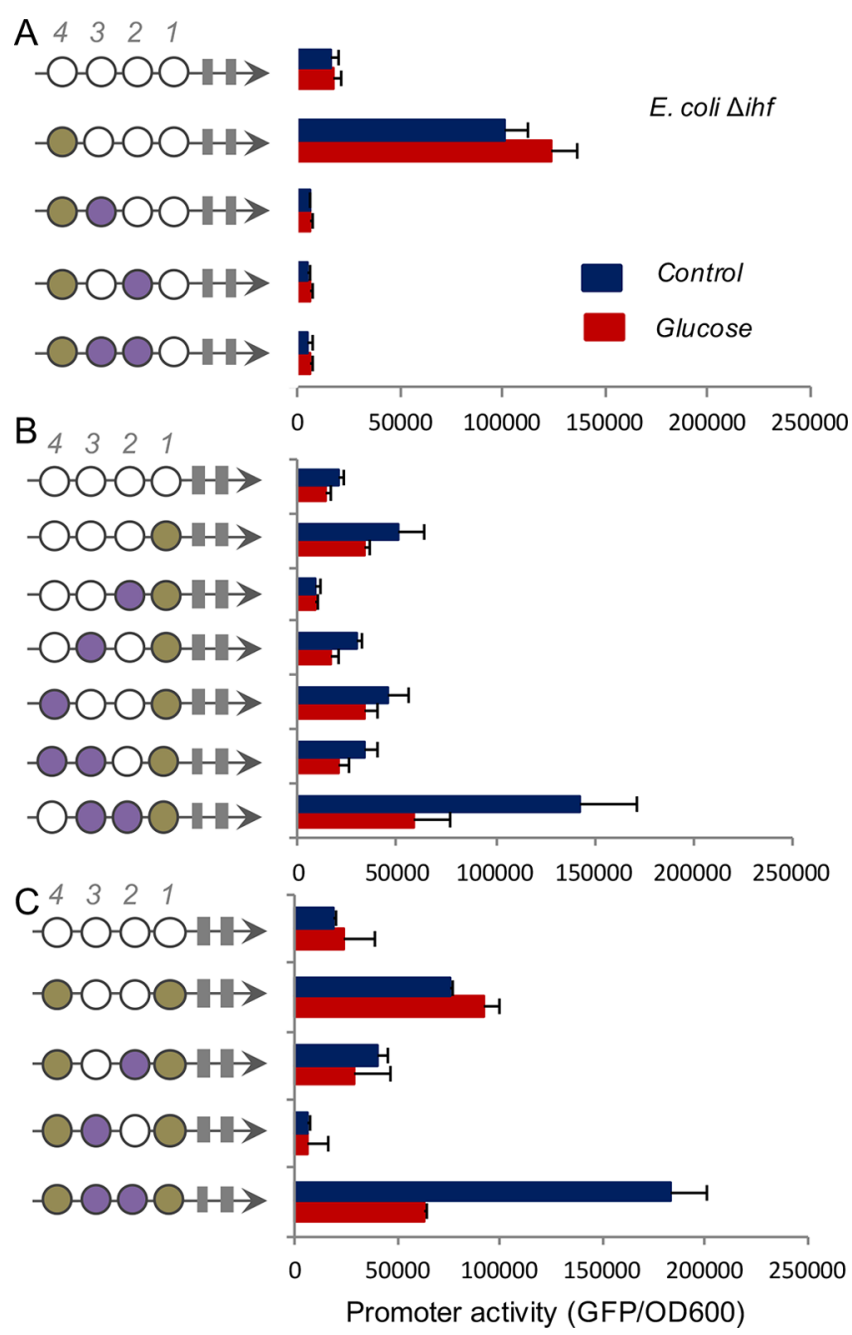

Figure 5. Systematic investigation of complex promoters for CRP and IHF in the E. coli $\Delta i h f$ strain. All experiments were performed in the absence (blue) or presence (red) of $0.4 \%$ glucose. (A) Synthetic promoters with a single IHF site fixed at position 4 and varying CRP sites at positions 3 and 2. (B) Synthetic promoters with a single IHF site fixed at position 1 and varying CRP sites at positions 4, 3, and 2 . (C) Synthetic promoters with two IHF sites fixed at positions 4 and 1 and varying CRP sites at positions 3 and 2 . Relative promoter activity was measured after $4 \mathrm{~h}$ of incubation. Plots were calculated based on the average of three independent experiments.

CRP activity since the addition of glucose to the media resulted in very similar expression profiles. This notion is also supported by the fact that addition of two CRP binding sites at positions 4 and 3 resulted in similar activity to that where only position 3 was occupied by a CRP cis-element. Additionally, introduction of two CRP binding sites at positions 3 and 2 generated completely different behavior, resulting in a promoter with strong activity that was completely dependent on CRP (as addition of glucose substantially decreased its activity, Figure $5 B)$. These results indicate that the emergence of strong CRPdependent activity requires two tandem CRP binding sites (at positions 3 and 2) followed by a single IHF cis-element (at position 1). Finally, when the CRP binding sites were combined with IHF cis-elements fixed at position 4 and 1 (Figure 5C), we observed the same behavior presented in Figure 5B, since addition of one site at position 3 or 2 strongly impairs promoter activity whereas two tandem sites generate a
CRP-dependent promoter with activity stronger than that of the parental architecture.

IHF cis-Elements Generates Fine-Tuning for CRP Activated Promoters. In the previous sections, we demonstrated that additional CRP cis-elements could influence the regulatory behavior of a promoter harboring IHF sites. Since CRP binding sites could strongly influence these promoters, we investigated how the addition of IHF could modulate promoters containing CRP cis-elements at position 1, which were previously demonstrated to generate strong CRP dependent activation (Figure 2). For this, we sampled several combinatorial promoters where additional IHF and CRP sites were mixed upstream of a CRP cis-element located at position 1. As shown in Figure 6A, all promoters displayed strong activity in the wild type strain of $E$. coli and this activity was severely impaired when glucose was added to the growth media. Additionally, certain degree of heterogeneity can be observed in promoter activities indicating that the additional sites contributed to the final activity observed. However, when the same experiments were performed in a $\Delta i h f$ mutant strain of $E$. coli, we observed that the level of heterogeneity was strongly reduced both in the active and repressed conditions (Figure 6B). Taken together, these data strongly indicate that additional IHF sites could produce a fine-tuning effect that modulates the final activity of the constructed combinatorial promoters.

Emergent Properties Are Consequence of the cisElements. Once we affirm the existence of the emergent properties in our promoters, we proceed to study whether this property was given by the cis-elements located upstream to the core promoter, or if in some way this emergent promoter activity was given by the generation of a new promoter formed in our constructions. For this, we focused on two promoters $\left(P_{I C C I}\right.$ and $\left.P_{N C C I}\right)$ with emergent properties to study this property further. For this, deletions of 5 and 15 base pairs were made in the core promoter (Figure 7A). As it is possible to note that, with the 5 base pair deletion, the -10 and -35 boxes remain intact, while upon deletion of 15 base pairs the -10 box is completely removed. These deletions were also performed for $P_{N N N N}$ as a control. The experiments were carried out in $w t$ and $\Delta$ ihf strains and in presence or absence of glucose. After these deletions, it was possible to conclude that the 5 base pairs deletion (D5) for both $P_{I C C I}$ and $P_{N C C I}$ promoter the activity remained similar to the parental promoter, showing no significant difference. On the other hand, after the 15 base pairs deletion (D15) the promoter activity fell sharply to almost zero (Figure $7 \mathrm{~B}$ and $7 \mathrm{C}$ ). In this way, it was possible to verify that the promoter activities as well as the emergent properties found in this work are due to the different architectures promoting the cis-elements upstream to the core promoter.

\section{DISCUSSION}

Regulation of gene expression at the level of RNAP recruitment to target promoters is known to be a combinatorial mechanism where multiple transcriptional factors binding to target cisregulatory elements and their interplay defines the timing and intensity of gene expression. This combinatorial control has been extensively described in bacteria and in single-celled and multicellular eukaryotes, and the so-called regulatory code is known to play a major role in the way living organisms develop and interact with the environment. ${ }^{27,42,43}$ However, while classical approaches to understand this code are based on a case-by-case dissection of the cis-regulatory elements of 


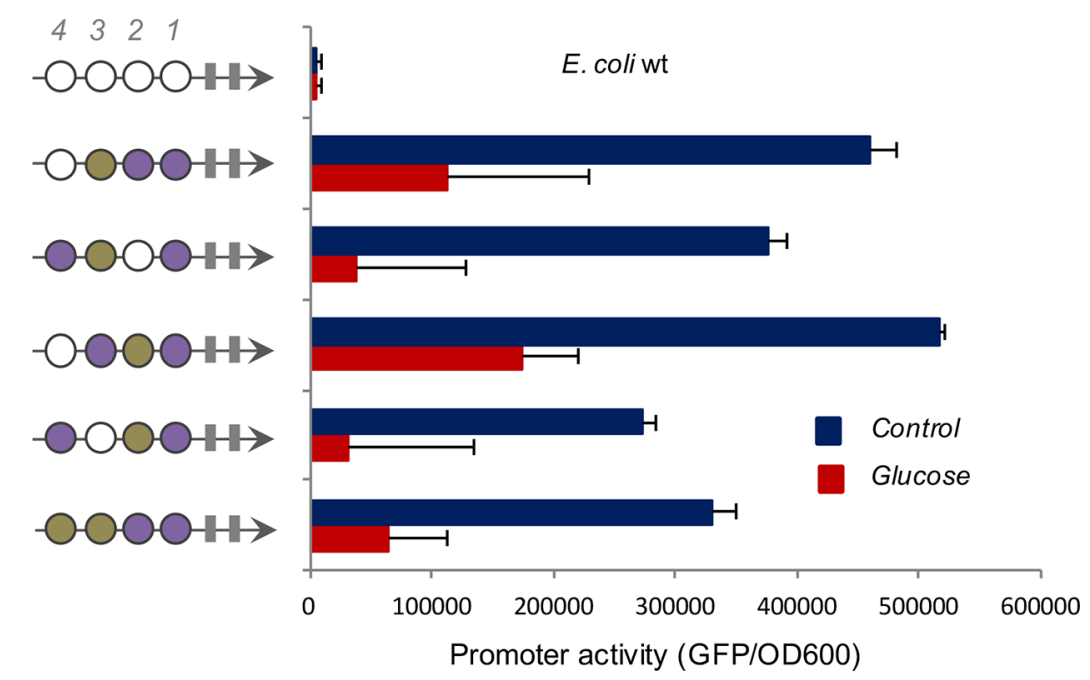

Figure 6. Fine-tuning of CRP-dependent synthetic promoters by IHF sites. Synthetic promoters with the CRP site fixed at position 1 and varying $\mathrm{CRP}$ and IHF sites at positions 4,3 , and 2 were assayed in the absence (left) or presence (right) of $0.4 \%$ glucose. (A) Analysis of promoter activity in the E. coli wild type strain. (B) Analysis of promoter activity in the E. coli $\Delta i h f$ strain. Relative promoter activity was measured after $4 \mathrm{~h}$ of incubation. Plots were calculated based on the average of three independent experiments.

A
Core promoter
$-10+1$
D5 mutant
AGGCACCCCAGGC TTT
TACACT TTAT GCTTCCGGCTCGTATGTTGTGTGGAG
D15 mutant
AGGCACCCCAGGC TTTACACT TTAT GCTTCCGGCTCGTATGTTGTG
AGGCACCCCAGGC TTTACACT TTAT GCTTCCGGCTC $-35$

$\mathrm{B}$

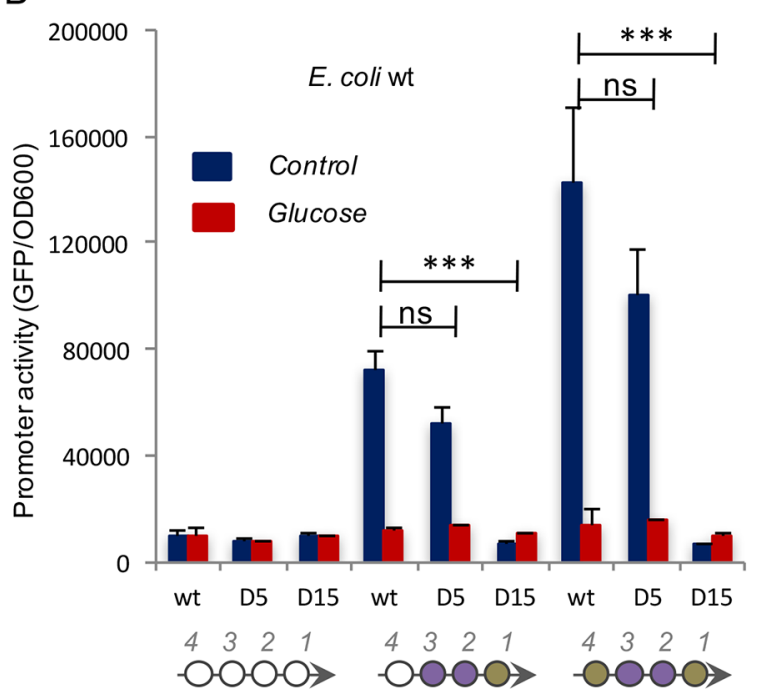

C

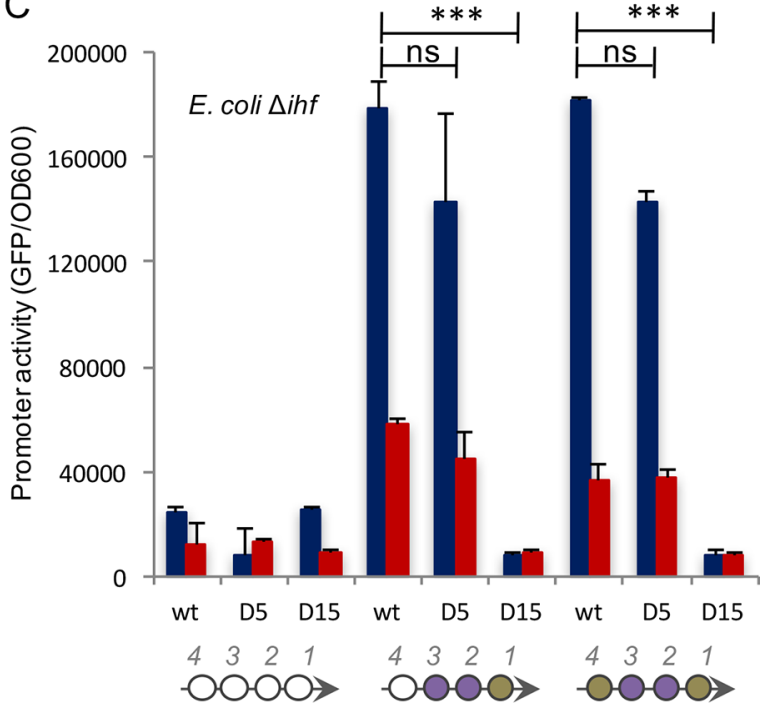

Figure 7. Emergent properties are consequence of the cis-elements. All experiments were performed in the absence (blue) or presence (red) of $0.4 \%$ glucose. (A) Deletions of $5 \mathrm{bp}$ (D5) and $15 \mathrm{bp}$ (D15) were performed on the core promoter of $P_{N N N N}$ (control), $P_{N C C I}$ and $P_{I C C I}$. (B) Analysis of promoter activity in the E. coli wild type strain. (C) Analysis of promoter activity in the E. coli $\Delta i h f$ strain. Relative promoter activities were measured after $4 \mathrm{~h}$ of incubation. Plots were calculated based on the average of three independent experiments. Statistics differences are highlighted by $(* * *)$ as analyzed using Student's $t$ test with p-value $p<0.0005$; ns, not significant.

particular genes, several studies have now described the systematic investigation of combinatorial promoters through the construction and evaluation of synthetic promoters built from cis-regulatory elements. In this sense, Cox III and colleagues constructed a library of synthetic promoters for two local activators (AraC and LuxR) and two local repressors (LacI and TetR) at three different promoter positions (upstream, downstream, or overlapping the core $-35 /-10$ box). From this work, the authors described a number of rules for engineering combinatorial promoters for synthetic biology; for instance, activators were only efficient upstream of the core whereas efficacy of repression was higher at the core and then at the downstream region, with only minor effects at the upstream position. ${ }^{30}$ However, this work only used local TFs, 
Table 1. Strains, Plasmids, and Primers Used in This Study

\begin{tabular}{|c|c|c|}
\hline $\begin{array}{l}\text { strains, plasmids, and } \\
\text { primers }\end{array}$ & description & reference \\
\hline \multicolumn{3}{|l|}{ Strains } \\
\hline E. coli $\mathrm{DH} 10 \mathrm{~B}$ & $\begin{array}{l}F^{-} \text {endA1 deoR } R^{+} \text {recA1 galE15 galK16 nupG rpsL } \Delta(\text { lac)X74 } \varphi 80 \text { lacZ } \Delta M 15 \text { araD139 } \Delta \text { (ara,leu)7697 mcrA } \Delta(\text { mrr-hsdRMS- } \\
\text { mcrBC) } \operatorname{Str}^{R} \lambda^{-}\end{array}$ & 51 \\
\hline E. coli BW25113 & $\begin{array}{l}\text { lacI }^{+} r r n B_{T 14} \Delta l a c Z_{W J 16} h s d R 514 \Delta a r a B A D_{A H 33} \Delta r h a B A D_{L D 78} r p h-1 \Delta(\operatorname{araB}-D) 567 \Delta(r h a D-B) 568 \Delta l a c Z 4787(:: r r n B-3) \\
\quad h s d R 514 \text { rph-1 }\end{array}$ & 52 \\
\hline E. coli JW1702 & E. coli BW25113 with $\Delta i h f$ mutation & 50 \\
\hline \multicolumn{3}{|l|}{ Plasmids } \\
\hline pMR1 & $\mathrm{Cm}^{\mathrm{R}}$; orip15a; Promoter probe vector with mCherry and GFPlva reporters & 18 \\
\hline pMR1- $P_{N N N N}$ & pMR1 with a reference promoter with four nonregulatory sequences & This study \\
\hline pMR1- $P_{I N N N}$ & pMR1 with a synthetic promoter with a IHF cis-element at position 4 & This study \\
\hline pMR1- $P_{\text {NINN }}$ & pMR1 with a synthetic promoter with a IHF cis-element at position 3 & This study \\
\hline pMR1-P $P_{N N I N}$ & pMR1 with a synthetic promoter with a IHF cis-element at position 2 & This study \\
\hline pMR1- $P_{N N N I}$ & pMR1 with a synthetic promoter with a IHF cis-element at position 1 & This study \\
\hline pMR1-P $P_{I I N N}$ & pMR1 with a synthetic promoter with IHF cis-elements at positions 4 and 3 & This study \\
\hline pMR1- $P_{N I N}$ & pMR1 with a synthetic promoter with IHF cis-elements at positions 3 and 2 & This study \\
\hline pMR1- $P_{N N I I}$ & pMR1 with a synthetic promoter with IHF cis-elements at positions 2 and 1 & This study \\
\hline pMR1- $P_{I N I N}$ & pMR1 with a synthetic promoter with IHF cis-elements at positions 4 and 2 & This study \\
\hline pMR1- $P_{\text {NINI }}$ & pMR1 with a synthetic promoter with IHF cis-elements at positions 3 and 1 & This study \\
\hline $\mathrm{pMR} 1-P_{I N N I}$ & pMR1 with a synthetic promoter with IHF cis-elements at positions 4 and 1 & This study \\
\hline pMR1-P & pMR1 with a synthetic promoter with IHF cis-elements at positions 4, 3, 2 and 1 & This study \\
\hline $\mathrm{pMR} 1-P_{\mathrm{CNNN}}$ & pMR1 with a synthetic promoter with a CRP cis-element at position 4 & This study \\
\hline pMR1- $P_{N C N N}$ & pMR1 with a synthetic promoter with a CRP cis-element at position 3 & This study \\
\hline pMR1- $P_{N N C N}$ & pMR1 with a synthetic promoter with a CRP cis-element at position 2 & This study \\
\hline pMR1- $P_{N N N C}$ & pMR1 with a synthetic promoter with a CRP cis-element at position 1 & This study \\
\hline pMR1-P $P_{C C N N}$ & pMR1 with a synthetic promoter with CRP cis-elements at positions 4 and 3 & This study \\
\hline pMR1- $P_{N C C N}$ & pMR1 with a synthetic promoter with CRP cis-elements at positions 3 and 2 & This study \\
\hline pMR1-P $P_{N N C C}$ & pMR1 with a synthetic promoter with CRP cis-elements at positions 2 and 1 & This study \\
\hline pMR1-P $P_{C N C N}$ & pMR1 with a synthetic promoter with CRP cis-elements at positions 4 and 2 & This study \\
\hline pMR1- $P_{N C N C}$ & pMR1 with a synthetic promoter with CRP cis-elements at positions 3 and 1 & This study \\
\hline pMR1-P $P_{C N N C}$ & pMR1 with a synthetic promoter with CRP cis-elements at positions 4 and 1 & This study \\
\hline pMR1-P $P_{I C N N}$ & pMR1 with a synthetic promoter with a IHF cis-element at position 4 and a CRP cis-element at position 3 & This study \\
\hline $\mathrm{pMR} 1-P_{I N C N}$ & pMR1 with a synthetic promoter with a IHF cis-element at position 4 and a CRP cis-element at position 2 & This study \\
\hline pMR1-P ICCN & pMR1 with a synthetic promoter with a IHF cis-element at position 4 and CRP cis-elements at positions 3 and 2 & This study \\
\hline pMR1-P $P_{I N C I}$ & pMR1 with a synthetic promoter with a IHF cis-elements at positions 1 and 4 and CRP cis-element at position 2 & This study \\
\hline pMR1-P $P_{I C N I}$ & pMR1 with a synthetic promoter with a IHF cis-elements at positions 1 and 4 and CRP cis-element at position 3 & This study \\
\hline pMR1-P $P_{I C C I}$ & pMR1 with a synthetic promoter with a IHF cis-elements at positions 1 and 4 and CRP cis-elements at positions 3 and 2 & This study \\
\hline pMR1-P $P_{N N C I}$ & pMR1 with a synthetic promoter with a IHF cis-element at position 1 and CRP cis-element at position 2 & This study \\
\hline pMR1-P $P_{N C N I}$ & pMR1 with a synthetic promoter with a IHF cis-element at position 1 and CRP cis-element at position 3 & This study \\
\hline pMR1-P $P_{C N N I}$ & pMR1 with a synthetic promoter with a IHF cis-element at position 1 and CRP cis-element at position 4 & This study \\
\hline pMR1-P $P_{C C N I}$ & pMR1 with a synthetic promoter with a IHF cis-element at position 1 and CRP cis-elements at positions 2 and 3 & This study \\
\hline $\mathrm{pMR} 1-P_{N C C I}$ & pMR1 with a synthetic promoter with a IHF cis-element at position 1 and CRP cis-elements at position 3 and 2 & This study \\
\hline pMR1- $P_{N I C C}$ & pMR1 with a synthetic promoter with a IHF cis-element at position 1 and CRP cis-element at position 2 & This study \\
\hline pMR1-P $P_{\text {CINC }}$ & pMR1 with a synthetic promoter with a IHF cis-element at position 3 and CRP cis-elements at positions 1 and 4 & This study \\
\hline pMR1-P $P_{N C I C}$ & pMR1 with a synthetic promoter with a IHF cis-element at position 2 and CRP cis-elements at positions 1 and 3 & This study \\
\hline pMR1-P $P_{C N I C}$ & pMR1 with a synthetic promoter with a IHF cis-element at position 2 and CRP cis-elements at positions 1 and 2 & This study \\
\hline pMR1-P $P_{I I C C}$ & pMR1 with a synthetic promoter with a IHF cis-element at position 4 and 3 and CRP cis-elements at positions 1 and 2 & This study \\
\hline pMR1-P $P_{N N N N-D 5}$ & Version pMR1- $P_{N N N N}$ of with a $5 \mathrm{bp}$ deletion at the $3^{\prime}$ region & This study \\
\hline pMR1- $P_{N N N N-D 15}$ & Version pMR $1-P_{N N N N}$ of with a $15 \mathrm{bp}$ deletion at the $3^{\prime}$ region; Removes the -10 region & This study \\
\hline pMR1- $P_{\text {NCCI-D5 }}$ & Version pMR1- $P_{N C C I}$ of with a $5 \mathrm{bp}$ deletion at the $3^{\prime}$ region & This study \\
\hline pMR1-P ${ }_{N C C I-D 15}$ & Version pMR $1-P_{N C C I}$ of with a $15 \mathrm{bp}$ deletion at the $3^{\prime}$ region; Removes the -10 region & This study \\
\hline pMR1-P ICCI-D5 & Version pMR1-P $P_{I C C I}$ of with a $5 \mathrm{bp}$ deletion at the $3^{\prime}$ region & This study \\
\hline $\begin{array}{l}\text { pMR1-P }{ }_{\text {ICCI-D15 }} \\
\text { Primers }^{a}\end{array}$ & Version pMR $1-P_{I C C I}$ of with a $15 \mathrm{bp}$ deletion at the $3^{\prime}$ region; Removes the -10 region & This study \\
\hline $\mathrm{P} 1-\mathrm{C} 5$ & AATTCTGTGAGTTAGCTCACA & This study \\
\hline $\mathrm{P} 1-\mathrm{C} 3$ & CGCCTGTGAGCTAACTCACAG & This study \\
\hline $\mathrm{P} 1-\mathrm{I} 5$ & AATTCCAATTTATTGATTTTA & This study \\
\hline $\mathrm{P} 1-\mathrm{I} 3$ & CGCСTAAAATCAATAAATTGG & This study \\
\hline $\mathrm{P} 1-\mathrm{N} 5$ & AATTCTCGCCTGCTTGTAGTA & This study \\
\hline $\mathrm{P} 1-\mathrm{N} 3$ & CGCCTACTACAAGCAGGCGAG & This study \\
\hline $\mathrm{P} 2-\mathrm{C} 5$ & GGCGTGTGAGTTAGCTCACA & This study \\
\hline
\end{tabular}




\section{Table 1. continued}

\begin{tabular}{|c|c|c|}
\hline $\begin{array}{l}\text { strains, plasmids, and } \\
\text { primers }\end{array}$ & description & reference \\
\hline $\mathrm{P} 2-\mathrm{C} 3$ & GCGGTGTGAGCTAACTCACA & This study \\
\hline $\mathrm{P} 2-\mathrm{I} 5$ & GGCGCAATTTATTGATTTTA & This study \\
\hline $\mathrm{P} 2-\mathrm{I} 3$ & GCGGTAAAATCAATAAATTG & This study \\
\hline P2-N5 & GGCGTCGCCTGCTTGTAGTA & This study \\
\hline $\mathrm{P} 2-\mathrm{N} 3$ & GCGGTACTACAAGCAGGCGA & This study \\
\hline $\mathrm{P} 3-\mathrm{C} 5$ & CCGCTGTGAGTTAGCTCACA & This study \\
\hline $\mathrm{P} 3-\mathrm{C} 3$ & CCAATGTGAGCTAACTCACA & This study \\
\hline P3-I5 & CCGCCAATTTATTGATTTTA & This study \\
\hline P3-I3 & ССАATAAAATCAATAAATTG & This study \\
\hline P3-N5 & CCGCTCGCCTGCTTGTAGTA & This study \\
\hline $\mathrm{P} 3-\mathrm{N} 3$ & CCAATACTACAAGCAGGCGA & This study \\
\hline $\mathrm{P} 4-\mathrm{C} 5$ & TTGGTGTGAGTTAGCTCACA & This study \\
\hline $\mathrm{P} 4-\mathrm{C} 3$ & CAAGTGTGAGCTAACTCACA & This study \\
\hline P4-I5 & TTGGCAATTTATTGATTTTA & This study \\
\hline $\mathrm{P} 4-\mathrm{I} 3$ & CAAGTAAAATCAATAAATTG & This study \\
\hline P4-N5 & TTGGTCGCCTGCTTGTAGTA & This study \\
\hline $\mathrm{P} 4-\mathrm{N} 3$ & CAAGTACTACAAGCAGGCGA & This study \\
\hline CoreP-5 & CTTGAGGCACCCCAGGCTTTACACTTTATGCTTCCGGCTCGTATGTTGTGTGGAG & This study \\
\hline CoreP-3 & GATCCTCCACACAACATACGAGCCGGAAGCATAAAGTGTAAAGCCTGGGGTGCCT & This study \\
\hline pMR1-F & CTCGCCСTTGCTCACC & This study \\
\hline pMR1-R & ACAAGAATTGGGACAACTCC & This study \\
\hline
\end{tabular}

which are limited to a few natural targets and, thus, are not found in naturally complex promoter architectures as global regulators are. Moreover, the work by Cox III only explored a single binding site at the upstream promoter regions, which does not allow the investigation of combinatorial effects generated by cis-element arrangements and identities in this region. Therefore, our work addresses a more realistic combinatorial situation by mimicking the manner in which promoters are organized naturally, and indeed, our result of ciselement mediated repression of gene expression has not been reported previously. The effect of promoter architecture in gene regulation has also been extensively investigated in single-celled eukaryotes such as yeast, with especial interest in the work of Sharon and co-workers. ${ }^{44}$ In this study, the authors synthesized and analyzed using a high-throughput approach, thousands of different promoters for several TFs of Saccharomyces cerevisiae, ${ }^{44}$ thus allowing them to investigate the effect of number, position, and affinity of binding sites on gene expression. However, the fundamental difference between transcription initiation in prokaryotes and eukaryotes, due to the sophisticated process of chromatin remodeling required in the latter, makes it impossible to extrapolate the conclusions drawn by Sharon et al. to a bacterial organism. However, the approach used in this study was analogous to the approach used by Sharon et al., since we could inspect the effect of binding site multiplicity, location, and identity.

From the results generated in this work, the most striking was the observation that a single CRP-binding site located immediately upstream of an IHF-binding site could completely abolish transcriptional activity independently of CRP function. This result appeared in several promoter architectures tested here and would indicate that the DNA sequence itself was modulating gene expression. However, introduction of an additional CRP binding site drastically changed this process, resulting in a CRP-activated promoter. It has now been widely demonstrated that DNA can display an allosteric effect on TFs, where the binding of a protein to DNA changes the way this protein interacts with other TFs. ${ }^{45-47}$ Moreover, another type of DNA-based allosteric event has been described where the binding of a protein to DNA can influence the binding of a second protein to an adjacent site independently of proteinprotein interaction, and that this influence is transmitted through the DNA molecule. ${ }^{46,47}$ In this sense, these processes could explain how two tandem cis-elements for CRP that are inactive alone (at positions 3 and 2 in Figure 2) generated a strong CRP-dependent promoter when in association with a single IHF binding site (the latter at position 1, Figure 5B). However, it certainly does not explain how a single CRP ciselement displays inhibitory effects in certain promoter architectures (as in many of those presented in Figure 4). Recently, an increasing number of reports have demonstrated that flanking DNA sequences can strongly affect the binding affinity of eukaryotic TFs for identical binding sites, ${ }^{48,49}$ thus explaining why in vitro and in vivo binding assays do not always correlate. In this process, these flanking sequences generate distortions in the local DNA shape that influences the way the TFs interacts with DNA, by altering the groove width and helical parameters of DNA. ${ }^{48}$ Though we could not find any report of this process influencing bacterial TFs, our results on synthetic complex promoters suggest that a similar process could influence the activity of bacterial promoters, thus explaining the intrinsic repressive activity of the CRP ciselement (independently of the presence of CRP protein) at some positions in promoters containing cis-elements for IHF. Our findings could thus be extended to naturally complex promoters and indicate that in those systems, not only would the nature of the TF recruited to the target promoter be imperative for gene expression, but also the cis-element itself could have a regulatory role in proximal sites. This evidence an unanticipated intrinsic complexity of natural bacterial promoters that should be considered both for synthetic biology projects as well as to understand the regulatory behavior of natural strains. Taken together, our results highlight the appearance of emergent properties in combinatorial control 
in bacteria, thus opening new venues for understanding combinatorial regulation in bacterial genes and open new venues that could be investigated in future studies.

\section{MATERIALS AND METHODS}

Plasmids, Bacterial Strains, and Growth Conditions. The plasmids, bacterial strains, and primers used in this study are listed in Table 1. For cloning procedures, the bacterial strain used was E. coli DH5 $\alpha$. E. coli BW25113 was used as the wild type strain (WT) whereas E. coli JW1702-1 was used as the mutant for IHF transcription factor, and both were obtained from the Keio collection. ${ }^{50}$ E. coli strains were grown at $37{ }^{\circ} \mathrm{C}$ in LB media with chloramphenicol at $34 \mu \mathrm{g} \mathrm{mL}^{-1}$ or in $\mathrm{M} 9$ minimal media $\left(6.4 \mathrm{~g} \mathrm{~L}^{-1} \mathrm{Na}_{2} \mathrm{HPO}_{4} \cdot 7 \mathrm{H}_{2} \mathrm{O}, 1.5 \mathrm{~g} \mathrm{~L}^{-1} \mathrm{KH}_{2} \mathrm{PO}_{4}\right.$, $\left.0.25 \mathrm{~g} \mathrm{~L}^{-1} \mathrm{NaCl}, 0.5 \mathrm{~g} \mathrm{~L}^{-1} \mathrm{NH}_{4} \mathrm{Cl}\right)$ supplemented with chloramphenicol at $17 \mu \mathrm{g} \mathrm{mL}^{-1}, 2 \mathrm{mM} \mathrm{MgSO}, 0.1 \mathrm{mM}$ casamino acids, and $1 \%$ glycerol as the sole carbon source. Where indicated, CRP response was depleted by using $0.4 \%$ of glucose.

Design of the Minimal Promoter Scaffold and Ligation Reactions. Promoters were constructed by ligation of $5^{\prime}$ end phosphorylated oligonucleotides ${ }^{27,30}$ acquired from Sigma-Aldrich (Table 1). All single strand nucleotides were designed to carry a discrete $16 \mathrm{bp}$ sequence ${ }^{8}$ containing a CRP binding site (C), IHF binding site (I), one Neutral (N) motif with no transcription factor binding (Figure 1B), and a core promoter based on the lac promoter (Table 1), which is a weak promoter and therefore requires activation. All these oligonucleotides were designed to carry three base pair overhangs corresponding to their corrected insertion region on the promoter (Figure 1A). The upper and lower strand corresponding to each position were mixed at equimolar concentrations and annealed by heating at $95{ }^{\circ} \mathrm{C}$ followed by gradual cooling to room temperature. External overhangs of the fourth cis-element position and the core promoters reassembled on the EcoRI and BamHI digested sites, allowing ligation to a previously digested EcoRI/BamHI pMR1 ${ }^{18}$ plasmid. All five fragments (four cis-elements positions plus core promoter) were mixed at equimolar concentrations in a pool with the final concentration of $5^{\prime}$ phosphate termini fixed at $15 \mu \mathrm{M}$. For the ligase reaction, $1 \mu \mathrm{L}$ of the pooled fragments was added to 50 ng EcoRI/BamHI pMR1 digested plasmid in the presence of ligase buffer and ligase enzyme to a final volume of $10 \mu \mathrm{L}$. After $1 \mathrm{~h}$ at $16^{\circ} \mathrm{C}$, the ligase reaction was inactivated for $15 \mathrm{~min}$ at 65 ${ }^{\circ} \mathrm{C}$ and one aliquot of $2 \mu \mathrm{L}$ was then electroporated into $50 \mu \mathrm{L}$ of $E$. coli $\mathrm{DH} 10 \mathrm{~B}$ competent cells. After $1 \mathrm{~h}$ of regenerating in 1 $\mathrm{mL} \mathrm{LB}$ media, the total volume was plated onto LB solid dishes supplemented with chloramphenicol at $34 \mu \mathrm{g} \mathrm{mL}{ }^{-1}$. Clones were confirmed by colony PCR using primers pMR1-F and pMR1-R (Table 1) using the pMR1 empty plasmid PCR reaction as a further length reference upon agarose gel electrophoresis. Clones with the potential correct length were submitted to Sanger DNA sequencing for confirming the correct promoter assembly.

GFP(LVA) Fluorescence Assay and Data Processing. To measure promoter activity, the library of 38 promoters was analyzed in different genetic backgrounds and conditions. For each experiment, a plasmid harboring the promoter of interest was used to transform $E$. coli wild type or E. coli $\Delta$ ihf mutant cells. Freshly plated single colonies were grown overnight in LB media, centrifuged, and resuspended in fresh M9 media. The culture $(10 \mu \mathrm{L})$ was then assayed in 96-well microplates in biological triplicates with $170 \mu \mathrm{L}$ of M9 media or M9 media supplemented with $0.4 \%$ glucose whenever required. Cell growth and GFP(LVA) fluorescence were quantified using a Victor X3 plate reader (PerkinElmer). GFP (LVA) is a GFP with a degradation tag. This degradation tag allows us to evaluate the expression over time in an efficient and robust way. Promoter response was calculated as arbitrary units by dividing the fluorescence levels by the optical density at $600 \mathrm{~nm}$ (reported as $\mathrm{GFP} / \mathrm{OD}_{600}$ ) after background correction. The same strain harboring the pMR1 empty plasmid was used as the threshold background signal during calculations. Fluorescence and absorbance measurements were taken at $30 \mathrm{~min}$ intervals over $8 \mathrm{~h}$ (However, for Figures 4, 5, 6 and 7 just the $4 \mathrm{~h}$ promoter activity $\left(\mathrm{GFP} / \mathrm{OD}_{600}\right)$ was shown). Technical triplicates and biological triplicates were included in all experiments. Raw data were processed using ad hoc $\mathrm{R}$ script (https://www.r-project.org/) and plots were constructed using $\mathrm{R}$ or $\mathrm{MeV}$ (www.tm4.org/mev.html).

\section{AUTHOR INFORMATION}

\section{Corresponding Author}

*Tel.: +55 163315 3229. Fax: +55 163633 0728. E-mail: silvarochar@gmail.com.

\section{ORCID}

Rafael Silva-Rocha: 0000-0001-6319-631X

\section{Author Contributions}

${ }^{\dagger}$ L.M.O.M. and L.M.A. contributed equally to this work

\section{Notes}

The authors declare no competing financial interest.

\section{ACKNOWLEDGMENTS}

The authors are thankful to lab members and to Dr. MariaEugenia Guazzaroni for critical discussion of this work. This work was supported by the Young Investigator Award of the Sao Paulo State Foundation (FAPESP, award number 2012/ 22921-8). LMOM was supported by a FAPESP Ph.D. fellowship (FAPESP, award number 2016/19179-9).

\section{REFERENCES}

(1) Browning, D. F., and Busby, S. J. W. (2004) The regulation of bacterial transcription initiation,. Nat. Rev. Microbiol. 2, 57-65.

(2) Prigent-Combaret, C., Brombacher, E., Vidal, O., Ambert, A., Lejeune, P., Landini, P., and Dorel, C. (2001) Complex regulatory network controls initial adhesion and biofilm formation in Escherichia coli via regulation of the csgD gene. J. Bacteriol. 183, 7213-7223.

(3) Vicente, M., Chater, K. F., and De Lorenzo, V. (1999) Bacterial transcription factors involved in global regulation. Mol. Microbiol. 33, $8-17$.

(4) Liu, X., and Matsumura, P. (1994) The FlhD/FlhC complex, a transcriptional activator of the Escherichia coli flagellar class II operons,. J. Bacteriol. 176, 7345-7351.

(5) Collado-Vides, J., Magasanik, B., and Gralla, J. D. (1991) Control site location and transcriptional regulation in Escherichia coli. Microbiol Rev. 55, 371-394.

(6) De Lorenzo, V., Herrero, M., Giovannini, F., and Neilands, J. B. (1988) Fur (ferric uptake regulation) protein and CAP (cataboliteactivator protein) modulate transcription of fur gene in Escherichia coli. Eur. J. Biochem. 173, 537-546.

(7) Miyada, C. G., Stoltzfus, L., and Wilcox, G. (1984) Regulation of the araC gene of Escherichia coli: catabolite repression, autoregulation, and effect on araBAD expression. Proc. Natl. Acad. Sci. U. S. A. 81, $4120-4124$.

(8) Little, J. W., Edmiston, S. H., Pacelli, L. Z., and Mount, D. W. (1980) Cleavage of the Escherichia coli lexA protein by the recA protease. Proc. Natl. Acad. Sci. U. S. A. 77, 3225-3229. 
(9) Hermsen, R., Ursem, B., and ten Wolde, P. R. (2010) Combinatorial gene regulation using auto-regulation. PLoS Comput. Biol. 6, e1000813.

(10) Buchler, N. E., Gerland, U., and Hwa, T. (2003) On schemes of combinatorial transcription logic. Proc. Natl. Acad. Sci. U. S. A. 100, 5136-5141.

(11) Martinez-Antonio, A., and Collado-Vides, J. (2003) Identifying global regulators in transcriptional regulatory networks in bacteria. Curr. Opin. Microbiol. 6, 482-489.

(12) Pérez-Rueda, E., and Collado-Vides, J. (2000) The repertoire of DNA-binding transcriptional regulators in Escherichia coli K-12, Nucleic Acids Res. 28, 1838-1847.

(13) Inada, T., Takahashi, H., Mizuno, T., and Aiba, H. (1996) Down regulation of cAMP production by cAMP receptor protein in Escherichia coli: an assessment of the contributions of transcriptional and posttranscriptional control of adenylate cyclase. Mol. Gen. Genet. 253, 198-204.

(14) Schmitz, A. (1981) Cyclic AMP receptor protein interacts with lactose operator DNA. Nucleic Acids Res. 9, 277-292.

(15) You, C., Okano, H., Hui, S., Zhang, Z., Kim, M., Gunderson, C. W., Wang, Y. P., Lenz, P., Yan, D., and Hwa, T. (2013) Coordination of bacterial proteome with metabolism by cyclic AMP signalling. Nature 500, 301-306.

(16) Azam, T. A., and Ishihama, A. (1999) Twelve species of the nucleoid-associated protein from Escherichia coli. Sequence recognition specificity and DNA binding affinity. J. Biol. Chem. 274, 3310533113.

(17) Biek, D. P., and Cohen, S. N. (1989) Involvement of integration host factor (IHF) in maintenance of plasmid pSC101 in Escherichia coli: mutations in the topA gene allow pSC101 replication in the absence of IHF. J. Bacteriol. 171, 2066-2074.

(18) Guazzaroni, M. E., and Silva-Rocha, R. (2014) Expanding the logic of bacterial promoters using engineered overlapping operators for global regulators. ACS Synth. Biol. 3, 666-675.

(19) Lee, D. J., Minchin, S. D., and Busby, S. J. W. (2012) Activating Transcription in Bacteria. Annu. Rev. Microbiol. 66, 125-152.

(20) Nandagopal, N., and Elowitz, M. B. (2011) Synthetic biology: integrated gene circuits. Science 333, 1244-1248.

(21) Voigt, C. A. (2006) Genetic parts to program bacteria. Curr. Opin. Biotechnol. 17, 548-557.

(22) Benner, S. a., and Sismour, a. M. (2005) Synthetic biology. Nat. Rev. Genet. 6, 533-543.

(23) Brophy, J. A., and Voigt, C. A. (2014) Principles of genetic circuit design. Nat. Methods 11, 508-520.

(24) Rhodius, V. A., Segall-Shapiro, T. H., Sharon, B. D., Ghodasara, A., Orlova, E., Tabakh, H., Burkhardt, D. H., Clancy, K., Peterson, T. C., Gross, C. A., and Voigt, C. A. (2013) Design of orthogonal genetic switches based on a crosstalk map of sigmas, anti-sigmas, and promoters. Mol. Syst. Biol. 9, 702.

(25) Guet, C. C., Elowitz, M. B., Hsing, W., and Leibler, S. (2002) Combinatorial synthesis of genetic networks. Science 296, 1466-1470.

(26) Gardner, T. S., Cantor, C. R., and Collins, J. J. (2000) Construction of a genetic toggle switch in Escherichia coli. Nature 403, 339-342.

(27) Kinkhabwala, A., and Guet, C. C. (2008) Uncovering cis regulatory codes using synthetic promoter shuffling. PLoS One 3, e2030.

(28) Isalan, M., Lemerle, C., Michalodimitrakis, K., Horn, C., Beltrao, P., Raineri, E., Garriga-Canut, M., and Serrano, L. (2008) Evolvability and hierarchy in rewired bacterial gene networks. Nature 452, 840845 .

(29) Murphy, K. F., Balázsi, G., and Collins, J. J. (2007) Combinatorial promoter design for engineering noisy gene expression. Proc. Natl. Acad. Sci. U. S. A. 104, 12726-12731.

(30) Cox, R. S., 3rd, Surette, M. G., and Elowitz, M. B. (2007) Programming gene expression with combinatorial promoters. Mol. Syst. Biol. 3, 145.
(31) Bintu, L., Buchler, N. E., Garcia, H. G., Gerland, U., Hwa, T., Kondev, J., and Phillips, R. (2005) Transcriptional regulation by the numbers: models. Curr. Opin. Genet. Dev. 15, 116-124.

(32) Bintu, L., Buchler, N. E., Garcia, H. G., Gerland, U., Hwa, T., Kondev, J., Kuhlman, T., and Phillips, R. (2005) Transcriptional regulation by the numbers: applications. Curr. Opin. Genet. Dev. 15, $125-135$.

(33) Bhalla, U. S., and Iyengar, R. (1999) Emergent properties of networks of biological signaling pathways. Science 283, 381-387.

(34) Yamada, M., Asaoka, S., Saier, M. H., Jr, and Yamada, Y. (1993) Characterization of the gcd gene from Escherichia coli K-12 W3110 and regulation of its expression. J. Bacteriol. 175, 568-571.

(35) Izu, H., Ito, S., Elias, M. D., and Yamada, M. (2002) Differential control by IHF and cAMP of two oppositely oriented genes, hpt and gcd, in Escherichia coli: significance of their partially overlapping regulatory elements. Mol. Genet. Genomics 266, 865-872.

(36) Kumari, S., Beatty, C. M., Browning, D. F., Busby, S. J., Simel, E. J., Hovel-Miner, G., and Wolfe, A. J. (2000) Regulation of acetyl coenzyme A synthetase in Escherichia coli. J. Bacteriol. 182, 41734179.

(37) Tebbutt, J., Rhodius, V. A., Webster, C. L., and Busby, S. J. W. (2002) Architectural requirements for optimal activation by tandem CRP molecules at a class I CRP-dependent promoter. FEMS Microbiol. Lett. 210, 55-60.

(38) Ushida, C., and Aiba, H. (1990) Helical phase dependent action of CRP: effect of the distance between the CRP site and the -35 region on promoter activity. Nucleic Acids Res. 18, 6325-6330.

(39) Giladi, H., Murakami, K., Ishihama, a., and Oppenheim, a. B. (1996) Identification of an UP element within the IHF binding site at the PL1-PL2 tandem promoter of bacteriophage lambda. J. Mol. Biol. 260, 484-491.

(40) Rossiter, A. E., Godfrey, R. E., Connolly, J. A., Busby, S. J. W., Henderson, I. R., and Browning, D. F. (2015) Expression of different bacterial cytotoxins is controlled by two global transcription factors, $\mathrm{CRP}$ and Fis, that co-operate in a shared-recruitment mechanism. Biochem. J. 466, 323-335.

(41) Amores, G. R., Guazzaroni, M. E., and Silva-Rocha, R. (2015) Engineering Synthetic cis-Regulatory Elements for Simultaneous Recognition of Three Transcriptional Factors in Bacteria. ACS Synth. Biol. 4, 1287-1294.

(42) Salgado, H., Peralta-Gil, M., Gama-Castro, S., Santos-Zavaleta, A., Muniz-Rascado, L., Garcia-Sotelo, J. S., Weiss, V., Solano-Lira, H., Martinez-Flores, I., Medina-Rivera, A., Salgado-Osorio, G., AlquiciraHernandez, S., Alquicira-Hernandez, K., Lopez-Fuentes, A., PorronSotelo, L., Huerta, A. M., Bonavides-Martinez, C., Balderas-Martinez, Y. I., Pannier, L., Olvera, M., Labastida, A., Jimenez-Jacinto, V., VegaAlvarado, L., Del Moral-Chavez, V., Hernandez-Alvarez, A., Morett, E., and Collado-Vides, J. (2013) RegulonDB v8.0: omics data sets, evolutionary conservation, regulatory phrases, cross-validated gold standards and more. Nucleic Acids Res. 41, D203-213.

(43) Raveh-Sadka, T., Levo, M., Shabi, U., Shany, B., Keren, L., Lotan-Pompan, M., Zeevi, D., Sharon, E., Weinberger, A., and Segal, E. (2012) Manipulating nucleosome disfavoring sequences allows finetune regulation of gene expression in yeast. Nat. Genet. 44, 743-750.

(44) Sharon, E., Kalma, Y., Sharp, A., Raveh-Sadka, T., Levo, M., Zeevi, D., Keren, L., Yakhini, Z., Weinberger, A., and Segal, E. (2012) Inferring gene regulatory logic from high-throughput measurements of thousands of systematically designed promoters. Nat. Biotechnol. 30, $521-530$.

(45) Kim, S., Brostromer, E., Xing, D., Jin, J., Chong, S., Ge, H., Wang, S., Gu, C., Yang, L., Gao, Y. Q., Su, X. D., Sun, Y., and Xie, X. S. (2013) Probing allostery through DNA. Science 339, 816-819.

(46) Lefstin, J. A., and Yamamoto, K. R. (1998) Allosteric effects of DNA on transcriptional regulators. Nature 392, 885-888.

(47) Chaires, J. B. (2008) Allostery: DNA does it, too. ACS Chem. Biol. 3, 207-209.

(48) Gordan, R., Shen, N., Dror, I., Zhou, T., Horton, J., Rohs, R., and Bulyk, M. L. (2013) Genomic regions flanking E-box binding sites 
influence DNA binding specificity of bHLH transcription factors through DNA shape. Cell Rep. 3, 1093-1104.

(49) Khoueiry, P., Rothbacher, U., Ohtsuka, Y., Daian, F., Frangulian, E., Roure, A., Dubchak, I., and Lemaire, P. (2010) A cis-regulatory signature in ascidians and flies, independent of transcription factor binding sites,. Curr. Biol. 20, 792-802.

(50) Baba, T., Ara, T., Hasegawa, M., Takai, Y., Okumura, Y., Baba, M., Datsenko, K. A., Tomita, M., Wanner, B. L., and Mori, H. (2006) Construction of Escherichia coli K-12 in-frame, single-gene knockout mutants: the Keio collection. Mol. Syst. Biol. 2, 20060008.

(51) Sambrook, J., Fritsch, E. F., and Maniatis, T. (1989) Molecular Cloning: A Laboratory Manual, Cold Spring Harbor, New York.

(52) Datsenko, K. A., and Wanner, B. L. (2000) One-step inactivation of chromosomal genes in Escherichia coli K-12 using PCR products. Proc. Natl. Acad. Sci. U. S. A. 97, 6640-6645. 


\section{CHAPTER ॥}

\section{Unraveling the Complex Interplay of Fis and IHF Through Synthetic Promoter Engineering}

This chapter was published as:

(Monteiro et al., 2020) MONTEIRO, Lummy Maria Oliveira; SANCHES-MEDEIROS, Ananda; WESTMANN, Caua Antunes; \& SILVA-ROCHA, Rafael. Unraveling the Complex Interplay of Fis and IHF Through Synthetic Promoter Engineering. Frontiers in bioengineering and biotechnology, v. 8, p. 1-13, 2020. 


\title{
Unraveling the Complex Interplay of Fis and IHF Through Synthetic Promoter Engineering
}

\author{
Lummy Maria Oliveira Monteiro*, Ananda Sanches-Medeiros, Cauã Antunes Westmann \\ and Rafael Silva-Rocha*
}

Ribeirão Preto Medical School (FMRP), University of São Paulo, Ribeirão Preto, Brazil

\section{OPEN ACCESS}

Edited by:

Tao Chen,

Tianjin University, China

Reviewed by:

Long Liu,

Jiangnan University, China Andrew Cameron,

University of Rochester, United States

Kaneyoshi Yamamoto,

Hosei University, Japan

${ }^{*}$ Correspondence: Lummy Maria Oliveira Monteiro lummymaria@gmail.com Rafael Silva-Rocha silvarochar@usp.br

Specialty section: This article was submitted to

Synthetic Biology,

a section of the journal Frontiers in Bioengineering and

Biotechnology

Received: 02 March 2020 Accepted: 30 April 2020

Published: 18 June 2020

Citation:

Monteiro LMO, Sanches-Medeiros A Westmann $C A$ and Silva-Rocha $R$ (2020) Unraveling the Complex Interplay of Fis and IHF Through Synthetic Promoter Engineering. Front. Bioeng. Biotechnol. 8:510. doi: 10.3389/fbioe.2020.00510
Bacterial promoters are usually formed by multiple cis-regulatory elements recognized by a plethora of transcriptional factors (TFs). From those, global regulators are key elements since these TFs are responsible for the regulation of hundreds of genes in the bacterial genome. For instance, Fis and IHF are global regulators that play a major role in gene expression control in Escherichia coli, and usually, multiple cis-regulatory elements for these proteins are present at target promoters. Here, we investigated the relationship between the architecture of the cis-regulatory elements for Fis and IHF in E. coli. For this, we analyze 42 synthetic promoter variants harboring consensus cis-elements for Fis and IHF at different distances from the core $-35 /-10$ region and in various numbers and combinations. We first demonstrated that although Fis preferentially recognizes its consensus cis-element, it can also recognize, to some extent, the consensus-binding site for $I H F$, and the same was true for IHF, which was also able to recognize Fis binding sites. However, changing the arrangement of the cis-elements (i.e., the position or number of sites) can completely abolish the non-specific binding of both TFs. More remarkably, we demonstrated that combining cis-elements for both TFs could result in Fis and IHF repressed or activated promoters depending on the final architecture of the promoters in an unpredictable way. Taken together, the data presented here demonstrate how small changes in the architecture of bacterial promoters could result in drastic changes in the final regulatory logic of the system, with important implications for the understanding of natural complex promoters in bacteria and their engineering for novel applications.

Keywords: regulatory network, cis-regulatory elements, complex promoters, global regulators, transcriptional crosstalk, fine-tuning

\section{INTRODUCTION}

Bacteria have evolved complex gene regulatory networks to coordinate the expression level of each gene in response to changing environmental conditions. In this aspect, a typical bacterium such as Escherichia coli uses around 300 different transcriptional factors (TFs) to control the expression of more than 5,000 genes, and gene regulation in bacteria has been extensively investigated in the last six decades (Lozada-Chavez, 2006). Among the known TFs from E. coli, global regulators are able to control the highest percentage of transcriptional units in response to significant physiological or environmental signals, such as the metabolic state of the cell, the availability of carbon sources, and the presence of oxygen (Martínez-Antonio et al., 2003; Ishihama, 2010), while local regulators are 
responsible for gene regulation in response to specific signals (such as sugars and metals) (Ishihama, 2010; Browning and Busby, 2016). Most TFs control gene expression through their interaction with specific DNA sequences located near the promoter region, the cis-regulatory element, or transcriptional factor binding site (Browning and Busby, 2004, 2016). Over the decades, many cis-regulatory elements for many TFs from E. coli have been experimentally characterized, mapped, and compiled in databases such as RegulonDB and EcoCyc (GamaCastro et al., 2016; Keseler et al., 2017). Analysis of these datasets demonstrates that TFs usually act in a combinatorial way to control gene expression, where multiple cis-regulatory elements for different TFs are located in the upstream region of the target genes (Guazzaroni and Silva-Rocha, 2014; Rydenfelt et al., 2014; Gama-Castro et al., 2016). Therefore, the arrangement of cis-regulatory elements at the target promoters is crucial to determine which TFs will be able to control the target gene and how these regulators interact with each other once bound to the DNA (Collado-Vides et al., 1991; Ishihama, 2010).

Several studies have explored the relationship between the architecture of cis-regulatory elements and the final logic of the target promoters, and initial attempts have focused on the mutation of cis-regulatory elements from natural promoters to investigate how these elements specify the promoter activity dynamics (Sawers, 1993; Darwin and Stewart, 1995; Izu et al., 2002; Setty et al., 2003). More recently, synthetic biology approaches have been used to construct artificial promoters through the combination of several cis-regulatory elements, and these have been characterized to decipher their architecture/dynamics relationship (Cox et al., 2007; Isalan et al., 2008; Kinkhabwala and Guet, 2008; Shis et al., 2014). However, while most synthetic biology approaches have focused on cis-elements for local regulators (which do not commonly regulate gene expression in a combinatorial manner), we recently investigated this combinatorial regulation problem with global regulators (Guazzaroni and Silva-Rocha, 2014; Amores et al., 2015; Monteiro et al., 2018). This is important because global regulators (such as IHF, Fis, and CRP) have numerous binding sites along the E. coli genome and frequently co-occur at target promoters (Guazzaroni and Silva-Rocha, 2014). Thus, Fis and IHF are two global regulators that play a critical role in coordinating gene expression in E. coli as well as in mediating DNA condensation in the cell (Azam and Ishihama, 1999; Browning and Busby, 2004; Browning et al., 2010; Ishihama, 2010). Fis, an abundant nucleoid-associated protein (NAP), is related to gene expression regulation in fast-growing cells, varying its function (as a repressor or activator transcriptional factor) according to its biding site position related to the core promoter (Hirvonen et al., 2001), while IHF is a NAP, which activity relates to changes in gene expression in cells during the transition from exponential to stationary phase (Azam and Ishihama, 1999; Azam et al., 2000; Browning et al., 2010). Moreover, IHF binds to AT-rich DNA motifs with well-defined sequence preferences, while Fis also prefers AT-rich regions with a more degenerate sequence preference (Déthiollaz et al., 1996; Ussery et al., 2001; Dorman and Deighan, 2003; Aeling et al., 2006). Additionally, cross-regulation between Fis and IHF has been demonstrated for several systems, and how specific vs. promiscuous DNA recognition can be achieved for these two global regulators is not fully understood (Browning et al., 2010; Ishihama, 2010; Rossiter et al., 2015).

We previously explored how complex synthetic promoters harboring cis-regulatory elements for CRP and IHF can generate diverse regulatory logic depending on the final architecture of synthetic promoters, demonstrating that it is not possible to predict the regulatory logic of complex multiple promoters from the known dynamics of their simple versions (Monteiro et al., 2018). Here, we further explore this approach to investigate the relationship between cis-regulatory elements for Fis and IHF. Using consensus binding sites for these 2 TFs at different promoter positions and in different numbers, we first demonstrated that while some promiscuous interactions occur between the TFs and the binding sites, some specific cis-regulatory architectures can completely abolish non-specific interactions. Additionally, complex promoters constructed by the combination of cis-elements for Fis and IHF can generate many completely different outputs, such as Fis-repressed promoters, IHF-repressed promoters, and systems where Fis and IHF act as activators. As these changes in promoter logic result from changes in promoter architecture only (and not on the affinity of the transcriptional factor to each individual cis-element), the data presented here reinforce the notion that complex bacterial promoters can display emergent properties, where their final behavior cannot be defined from the characterization of the individual component. Taken together, our findings present a comprehensive strategy for fine-tuning gene circuits to perform optimally in a given context (e.g., engineering of synthetic promoters) as well as provide insights for the understanding of natural complex promoters controlled by global regulators.

\section{RESULTS AND DISCUSSION Generation of Complex Promoters for Fis}

In order to investigate the effect of promoter architecture in the regulation by Fis and IHF, we evaluated the effect of 12 complex promoters constructed in early work (Monteiro et al., 2018) and we constructed 30 new combinatorial promoters with consensus DNA sequences for Fis (Fis-BS) and IHF (IHF-BS) binding sites positioned upstream of a weak core promoter $(-35 /-10$ region) at specific positions (1-4) centered at the $-61,-81$, -101 , and -121 regions related to the transcriptional start site (TSS) (Figure 1). For that, we generated double-strand DNA sequences for Fis-BS, IHF-BS, and a neutral sequence (Neg) with no related transcriptional binding site, which were combined for the generation of a library of synthetic promoters, merging the transcriptional binding sites for Fis, IHF, and/or neutral sequence for each position (Table 1). The complex promoters were assembled by DNA ligation and cloned into pMR1, a midcopy number vector harboring mCherry and GFPlva as reporter fluorescent proteins (Figure 1). The resulting reporter plasmids (with each promoter controlling only by GFPlva expression) were used to transform competent $E$. coli wild-type strain 


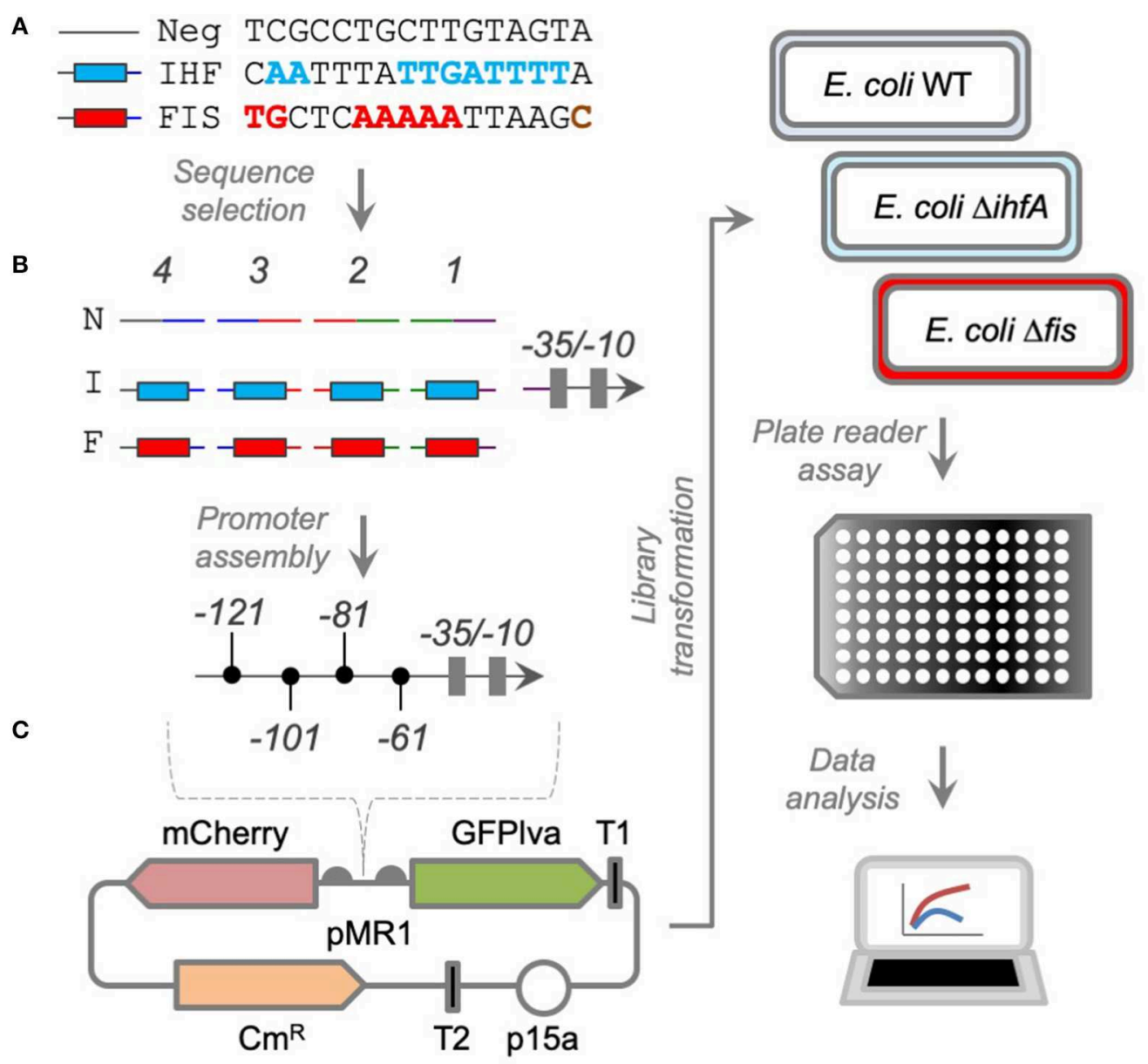

FIGURE 1 | Strategies to construct synthetic complex promoters. (A) DNA sequences harboring the consensus sequence for IHF or Fis binding were selected, along with a control sequence that cannot be recognized by any TF. (B) Double-stranded DNA fragments were produced with cohesive ends specific for each promoter position (numbered from 1 to 4) and assembled together with a weak core promoter harboring the -35/-10 boxes for RNAP recognition (Guazzaroni and Silva-Rocha, 2014). (C) The fragments were cloned into a promoter probe vector (pMR1) harboring resistance to chloramphenicol (CmR), a medium-copy number origin of replication (p15a), and two reporter genes (mCherry and GFPIva). The libraries were introduced into wild-type and mutant strains of E. coli from the KEIO collection (Baba et al., 2006). The resultant strains were analyzed at the population level in a plate reader and the data processed using script in R.

(BW25113-WT) and/or E. coli mutants for ihfA ( $\Delta$ ihfA) and fis ( $\Delta$ fis) (from Keio collection) (Baba et al., 2006). Using these constructs, we assayed promoter activity for $8 \mathrm{~h}$ in minimal media (M9 complete), measuring the relative GFP expression (GFP/OD) in all strains in the plate reader fluorimeter Victor X3 (PerkinElmer). As a negative control, we used the Neg sequence occupying the 4 possible positions before the core promoter. All data presented in this work are referred to $4 \mathrm{~h}$ of cell growth. In the next sections, we present the results of the promoter analysis per category to uncover the cis-regulatory logic for each variant.

\section{Changing the Fis Binding Site Architecture Modulates Fis and IHF Binding Specificity}

We analyzed the architecture effect for Fis cis-regulatory elements by evaluating the influence of position and sequence combination for Fis-BS. For that, we used promoters merging Fis-BS and Neg sequences to measure relative GFP expression (GFP/OD) levels after $4 \mathrm{~h}$ of cell growth in wild-type, $\Delta$ fis, and $\triangle i h f A$ E. coli strains, and normalized the results to our negative control (top bars in Figure 2). The results displayed in Figure 2 show that most of the promoters harboring Fis-BS exhibit low activity in wild-type $E$. coli, comparable to the negative control. However, when these promoters were assayed in E. coli $\Delta$ fis strain (red bars), 4 of them displayed a significant increase in activity compared to the wild-type strain (green and gray in Figure 2). Particularly, in the presence of Fis protein, Fis could occupy Fis-BS and act as a repressor of promoter activity. However, not all architectures with Fis-BS at the 4th or 3rd positions display this promoter behavior. This phenomenon only occurs in two other cases with more than 1 Fis-BS combination (promoters shaded in green in Figure 2). This 
TABLE 1 | Strains, plasmids, and primers used in this study.

\begin{tabular}{|c|c|c|}
\hline $\begin{array}{l}\text { Strains, plasmids, } \\
\text { and primers }\end{array}$ & Description & References \\
\hline \multicolumn{3}{|l|}{ Strains } \\
\hline E. coli $\mathrm{DH} 10 \mathrm{~B}$ & 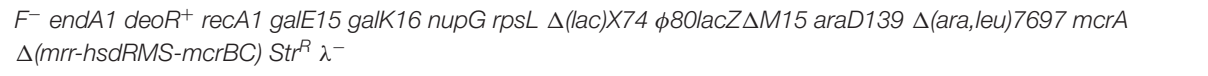 & Sambrook et al., 1989 \\
\hline E. coli BW25113 & $\begin{array}{l}\text { lacl+rrnBT14 } \Delta \text { lacZWJ16 hsdR514 } \triangle a r a B A D A H 33 \Delta r h a B A D L D 78 \text { rph-1 } \Delta(\operatorname{araB}-D) 567 \Delta(r h a D-B) 568 \\
\text { slacZ4787(::rrnB-3) hsdR514 rph-1 }\end{array}$ & $\begin{array}{l}\text { Datsenko and Wanner } \\
2000\end{array}$ \\
\hline E. coli JW1702 & E. coli BW25113 with $\triangle$ ihfA mutation & Baba et al., 2006 \\
\hline E. coli JW3229 & E. coli BW25113 with $\Delta$ fis mutation & Baba et al., 2006 \\
\hline \multicolumn{3}{|l|}{ Plasmids } \\
\hline pMR1 & $\mathrm{Cm}^{\mathrm{R}}$; orip15a; Promoter probe vector with mCherry and GFPlva reporters & $\begin{array}{l}\text { Guazzaroni and } \\
\text { Silva-Rocha, } 2014\end{array}$ \\
\hline pMR1-NNNN & pMR1 with a reference promoter with 4 non-regulatory sequences & Monteiro et al., 2018 \\
\hline pMR1-FNNN & pMR1 with a synthetic promoter with a Fis cis-elements at position 4 & This study \\
\hline pMR1-NFNN & pMR1 with a synthetic promoter with a Fis cis-elements at position 3 & This study \\
\hline pMR1-NNFN & pMR1 with a synthetic promoter with a Fis cis-elements at position 2 & This study \\
\hline pMR1-NNNF & pMR1 with a synthetic promoter with a Fis cis-elements at position 1 & This study \\
\hline pMR1-NNFF & pMR1 with a synthetic promoter with Fis cis-elements at positions 2 and 1 & This study \\
\hline pMR1-FNNF & pMR1 with a synthetic promoter with Fis cis-elements at positions 4 and 1 & This study \\
\hline pMR1-FFNN & pMR1 with a synthetic promoter with Fis cis-elements at positions 4 and 3 & This study \\
\hline pMR1-NFFN & pMR1 with a synthetic promoter with Fis cis-elements at positions 3 and 2 & This study \\
\hline pMR1-NFNF & pMR1 with a synthetic promoter with Fis cis-elements at positions 3 and 1 & This study \\
\hline pMR1-FNFN & pMR1 with a synthetic promoter with Fis cis-elements at positions 4 and 2 & This study \\
\hline pMR1-FFNF & pMR1 with a synthetic promoter with Fis cis-elements at positions 4, 3 and 1 & This study \\
\hline pMR1-FNFF & pMR1 with a synthetic promoter with Fis cis-elements at positions 4, 2 and 1 & This study \\
\hline pMR1-NFFF & pMR1 with a synthetic promoter with Fis cis-elements at positions 3, 2 and 1 & This study \\
\hline pMR1-FFFN & pMR1 with a synthetic promoter with Fis cis-elements at positions 4, 3 and 2 & This study \\
\hline pMR1-FFFF & pMR1 with a synthetic promoter with Fis cis-elements at positions 4, 3, 2 and 1 & This study \\
\hline pMR1-INNN & pMR1 with a synthetic promoter with a IHF cis-element at position 4 & Monteiro et al., 2018 \\
\hline pMR1-NINN & pMR1 with a synthetic promoter with a IHF cis-element at position 3 & Monteiro et al., 2018 \\
\hline pMR1-NNIN & pMR1 with a synthetic promoter with a IHF cis-element at position 2 & Monteiro et al., 2018 \\
\hline pMR1-NNNI & pMR1 with a synthetic promoter with a IHF cis-element at position 1 & Monteiro et al., 2018 \\
\hline pMR1-IINN & pMR1 with a synthetic promoter with IHF cis-elements at positions 4 and 3 & Monteiro et al., 2018 \\
\hline pMR1-NIIN & pMR1 with a synthetic promoter with IHF cis-elements at positions 3 and 2 & Monteiro et al., 2018 \\
\hline pMR1-NNII & pMR1 with a synthetic promoter with IHF cis-elements at positions 2 and 1 & Monteiro et al., 2018 \\
\hline pMR1-ININ & pMR1 with a synthetic promoter with IHF cis-elements at positions 4 and 2 & Monteiro et al., 2018 \\
\hline pMR1-NINI & pMR1 with a synthetic promoter with IHF cis-elements at positions 3 and 1 & Monteiro et al., 2018 \\
\hline pMR1-INNI & pMR1 with a synthetic promoter with IHF cis-elements at positions 4 and 1 & Monteiro et al., 2018 \\
\hline pMR1-III & pMR1 with a synthetic promoter with IHF cis-elements at positions 4, 3, 2 and 1 & Monteiro et al., 2018 \\
\hline pMR1-FNNI & pMR1 with a synthetic promoter with a IHF cis-element at position 1 and Fis cis- element at position 4 & This study \\
\hline pMR1-NFNI & pMR1 with a synthetic promoter with a IHF cis-element at position 1 and Fis cis- element at position 3 & This study \\
\hline pMR1-NNFI & pMR1 with a synthetic promoter with a IHF cis-element at position 1 and Fis cis- element at position 2 & This study \\
\hline pMR1-NFFI & pMR1 with a synthetic promoter with a IHF cis-element at position 1 and Fis cis- elements at positions 3 and 2 & This study \\
\hline pMR1-FFNI & pMR1 with a synthetic promoter with a IHF cis-element at position 1 and Fis cis- elements at positions 4 and 3 & This study \\
\hline pMR1-IFNN & pMR1 with a synthetic promoter with a IHF cis-element at position 4 and Fis cis- element at position 3 & This study \\
\hline pMR1-INFN & pMR1 with a synthetic promoter with a IHF cis-element at position 4 and Fis cis- element at position 2 & This study \\
\hline pMR1-INNF & pMR1 with a synthetic promoter with a IHF cis-element at position 4 and Fis cis- element at position 1 & This study \\
\hline pMR1-IFFN & pMR1 with a synthetic promoter with a IHF cis-element at position 4 and Fis cis- elements at positions 3 and 2 & This study \\
\hline pMR1-IFNF & pMR1 with a synthetic promoter with a IHF cis-element at position 4 and Fis cis- elements at positions 3 and 1 & This study \\
\hline pMR1-INFF & pMR1 with a synthetic promoter with a IHF cis-element at position 4 and Fis cis- elements at positions 2 and 1 & This study \\
\hline pMR1-IFFF & pMR1 with a synthetic promoter with a IHF cis-element at position 4 and Fis cis- elements at positions 3,2 and 1 & This study \\
\hline pMR1-IFFI & pMR1 with a synthetic promoter with a IHF cis-elements at positions 4 and 1. Fis cis- elements at positions 3 and 2 & This study \\
\hline
\end{tabular}


TABLE 1 | Continued

\begin{tabular}{|c|c|c|}
\hline $\begin{array}{l}\text { Strains, plasmids, } \\
\text { and primers }\end{array}$ & Description & References \\
\hline pMR1-IFNI & pMR1 with a synthetic promoter with a IHF cis-elements at positions 4 and 1. Fis cis- element at position 3 & This study \\
\hline pMR1-INFI & pMR1 with a synthetic promoter with a IHF cis-elements at positions 4 and 1. Fis cis- element at position 2 & This study \\
\hline \multicolumn{3}{|l|}{ Primers } \\
\hline P1-N5 & AATTCTCGCCTGCTTGTAGTA* & Monteiro et al., 2018 \\
\hline P1-N3 & CGCCTACTACAAGCAGGCGAG & Monteiro et al., 2018 \\
\hline P2-N5 & GGCGTCGCCTGCTTGTAGTA & Monteiro et al., 2018 \\
\hline P2-N3 & GCGGTACTACAAGCAGGCGA & Monteiro et al., 2018 \\
\hline P3-N5 & CCGCTCGCCTGCTTGTAGTA & Monteiro et al., 2018 \\
\hline P3-N3 & CCAATACTACAAGCAGGCGA & Monteiro et al., 2018 \\
\hline P4-N5 & TTGGTCGCCTGCTTGTAGTA & Monteiro et al., 2018 \\
\hline P4-N3 & CAAGTACTACAAGCAGGCGA & Monteiro et al., 2018 \\
\hline P1-15 & AATTCCAATTTATTGATITTA* & Monteiro et al., 2018 \\
\hline P1-13 & CGCCTAAAATCAATAAATTGG & Monteiro et al., 2018 \\
\hline P4-15 & TTGGCAATITATTGATITA & Monteiro et al., 2018 \\
\hline P4-I3 & CAAGTAAAATCAATAAATTG & Monteiro et al., 2018 \\
\hline P1-F5 & АATTCTGCTCAAAAATTAAGC* & This study \\
\hline P1-F3 & CGCCGCTTAATIITGAGCAG & This study \\
\hline P2-F5 & GGCGTGCTCAAAAATTAAGC & This study \\
\hline P2-F3 & GCGGGCTTAATIITGAGCA & This study \\
\hline P3-F5 & CCGCTGCTCAAAAATTAAGC & This study \\
\hline P3-F3 & CCAAGCTTAATIITGAGCA & This study \\
\hline P4-F5 & TTGGTGCTCAAAAATTAAGC & This study \\
\hline P4-F3 & CAAGGCTTAATIITGAGCA & This study \\
\hline CoreP-5 & CTTGAGGCACCCCAGGCTITACACTTATGCTTCCGGCTCGTATGTTGTGTGGAG & Monteiro et al., 2018 \\
\hline CoreP-3 & GATCCTCCACACAACATACGAGCCGGAAGCATAAAGTGTAAAGCCTGGGGTGCCT* & Monteiro et al., 2018 \\
\hline pMR1-F & CTCGCCCTTGCTCACC & Monteiro et al., 2018 \\
\hline pMR1-R & ACAAGAATTGGGACAACTCC & Monteiro et al., 2018 \\
\hline
\end{tabular}

${ }^{*}$ Restriction sites are underlined in the primer sequences.

reveals a complex association between promoter architecture and expression profile, which seems to be dependent on the Fis-BS position and arrangement.

We also assayed Fis-BS promoters in the E. coli $\triangle$ ihfA strain (blue bars) to evaluate the specificity of Fis for Fis-BS. Strikingly, despite most promoters display similar activity levels in the $\triangle i h f A$ strain as in the wild-type, 1 single promoter variant harboring Fis-BS at the 3rd position ( -101 relative to the TSS) displayed a substantial increase in activity in the ihfA mutant relative to the wild-type strain (promoter shaded in gray in Figure 2). This result indicates that IHF also acts as a repressor of this promoter variant. Although it was restricted to a single promoter variant, these results suggest that non-specific IHF binding to the Fis-BS exists, suggesting that promiscuous regulatory interaction could occur and seems to be dependent on promoter architecture, since this phenomenon is detected only for Fis-BS at the $3 \mathrm{rd}$ position. Altogether, these results suggest a complex interplay between the position and combination of Fis-BS and the regulation of gene expression.

\section{IHF Binding Sites Can Be Recognized by the Fis Regulator in an Architecture-Dependent Manner}

Using the same strategy as in Figure 2, we investigated the regulatory logic of promoters harboring multiple cis-regulatory elements for IHF, merging IHF-BS, and Neg sequences. Figure 3 shows that most promoters displayed low activity in the wild type strain of E. coli and higher activity in E. coli $\triangle i h f A$ (blue bars), in agreement with previous data on complex IHF promoters (green and gray shaded) (Monteiro et al., 2018). However, when these promoters were assayed in E. coli $\Delta$ fis strain (red bars), we observed that 4 promoter architectures also displayed higher activity in this mutant (promoters shaded in green in the figure), indicating that Fis was also able to repress these promoter variants, highlighting a possible crosstalk (CepedaHumerez et al., 2015; Friedlander et al., 2016) between these 2 TFs, which should be further investigated in the future. However, it is worth noticing that the promoter variants harboring cisregulatory elements for IHF at 4 th or $3 \mathrm{rd}$ and 4 th positions 


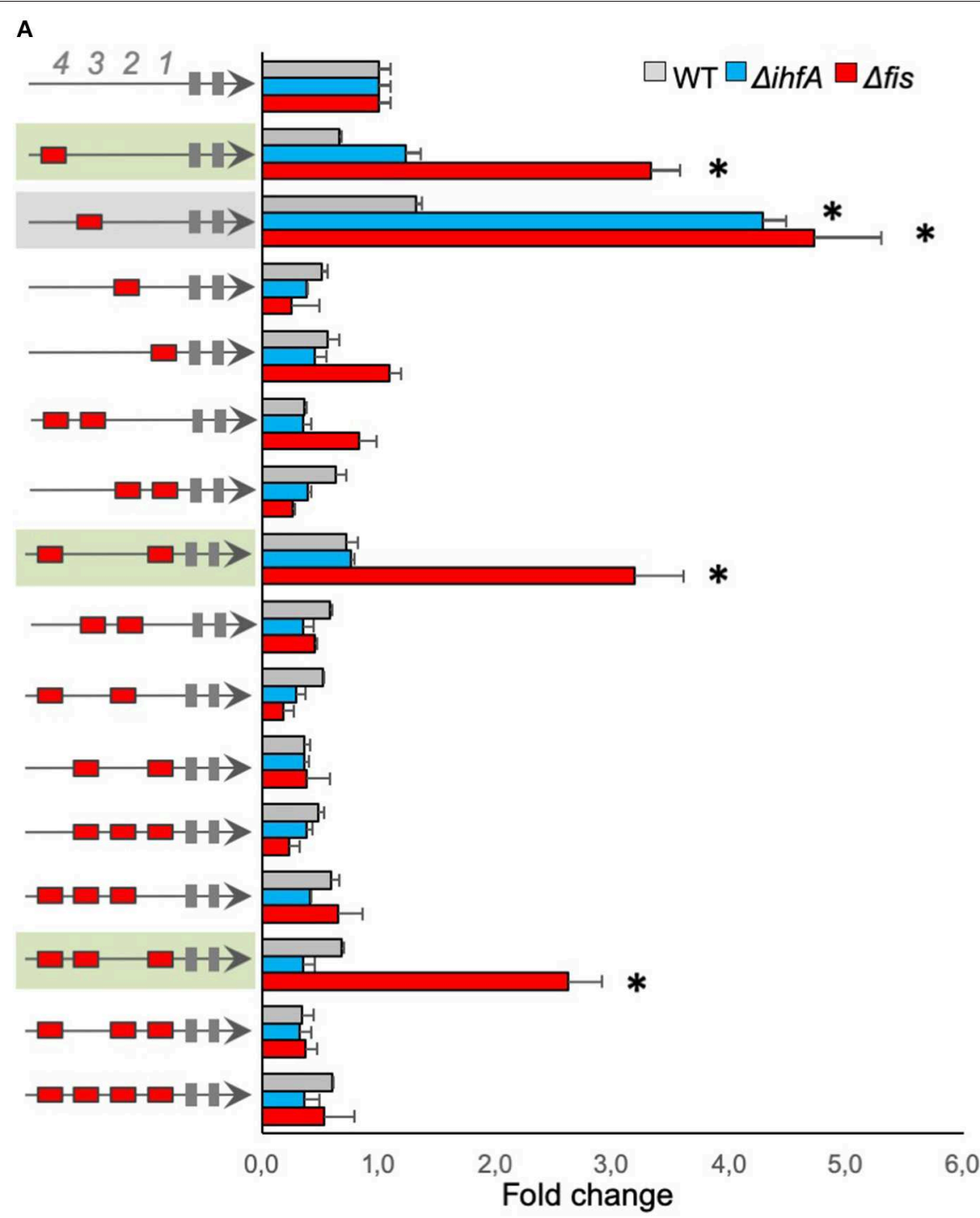

B
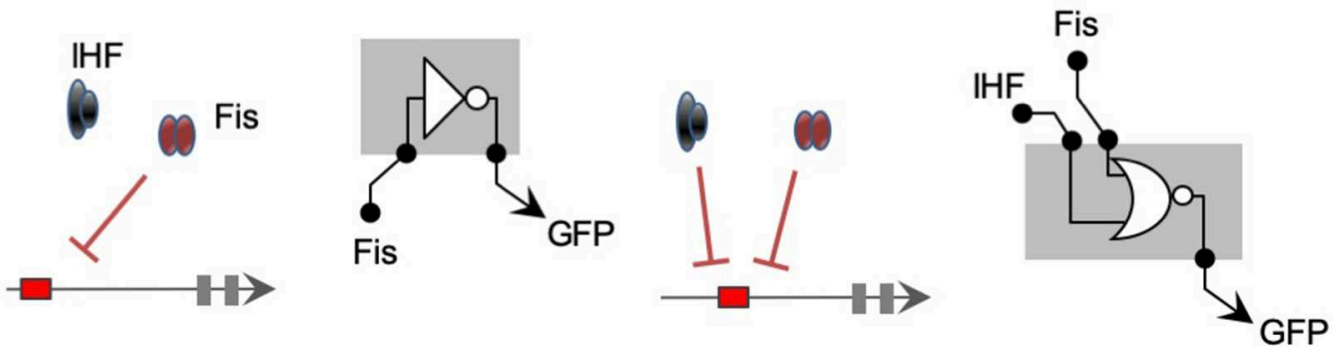

FIGURE 2 | The activity of promoters harboring Fis-binding sites (A) The architecture of the synthetic promoter is shown on the left (red boxes represent Fis-BS). Promoter activities are shown in bars and normalized based on the activity of the reference promoter (i.e., a promoter with 4 neutral sequences). Promoter analyses were performed for $4 \mathrm{~h}$ of growth, three genetic backgrounds of $E$. coli (wild type-gray bars, $\Delta$ fis - red bars, and $\Delta$ ihf $A-$ blue bars). Promoters that displayed a significant increase in activity compared to the wild-type strain were shaded in green or gray for easy viewing. Statistical differences between synthetic promoters and their control (wild type condition) are highlighted by $\left(^{*}\right)$ as analyzed using Student's $t$-test with $p<0.05$. (B) Summary of most significant changes in promoter architecture leading to changes in promoter logic.

( -101 and -121 relative to the TSS) displayed both a strong repression by IHF but no modulation by Fis (promoter shaded in gray in Figure 3). Again, these results reinforce that the gene expression pattern and the promiscuous or specific binding to transcriptional factors allows for the fine-tuning of promoter activities based on their architectures. 


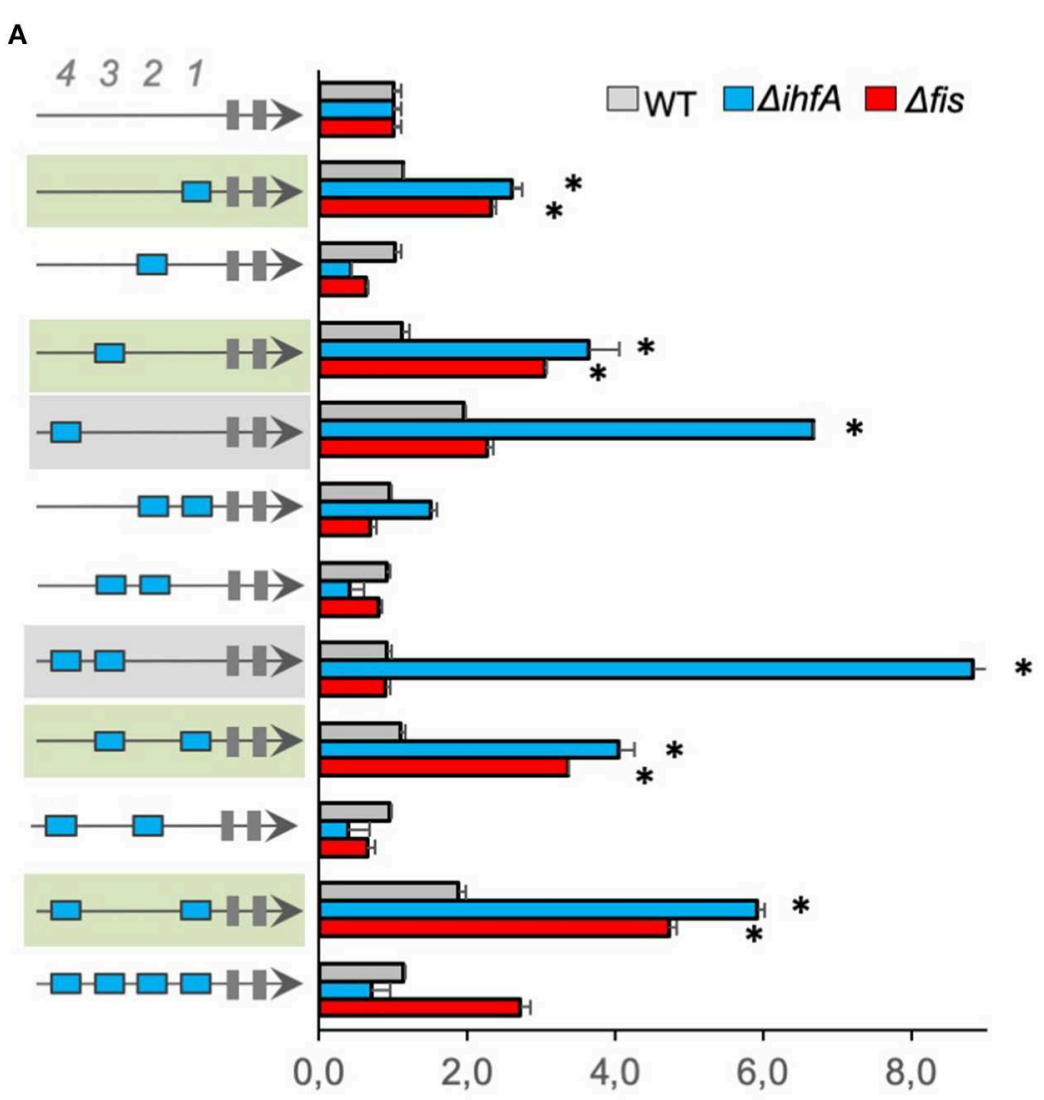

Fold change

B
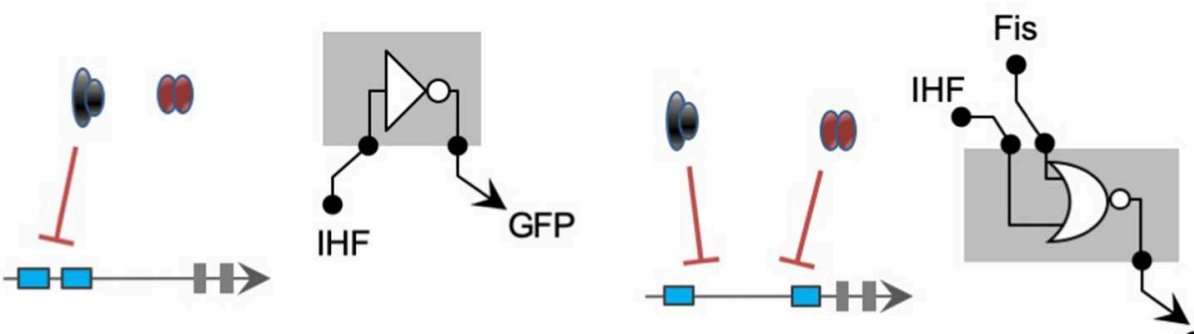

GFP

FIGURE 3 | The activity of promoters harboring IHF-binding sites. (A) The architecture of the synthetic promoter is shown on the left (blue boxes represent IHF-BS). Promoter activities are shown in bars and normalized based on the activity of the reference promoter (i.e., a promoter with 4 neutral sequences). Eleven promoter variants previously described (Monteiro et al., 2018) were analyzed in wild type (gray bars) $\Delta$ fis (red bars), and $\Delta$ ihfA (blue bars) mutant strains of $E$. coli. Promoter architectures that displayed higher activity in $E$. coli $\Delta$ fis and $\triangle$ ihfA are shaded in green, indicating that Fis was also able to repress these promoter variants, highlighting a possible crosstalk. Promoter that displayed a strong repression by IHF but no modulation by Fis are shaded in gray, reinforce that the gene expression pattern and the promiscuous or specific binding to transcriptional factors allows for the fine-tuning of promoter activities based on their architectures. Statistical differences between synthetic promoters and their control (wild type condition) are highlighted by ${ }^{*}$ ) as analyzed using Student's $t$-test with $p<0.05$. (B) Summary of most significant changes in promoter architecture leading to changes in promoter logic. Statistical differences between synthetic promoters and their control are highlighted by $\left({ }^{*}\right)$ as analyzed using Student's $t$-test with $p<0.05$.

\section{Merging IHF-BS and Fis-BS Leads to an Unpredictable Expression Pattern}

After we investigated the regulatory interactions for promoters harboring cis-regulatory elements for a single transcriptional factor (IHF or Fis), we constructed promoters combining binding sites for both TFs and Neg sequences. In order to systematically investigate the effect of combined transcriptional factor-binding sites on promoter logic, we first fixed 1 IHF-BS at the 1st position (-61) and varied Fis-BS for the 2nd, 3rd, and 4th positions. As shown in Figure 4A, 1 promoter harboring 1 single IHF-BS at 
A

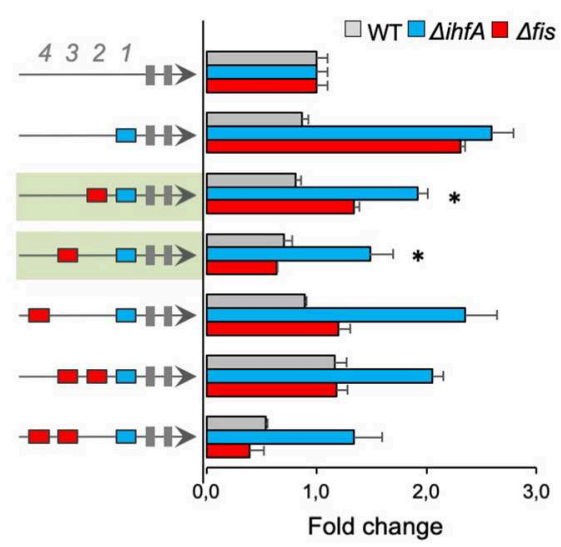

C

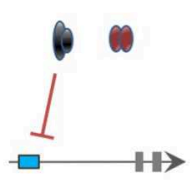

B
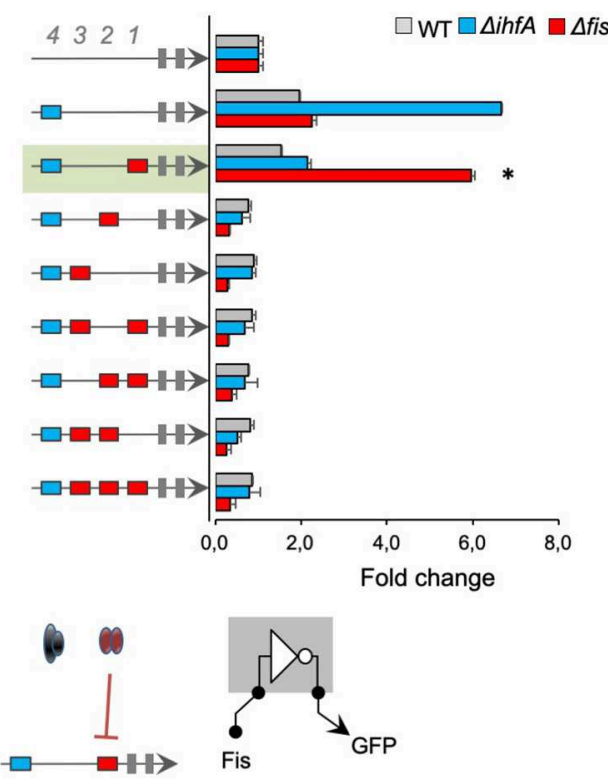

FIGURE 4 | The activity of promoters with combined IHF- and Fis-binding sites. The architecture of the synthetic promoter is shown on the left (blue boxes represent IHF-BS and red boxes represent Fis-BS). Promoter activities are shown in bars and normalized based on the activity of the reference promoter (i.e., a promoter with 4 neutral sequences). Promoter variants were analyzed in wild type (gray bars) $\Delta$ fis (red bars), and $\Delta$ ihfA (blue bars) mutant strains of $E$. coli. (A) Characterization of promoters with a single IHF-BS fixed at position $1(-61)$ and varying Fis-BS. Promoters shaded in green present reduced activity in the ihfA and fis mutant strains, compared to IHF-BS at the 1st position. Statistical differences between synthetic promoters and their control (PNNNI) are highlighted by $\left({ }^{\star}\right)$ as analyzed using Student's $t$-test with $p<0.05$. (B) Characterization of promoters with a single IHF-BS fixed position 4 (-121) and varying Fis-BS. Promoter shaded in green displayed increased activity in the E. coli $\Delta$ fis strain, while it showed no activity in the wild type and $\triangle i h f A$ strains. Statistical differences between this promoter in $\triangle$ fis condition and wild type and $\Delta$ ihfA are highlighted by $\left(^{*}\right)$ as analyzed using Student's $t$-test with $p<0.05$. (C) Summary of most significant changes in promoter architecture leading to changes in promoter logic. Statistical differences between synthetic promoters and their control are highlighted by $\left(^{\star}\right)$ as analyzed using Student's $t$-test with $p<0.05$.

the 1 st position showed no activity in the wild-type E. coli strain but increased activity in the fis and ihfA mutant strains. However, adding Fis-BS at the 2 nd or 3 rd position resulted in promoters with reduced activity in the ihf $A$ and fis mutant strains, compared to IHF-BS at the 1st position (promoters shaded in green in Figure 4A). Comparison of these green shaded promoters to promoters with 1 single Fis-BS at the 2 nd or 3 rd positions in Figure 2, we cannot observe any patterns between the merging of binding sites for these transcriptional factors, that is, the activity of promoters consisting of both Fis-BS and IHF-BS is not the sum of behaviors from Fis-BS and IHF-BS individually. When 1 single IHF-BS was fixed at the 4th position $(-121)$, the resulting promoter displayed strong activity in $\triangle i h f A$ strains (Figure 4B). However, when 1 single Fis-BS was added at the 1 st position $(-61)$, the resulting promoter displayed increased activity in the E. coli $\Delta$ fis strain, while it showed no activity in the wild type and $\triangle i h f A$ strains. Therefore, this promoter architecture may be being repressed, especially by Fis regulator (shaded in green). However, for promoters with Fis-BS fixed at the 1st position (Figure 2), we observed a reduction in the promoter activity in the $\Delta$ fis strain, demonstrating that the presence of IHF in this specific position may influence a positive expression in the absence of Fis. Finally, the addition of 1 single or multiple FisBS at different positions completely blocked promoter activity, and this was not relieved in either $\Delta$ fis or $\Delta i h f A$ strains, showing that transcriptional factors and binding site sequences of IHF and Fis contribute to promoter complexity. A mutant for ihfA and fis should be a compelling model to completely understand this promoter logic, but a mutant for both TFs has proven to be difficult to construct. It is important to note that IHF and Fis, which are transcriptional factors, are also NAPs, so the gene expression identified here could be related to possible changes in the DNA geometry (Déthiollaz et al., 1996). Taken together, these results also suggest that Fis and IHF proteins and their binding sites exert complex regulatory patterns, hampering promoter behavior predictions.

\section{Combination of Fis and IHF Binding Sites Generates Strong Fis and IHF Activated Promoters}

In all promoters presented until this point, while the combination of different cis-regulatory genes was able to determine the regulatory logic displayed by IHF and Fis, the 2 TFs acted as repressors of promoter activity (Figures 2-4). However, this behavior shifted when we constructed promoter versions harboring IHF-BS at the 1st and 4th positions and varying sites for Fis-BS (Figure 5). As shown in this figure, when 1 


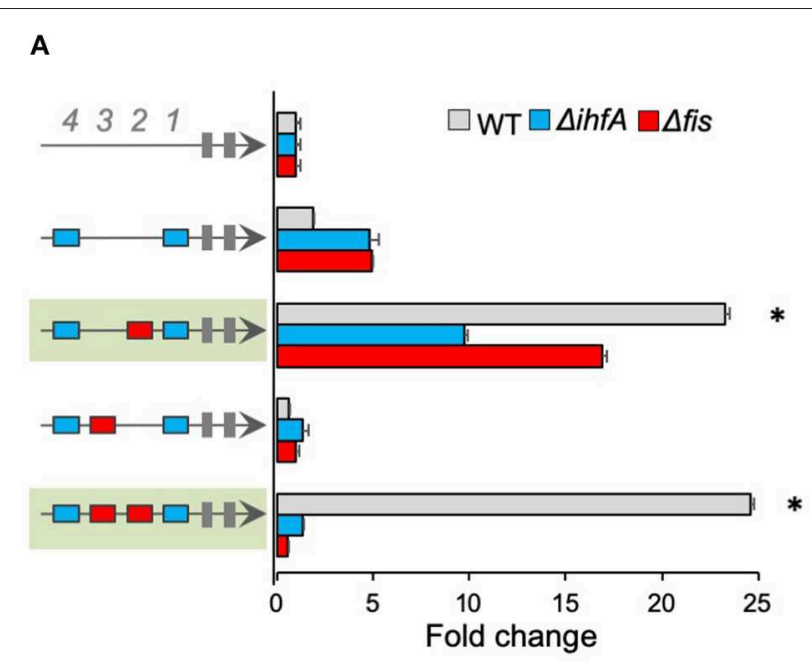

B
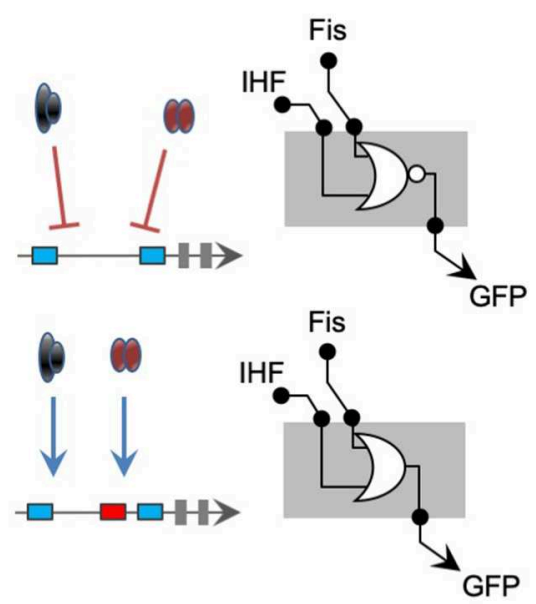

FIGURE $\mathbf{5}$ | Analysis of promoters with 2 fixed IHF-binding sites. (A) The architecture of the synthetic promoter is shown on the left (blue boxes represent IHF-BS and red boxes represent Fis-BS). Promoter activities are shown in bars and normalized based on the activity of the reference promoter (i.e., a promoter with 4 neutral sequences). Promoter variants were analyzed in wild type (gray bars) $\Delta$ fis (red bars), and $\triangle$ ihfA (blue bars) mutant strains of $E$. coli. For this analysis, IHF cis-regulatory elements were placed at positions 1 and 4 , and additional Fis-BS were introduced into the promoters. Promoter that displayed a strong activity in the wild-type when compared to the $\Delta$ fis or $\triangle i h f A$ mutant of $E$. coli are shaded in green. Statistical differences between synthetic promoters in wild type condition and $\triangle$ fis and $\triangle i h f A$ condition are highlighted by $\left(^{*}\right)$ as analyzed using Student's $t$-test with $p<0.05$. (B) Summary of most significant changes in promoter architecture leading to changes in promoter logic. Statistical differences between synthetic promoters and their control are highlighted by $\left({ }^{*}\right)$ as analyzed using Student's $t$-test with $p$ $<0.05$.

single Fis-BS was added at the 2 nd position $(-81)$, the resulting promoter displayed a strong activity in the wild-type strain of E. coli, when compared to the version lacking this element (promoter in the green shaded region in Figure 5). Furthermore, when these promoters were assayed in E. coli $\Delta$ fis or $\Delta i h f A$, we observed a substantial reduction in their activity, indicating that both TFs acted as activators of the combinatorial promoter. The same behavior was also observed for a promoter harboring
2 IHF-BS (at the 1st and 4th positions) and 2 Fis-BS (2nd and 3rd positions), where reduction in the gene expression was even more evident. The same does not occur for a promoter harboring the 2 sites of IHF-BS and Fis-BS at the 3rd position, indicating the dependence and complexity of the relationship between promoter architecture and gene expression. These results highlight the rise of emergent properties in complex promoters for global regulators (Monteiro et al., 2018), as increasing the number of cis-regulatory elements can drastically shift the final regulatory logic of the system.

\section{Conclusions}

Bacteria are naturally endowed with complex promoters harboring multiple binding sites for several TFs. While several works based on mathematical modeling have argued that combinatorial regulation can be predicted from the characterization of individual promoter elements (Yuh, 1998; Bintu et al., 2005; Hermsen et al., 2006; Zong et al., 2018), along with the previous report (Monteiro et al., 2018) and here we provide growing evidence that small changes in the architecture of cis-regulatory elements can drastically change the final response of the system (Kreamer et al., 2016). The unpredictable behaviors observed in these studies might also depict a deeper evolutionary trend in gene regulation that has selected molecular systems/mechanisms capable of promoting both evolvability and robustness of gene expression levels through non-linear gene regulation (Steinacher et al., 2016). Thus, understanding the way the architecture of cis-regulatory elements determines gene expression behavior is pivotal not only to understand natural bacterial systems but also to provide novel conceptual frameworks for the construction of synthetic promoters for biotechnological applications (Monteiro et al., 2019b). Frequently, in genetic bioengineering applications, it is also necessary to fine-tune and balance specific gene expression due to the complexity of regulatory networks (Boyle and Silver, 2012; Scalcinati et al., 2012; Steinacher et al., 2016). Several recent studies have focused on the improvement of this strategy for diverse purposes (Egbert and Klavins, 2012; Siegl et al., 2013; Hwang et al., 2018). The present adjusting approach could be used as a strategy for the fine-tuning of genetic circuits to perform optimally in a given context. Our approach provided a library (from this study and from our previous work (Monteiro et al., 2018) of 74 promoter architectures characterized in different strains and conditions for in total of 230 outputs (different promoters in different strains and growth conditions) (Figure 6 and Table S1). Promoters from our synthetic promoter library with small adaptations could be used for diverse purposes in the biotechnological and bacterial network gene regulation fields.

Abstracting all the gene regulations investigated in this work, we are able to provide a visual summary of the findings reported here from a Boolean logic perspective (Figure 7). As shown in Figure 7A, changing a perfect Fis binding in $20 \mathrm{bp}$ (from position -121 to -101$)$ can turn a specific Fis-repressed promoter into a system repressed by both Fis and IHF. Using a more formal logic gate definition (Amores et al., 2015), this modification can turn a promoter with a NOT logic into one with an NOR logic. However, a promoter harboring 2 IHF-binding sites at 
A

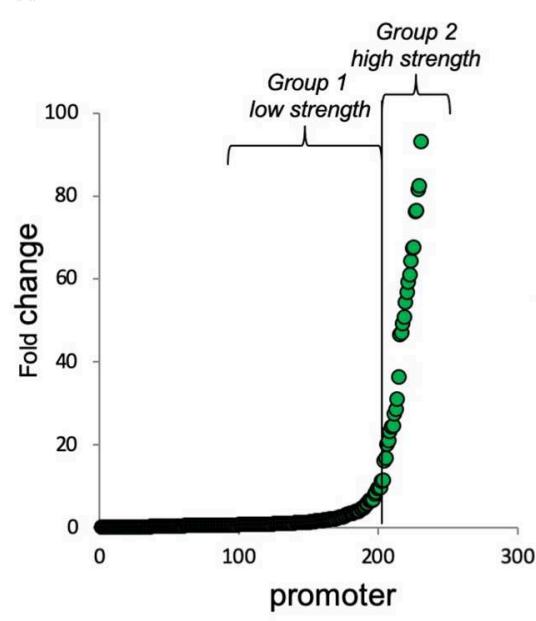

B

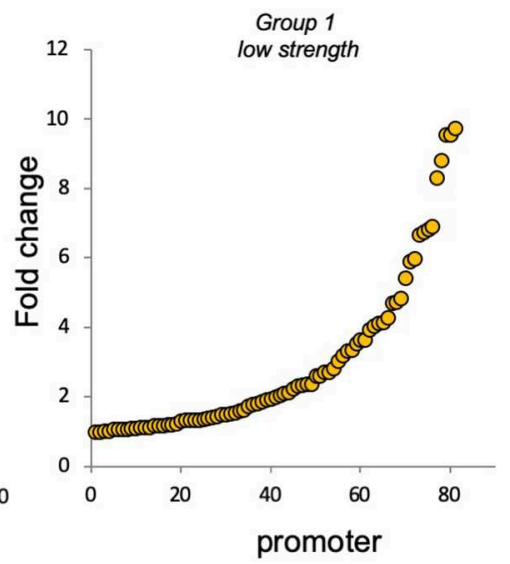

C

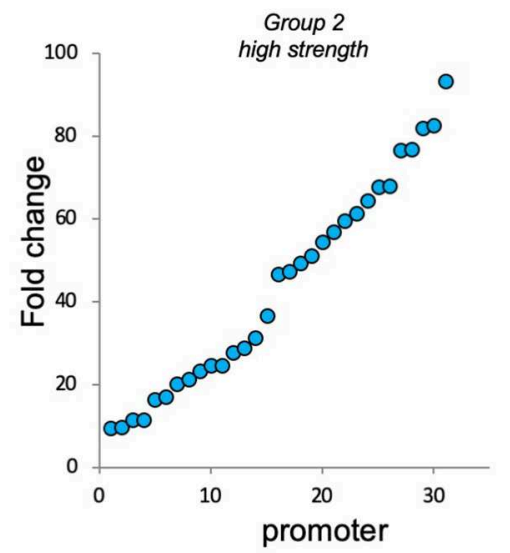

FIGURE 6 | Fold change of complex synthetic promoters at $4 \mathrm{~h}$ of growth. Complex promoters' approach could be used as a strategy for the fine-tuning of genetic circuits to perform optimally in a given context. A total of 230 promoter characterizations (74 architectures characterized in different strains and conditions). All promoter details are shown in Table S1. (A) All 230 promoter characterizations (from the lowest to the highest fold change) that were divided into 2 groups of interests. (B) Promoters with fold change between 1 and 10 (group 1: low strength). (C) Promoters with fold change up to 10 (group 2 -high strength).

positions -121 and -101 displayed specific IHF-repression, while changing the second binding site to position -61 resulted in a promoter repressed by both IHF and Fis (Figure 7B). In terms of promoter logic, this change in cis-element architecture also turns a promoter with NOT logic into one with an NOR logic. When a single IHF-binding site was presented at position -121, the final promoter was only repressed by IHF (Figure 7C). Yet, introducing an additional Fis-binding site at position -61 of this promoter turned it into a system exclusively repressed by Fis. This change maintained the NOT logic of the promoter but changed the TF able to repress the activity. Finally, and more remarkably, while a promoter with 2 IHF-BS (at positions -121 and -61) was repressed by both Fis and IHF, adding a third binding site for Fis at position -81 resulted in a promoter strongly activated by both TFs (Figure 7D). Therefore, this single-change cis-element architecture turned a promoter with NOR logic into an entirely OR promoter responsive to the same TFs. This remarkable regulatory versatility and unpredictability unveiled by synthetic combinatorial promoter shows that we only start to understand the complexity of gene regulation in bacteria. While the work presented here covers two of the main global regulators of $E$. coli, further studies are still necessary to uncover the hidden complexity of combinatorial gene regulation in this bacterium.

\section{MATERIALS AND METHODS}

\section{Plasmids, Bacterial Strains, and Growth Conditions}

E. coli $\mathrm{DH} 10 \mathrm{~B}$ was used for cloning procedures, while E. coli BW25113 was used as the wild-type strain (WT); E. coli JW17021 was used as a mutant for the IHF transcription factor (TF), and E. coli JW3229 was used as a mutant for the Fis TF. All strains were obtained from the Keio collection. For the procedures and analyses, $E$. coli strains were grown in $\mathrm{M} 9$ minimal media (6.4 g/L, $\mathrm{Na}_{2} \mathrm{HPO}_{4} \bullet 7 \mathrm{H}_{2} \mathrm{O}, 1.5 \mathrm{~g} / \mathrm{L} \mathrm{KH} \mathrm{KO}_{4}, 0.25 \mathrm{~g} / \mathrm{L} \mathrm{NaCl}, 0.5$ $\mathrm{g} / \mathrm{L} \mathrm{NH}_{4} \mathrm{Cl}$ ) supplemented with chloramphenicol at $34 \mu \mathrm{g} / \mathrm{mL}$, $2 \mathrm{mM} \mathrm{MgSO}_{4}, 0.1 \mathrm{mM}$ casamino acids, and $1 \%$ glycerol as the sole carbon source (Complete M9) at $37^{\circ} \mathrm{C}$. Plasmids, bacterial strains, and primers used in this study are listed in Table $\mathbf{1 .}$

\section{Design of Synthetic Promoter Scaffolds and Ligation Reactions}

The construction of synthetic promoters was performed by the ligation reaction of $5^{\prime}$-end phosphorylated oligonucleotides acquired from Sigma Aldrich (Table 1). The design of all single strands was projected to carry a 16 bp sequence containing the Fis binding site (F), IHF binding site (I), or a neutral motif $(\mathrm{N})$, which is a sequence where any TF is able to bind (Figure 1A). These locations were identified as positions $1,2,3$, and 4 , respectively (Figure 1B) and to be located at $-61,-81,-101$, or -121 bp upstream of the core promoter (Figure 1C). In addition to the 16 bp oligonucleotides, all single strands were designed to contain 3 base pairs overhang for its corrected insertion on the promoter (Figure 1C). Additionally, a core promoter based on the lac promoter, which is a weak promoter and therefore requires activation. The design of the synthetic promoters and the positions of the cis-elements were made based on strategies already performed by our group (Monteiro et al., 2018), aiming to arrange the cis-elements aligned to the transcription initiation site, considering the DNA curvature. To assemble the synthetic promoters, the $5^{\prime}$ and $3^{\prime}$ strands corresponding to each position were mixed at equimolar concentrations and annealed by heating at $95^{\circ} \mathrm{C}$ for $5 \mathrm{~min}$, followed by gradual cooling to room temperature $\left(25^{\circ} \mathrm{C}\right)$ for $5 \mathrm{~min}$, and finally maintained at $0^{\circ} \mathrm{C}$ for $5 \mathrm{~min}$. The external overhangs of the cis-element at position 4 and the core promoter were designed to carry EcoRI and BamHI 

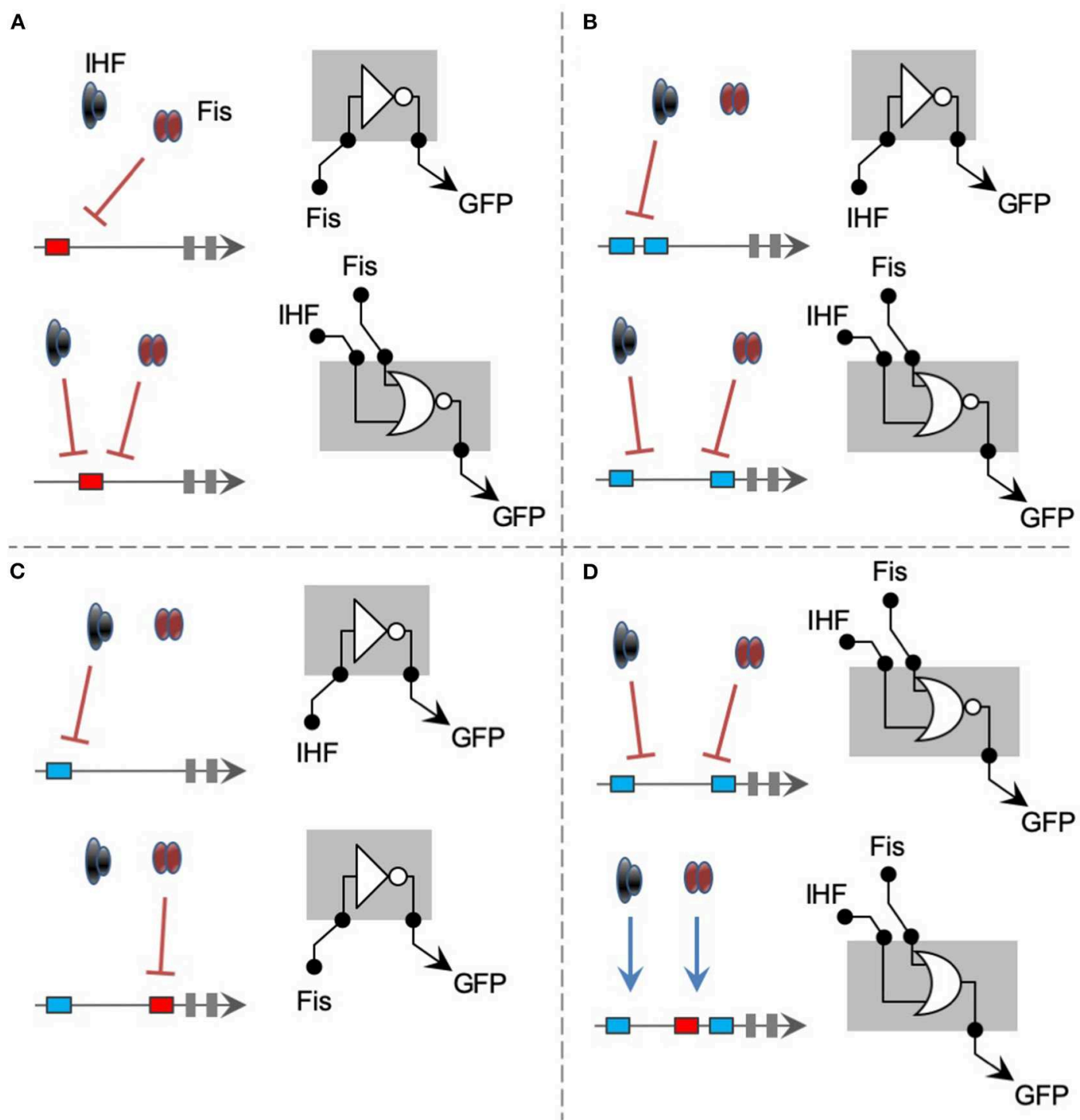

FIGURE 7 | Summary of most significant changes in promoter architecture leading to changes in promoter logic. The figures are represented using logic gate representation for gene regulation, even. (A) The change of a single Fis-BS from position -121 to -101 turns a NOT gate for Fis into an NOR gate for Fis and IHF. (B) Two IHF-BSs (at positions -121 and -101) worked as a NOT gate for IHF, while changing 1 site to position -61 generates an NOR gate for both IHF and Fis. (C) While a single IHF-binding site at position -121 results into a NOT gate for IHF, adding a Fis-binding site to the position -61 creates a NOT gate exclusively dependent on Fis. (D) Finally, adding a Fis-BS (position -81) to the NOR gate promoter presented in B drastically changes its logic to an OR gate, where the 2 TFs act as activators.

digested sites. In this way, it was allowed to ligate to a previously digested EcoRI/BamHI pMR1 plasmid. All five fragments (4 ciselements positions plus core promoter) were mixed equally in a pool with the final concentration of $5^{\prime}$ phosphate termini fixed at $15 \mu \mathrm{M}$. For the ligase reaction, $1 \mu \mathrm{L}$ of the fragment pool was added to $50 \mathrm{ng}$ EcoRI/BamHI pMR1 digested plasmid in the presence of ligase buffer and ligase enzyme to a final volume of $10 \mu \mathrm{L}$. Ligation was performed for $1 \mathrm{~h}$ at $16^{\circ} \mathrm{C}$, after which the ligase reaction was inactivated for $15 \mathrm{~min}$ at $65^{\circ} \mathrm{C}$. Two $\mu \mathrm{L}$ of the ligation was used to electroporate $50 \mu \mathrm{L}$ of $E$. coli DH10B competent cells. After 1 -h regenerating in $1 \mathrm{~mL} \mathrm{LB}$ media, the total volume was plated in LB solid dishes supplemented with chloramphenicol at $34 \mu \mathrm{g} / \mathrm{mL}$. Clones were confirmed by colony PCR with primers pMR1-F and pMR1-R (Table 1) using pMR1 empty plasmid PCR reaction as further length reference on electrophorese agarose gel. Clones with a potential correct length were submitted to Sanger DNA sequencing to confirm correct promoter assembly.

\section{Promoter Activity Analysis and Data Processing}

Promoter activity was measured for all 42 promoters at different genetic backgrounds and conditions. For each experiment, 
the plasmid containing the promoter of interest was used to transform E. coli wild type, E. coli $\triangle i h f A$ mutant, or E. coli $\Delta f i s$ mutant, as indicated. Freshly plated single colonies were selected with sterile loops and then inoculated in $1 \mathrm{~mL}$ of M9 media. After $16 \mathrm{~h} 10 \mu \mathrm{L}$ of this culture was assayed in 96 wells microplates in biological triplicate with $190 \mu \mathrm{L}$ of M9 media. Cell growth and GFP fluorescence were quantified using a Victor X3 plate reader (PerkinElmer) that was measured for $8 \mathrm{~h}$ at intervals of $30 \mathrm{~min}$. All graphics were constructed based on $4 \mathrm{~h}$ of cell growth since under our experimental setup and previous work (Monteiro et al., 2018), most promoters reach maximal activity at $4 \mathrm{~h}$ of growth. Therefore, this is the best time point to compare maximal promoter activity. Promoter activities were calculated as arbitrary units dividing the GFP fluorescence levels by the optical density at $600 \mathrm{~nm}$ (reported as $\mathrm{GFP} / \mathrm{OD}_{600}$ ) after background correction. Technical triplicates and biological triplicates were performed in all experiments. Raw data were processed using ad hoc $\mathrm{R}$ script (https://www.r-project.org/), and plots were constructed using $\mathrm{R}$ (version R-3.6.3). For all analyses, we calculated fold-change expression using pMR1-NNNN as the promoter reference.

\section{DATA AVAILABILITY STATEMENT}

The raw data supporting the conclusions of this article will be made available by the authors, without undue reservation, to any qualified researcher.

\section{REFERENCES}

Aeling, K. A., Opel, M. L., Steffen, N. R., Tretyachenko-Ladokhina, V., Hatfield, G. W., Lathrop, R. H., et al. (2006). Indirect recognition in sequence-specific DNA binding by Escherichia coli integration host factor. J. Biol. Chem. 281, 39236-39248. doi: 10.1074/jbc.M606363200

Amores, G. R., Guazzaroni, M. E., and Silva-Rocha, R. (2015). Engineering synthetic cis-regulatory elements for simultaneous recognition of three transcriptional factors in bacteria. ACS Synth. Biol. 4, 1287-1294. doi: 10.1021/acssynbio.5b00098

Azam, T. A., Hiraga, S., and Ishihama, A. (2000). Two types of localization of the DNA-binding proteins within the Escherichia coli nucleoid. Genes Cells 5, 613-626. doi: 10.1046/j.1365-2443.2000.00350.x

Azam, T. A., and Ishihama, A. (1999). Twelve species of the nucleoidassociated protein from Escherichia coli. J. Biol. Chem. 274, 33105-33113. doi: 10.1074/jbc.274.46.33105

Baba, T., Ara, T., Hasegawa, M., Takai, Y., Okumura, Y., Baba, M., et al. (2006). Construction of Escherichia coli K-12 in-frame, single-gene knockout mutants: the Keio collection. Mol. Syst. Biol. 2, 1-11. doi: 10.1038/msb4100050

Bintu, L., Buchler, N. E., Garcia, H. G., Gerland, U., Hwa, T., Kondev, J., et al. (2005). Transcriptional regulation by the numbers: models. Curr. Opin. Genet. Dev. 15, 116-124. doi: 10.1016/j.gde.2005.02.007

Boyle, P. M., and Silver, P. A. (2012). Parts plus pipes: synthetic biology approaches to metabolic engineering. Metab. Eng. 14, 223-232. doi: 10.1016/j.ymben.2011.10.003

Browning, D. F., and Busby, S. J. (2004). The regulation of bacterial transcription initiation. Nat. Rev. Microbiol. 2, 57-65. doi: 10.1038/nrmicro787

Browning, D. F., and Busby, S. J. W. (2016). Local and global regulation of transcription initiation in bacteria. Nat. Rev. Microbiol. 14, 638-650. doi: 10.1038/nrmicro.2016.103

Browning, D. F., Grainger, D. C., and Busby, S. J. (2010). Effects of nucleoidassociated proteins on bacterial chromosome structure and gene expression. Curr. Opin. Microbiol. 13, 773-780. doi: 10.1016/j.mib.2010.09.013

\section{AUTHOR CONTRIBUTIONS}

RS-R and LM designed the experimental strategy. LM, AS-M, and CW performed the experiments. LM, AS-M, CW, and RS-R analyzed and interpreted the data. LM and RS-R wrote the manuscript. All authors have read and approved the final version of the manuscript.

\section{FUNDING}

This work was supported by the São Paulo Research Foundation (FAPESP, award \# 2012/22921-8 and 2017/50116-6). LM, AS-M, and CW were supported by FAPESP PhD and Master Fellowships (award \# 2016/19179-9, 2018/04810-0, and 2016/05472-6).

\section{ACKNOWLEDGMENTS}

The authors are thankful to their lab colleagues for insightful comments on this work. This manuscript has been released as a pre-print at bioRxiv (Monteiro et al., 2019a).

\section{SUPPLEMENTARY MATERIAL}

The Supplementary Material for this article can be found online at: https://www.frontiersin.org/articles/10.3389/fbioe. 2020.00510/full\#supplementary-material

Cepeda-Humerez, S. A., Rieckh, G., and Tkačik, G. (2015). Stochastic proofreading mechanism alleviates crosstalk in transcriptional regulation. Phys. Rev. Lett. 115:248101. doi: 10.1103/PhysRevLett.115. 248101

Collado-Vides, J., Magasanik, B., and Gralla, J. D. (1991). Control site location and transcriptional regulation in Escherichia coli. Microbiol. Rev. 55, 371-394.

Cox, R. S., Surette, M. G., and Elowitz, M. B. (2007). Programming gene expression with combinatorial promoters. Mol. Syst. Biol. 3:145. doi: 10.1038/msb4100187

Darwin, A. J., and Stewart, V. (1995). Nitrate and nitrite regulation of the fnr-dependentaeg-46.5 promoter of Escherichia coli $\mathrm{K}-12$ is mediated by competition between homologous response regulators (NarL and NarP) for a common DNA-binding site. J. Mol. Biol. 251, 15-29. doi: 10.1006/jmbi.1995.0412

Datsenko, K. A., and Wanner, B. L. (2000). One-step inactivation of chromosomal genes in Escherichia coli K-12 using PCR products. Proc. Natl. Acad. Sci. U.S.A. 97, 6640-6645. doi: 10.1073/pnas.120163297

Déthiollaz, S., Eichenberger, P., and Geiselmann, J. (1996). Influence of DNA geometry on transcriptional activation in Escherichia coli. EMBO J. 15, 5449-5458. doi: 10.1002/j.1460-2075.1996. tb00928.x

Dorman, C. J., and Deighan, P. (2003). Regulation of gene expression by histone-like proteins in bacteria. Curr. Opin. Genet. Dev. 13, 179-184. doi: 10.1016/S0959-437X(03)00025-X

Egbert, R. G., and Klavins, E. (2012). Fine-tuning gene networks using simple sequence repeats. Proc. Natl. Acad. Sci. U.S.A. 109, 16817-16822. doi: 10.1073/pnas.1205693109

Friedlander, T., Prizak, R., Guet, C. C., Barton, N. H., and Tkačik, G. (2016). Intrinsic limits to gene regulation by global crosstalk. Nat. Commun. 7:12307. doi: 10.1038/ncomms12307

Gama-Castro, S., Salgado, H., Santos-Zavaleta, A., Ledezma-Tejeida, D., MuñizRascado, L., García-Sotelo, J. S., et al. (2016). RegulonDB version 9.0: high-level integration of gene regulation, coexpression, motif clustering and beyond. Nucl. Acids Res. 44, D133-D143. doi: 10.1093/nar/gkv1156 
Guazzaroni, M.-E., and Silva-Rocha, R. (2014). Expanding the logic of bacterial promoters using engineered overlapping operators for global regulators. ACS Synth. Biol. 3, 666-675. doi: 10.1021/sb500084f

Hermsen, R., Tans, S., and ten Wolde, P. R. (2006). Transcriptional regulation by competing transcription factor modules. PLoS Comput. Biol. 2:e164. doi: 10.1371/journal.pcbi.0020164

Hirvonen, C. A., Ross, W., Wozniak, C. E., Marasco, E., Anthony, J. R., Aiyar, S. E., et al. (2001). Contributions of UP elements and the transcription factor FIS to expression from the seven rrn P1 promoters in Escherichia coli. J. Bacteriol. 183, 6305-6314. doi: 10.1128/JB.183.21.6305-6314.2001

Hwang, H. J., Lee, S. Y., and Lee, P. C. (2018). Engineering and application of synthetic nar promoter for fine-tuning the expression of metabolic pathway genes in Escherichia coli. Biotechnol. Biofuels 11:103. doi: 10.1186/s13068-018-1104-1

Isalan, M., Lemerle, C., Michalodimitrakis, K., Horn, C., Beltrao, P., Raineri, E., et al. (2008). Evolvability and hierarchy in rewired bacterial gene networks. Nature 452, 840-845. doi: 10.1038/nature06847

Ishihama, A. (2010). Prokaryotic genome regulation: multifactor promoters, multitarget regulators and hierarchic networks. FEMS Microbiol. Rev. 34, 628-645. doi: 10.1111/j.1574-6976.2010.00227.x

Izu, H., Ito, S., Eilas, M. D., Yamada, M. (2002). Differential control by IHF and cAMP of two oppositely oriented genes, hpt and gcd, in Escherichia coli : significance of their partially overlapping regulatory elements. Mol. Genet. Genomics 266, 865-872. doi: 10.1007/s00438-001-0608-7

Keseler, I. M., Mackie, A., Santos-Zavaleta, A., Billington, R., BonavidesMartínez, C., Caspi, R., et al. (2017). The EcoCyc database: reflecting new knowledge about Escherichia coli K-12. Nucl. Acids Res. 45, D543D550. doi: 10.1093/nar/gkw1003

Kinkhabwala, A., and Guet, C. C. (2008). Uncovering cis regulatory codes using synthetic promoter shuffling. PLoS ONE 3:e2030. doi: 10.1371/journal.pone.0002030

Kreamer, N. N., Phillips, R., Newman, D. K., and Boedicker, J. Q. (2016). Predicting the impact of promoter variability on regulatory outputs. Sci. Rep. 5:18238. doi: $10.1038 /$ srep18238

Lozada-Chavez, I. (2006). Bacterial regulatory networks are extremely flexible in evolution. Nucl. Acids Res. 34, 3434-3445. doi: 10.1093/nar/gkl423

Martínez-Antonio, A., Collado-Vides, J., Balleza, E., López-Bojorquez, L. N., Martínez-Antonio, A., Resendis-Antonio, O., et al. (2003). Identifying global regulators in transcriptional regulatory networks in bacteria. Curr. Opin. Microbiol. 33, 482-489. doi: 10.1016/j.mib.2003. 09.002

Monteiro, L. M. O., Arruda, L. M., Sanches-Medeiros, A., Martins-Santana, L., Alves, L. D. F., Defelipe, L., et al. (2019b). Reverse engineering of an aspirinresponsive transcriptional regulator in Escherichia coli. ACS Synth. Biol. 8, 1890-1900. doi: 10.1021/acssynbio.9b00191

Monteiro, L. M. O., Arruda, L. M., and Silva-Rocha, R. (2018). Emergent properties in complex synthetic bacterial promoters. ACS Synth. Biol. 7, 602-612. doi: 10.1021/acssynbio.7b00344

Monteiro, L. M. O., Sanches-Medeiros, A., Westmann, C. A., and SilvaRocha, R. (2019a). Modulating Fis and IHF binding specificity, crosstalk and regulatory logic through the engineering of complex promoters. bioRxiv. 1-11. doi: $10.1101 / 614396$
Rossiter, A. E., Godfrey, R. E., Connolly, J. A., Busby, S. J. W., Henderson, I. R., and Browning, D. F. (2015). Expression of different bacterial cytotoxins is controlled by two global transcription factors, CRP and Fis, that co-operate in a shared-recruitment mechanism. Biochem. J. 466, 323-335. doi: 10.1042/BJ20141315

Rydenfelt, M., Garcia, H. G., Cox, R. S., and Phillips, R. (2014). The influence of promoter architectures and regulatory motifs on gene expression in Escherichia coli. PLoS ONE 9:e114347. doi: 10.1371/journal.pone.0114347

Sambrook, J., Fritsch, E., and Maniatis, T. (1989). Molecular Cloning: A Laboratory Manual. Available online at: https://www.cabdirect.org/cabdirect/abstract/ 19901616061 (accessed April 2, 2020).

Sawers, G. (1993). Specific transcriptional requirements for positive regulation of the anaerobically inducible pfl operon by ArcA and FNR. Mol. Microbiol. 10, 737-747. doi: 10.1111/j.1365-2958.1993.tb00944.x

Scalcinati, G., Knuf, C., Partow, S., Chen, Y., Maury, J., Schalk, M., et al. (2012). Dynamic control of gene expression in Saccharomyces cerevisiae engineered for the production of plant sesquitepene $\alpha$-santalene in a fed-batch mode. Metab. Eng. 14, 91-103. doi: 10.1016/j.ymben.2012.01.007

Setty, Y., Mayo, A. E., Surette, M. G., and Alon, U. (2003). Detailed map of a cis-regulatory input function. Proc. Natl. Acad. Sci. U.S.A. 100, 7702-7707. doi: 10.1073/pnas. 1230759100

Shis, D. L., Hussain, F., Meinhardt, S., Swint-Kruse, L., and Bennett, M. R. (2014). Modular, multi-input transcriptional logic gating with orthogonal LacI/GalR family chimeras. ACS Synth. Biol. 3, 645-651. doi: 10.1021/sb500262f

Siegl, T., Tokovenko, B., Myronovskyi, M., and Luzhetskyy, A. (2013). Design, construction and characterisation of a synthetic promoter library for fine-tuned gene expression in actinomycetes. Metab. Eng. 19, 98-106. doi: 10.1016/j.ymben.2013.07.006

Steinacher, A., Bates, D. G., Akman, O. E., and Soyer, O. S. (2016). Nonlinear dynamics in gene regulation promote robustness and evolvability of gene expression levels. PLoS ONE 11:e0153295. doi: 10.1371/journal.pone.0153295

Ussery, D., Schou Larsen, T., Trevor Wilkes, K., Friis, C., Worning, P., Krogh, A., et al. (2001). Genome organisation and chromatin structure in Escherichia coli. Biochimie 83, 201-212. doi: 10.1016/S0300-9084(00)01225-6

Yuh, C. (1998). Genomic cis-regulatory logic: experimental and computational analysis of a sea urchin gene. Science 279, 1896-1902. doi: 10.1126/science.279.5358.1896

Zong, D. M., Cinar, S., Shis, D. L., Josić, K., Ott, W., and Bennett, M. R. (2018). Predicting transcriptional output of synthetic multi-input promoters. ACS Synth. Biol. 7, 1834-1843. doi: 10.1021/acssynbio.8b00165

Conflict of Interest: The authors declare that the research was conducted in the absence of any commercial or financial relationships that could be construed as a potential conflict of interest.

Copyright (C) 2020 Monteiro, Sanches-Medeiros, Westmann and Silva-Rocha. This is an open-access article distributed under the terms of the Creative Commons Attribution License (CC BY). The use, distribution or reproduction in other forums is permitted, provided the original author(s) and the copyright owner(s) are credited and that the original publication in this journal is cited, in accordance with accepted academic practice. No use, distribution or reproduction is permitted which does not comply with these terms. 


\section{CHAPTER III}

\section{Reverse Engineering of an Aspirin-Responsive Transcriptional Regulator in Escherichia coli}

This chapter was published as:

(Monteiro et al., 2019) MONTEIRO, Lummy Maria Oliveira; ARRUDA, Letícia Magalhaes; SANCHES-MEDEIROS, Ananda; MARTINS-SANTANA, Leonardo; ALVES, Luana de Fátima; DEFELIPE, Lucas; TURJANSKI, Adrian Gustavo; GUAZZARONI, Marı-Eugenia \& SILVAROCHA, Rafael. Reverse engineering of an aspirin-responsive transcriptional regulator in Escherichia coli. ACS synthetic biology, v. 8, n. 8, p. 1890-1900, 2019. 


\title{
SyntheticBiology \\ Reverse Engineering of an Aspirin-Responsive Transcriptional Regulator in Escherichia coli
}

\author{
Lummy Maria Oliveira Monteiro, ${ }^{\dagger}$ Letícia Magalhães Arruda, ${ }^{\dagger}$ Ananda Sanches-Medeiros, ${ }^{\dagger}$
} Leonardo Martins-Santana, ${ }^{\dagger}$ Luana de Fátima Alves, ${ }^{\ddagger}$ Lucas Defelipe, ${ }^{\S, \| ®}$ Adrian Gustavo Turjanski, ${ }^{\S}, \|$

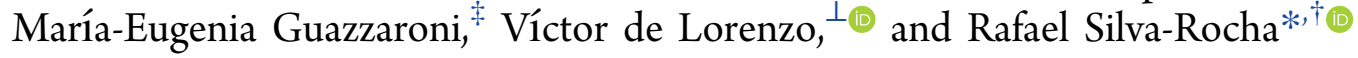

${ }^{\dagger}$ Cell and Molecular Biology Department, FMRP - University of São Paulo, Ribeirão Preto, São Paulo 14049-900, Brazil

${ }^{\ddagger}$ Biology Department, FFCLRP - University of São Paulo, Ribeirão Preto, São Paulo 14040-901, Brazil

${ }^{\S}$ Departamento de Química Biológica, Facultad de Ciencias Exactas y Naturales, Universidad de Buenos Aires, Buenos Aires 1428, Argentina

"IQUIBICEN/UBA-CONICET, Facultad de Ciencias Exactas y Naturales, Universidad de Buenos Aires, Buenos Aires 1428, Argentina

${ }^{\perp}$ Systems Biology Program, National Center of Biotechnology - CSIC, Madrid 28049, Spain

\section{Supporting Information}

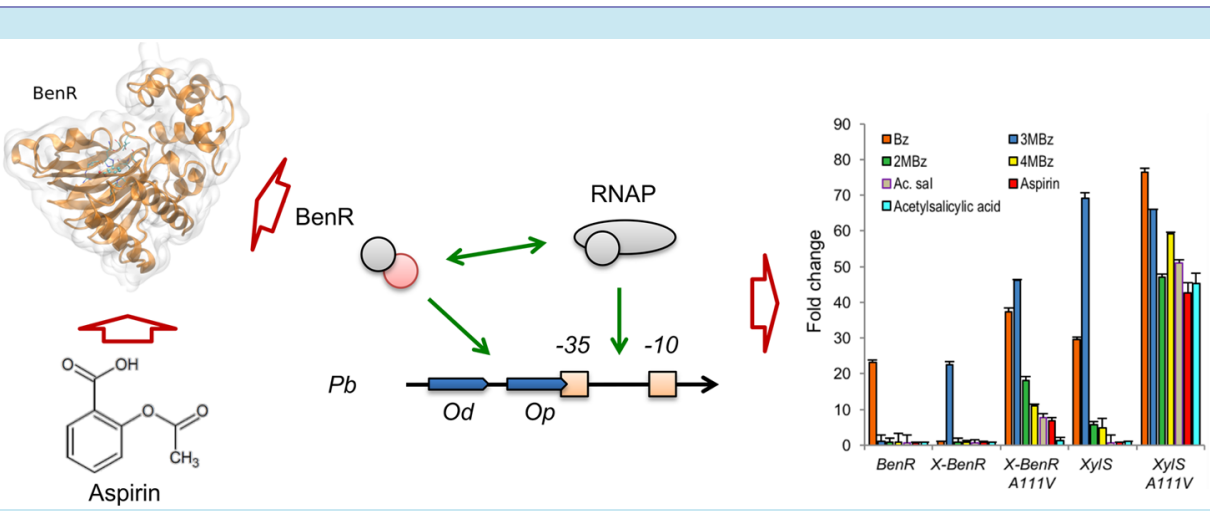

ABSTRACT: Bacterial transcription factors (TFs) are key devices for the engineering of complex circuits in many biotechnological applications, yet there are few well-characterized inducer-responsive TFs that could be used in the context of an animal or human host. We have deciphered the inducer recognition mechanism of two AraC/XylS regulators from Pseudomonas putida (BenR and XylS) for creating a novel expression system responsive to acetyl salicylate (i.e., aspirin). Using protein homology modeling and molecular docking with the cognate inducer benzoate and a suite of chemical analogues, we identified the conserved binding pocket of BenR and XylS. By means of site-directed mutagenesis, we identified a single amino acid position required for efficient inducer recognition and transcriptional activation. Whereas this modification in BenR abolishes protein activity, in XylS, it increases the response to several inducers, including acetyl salicylic acid, to levels close to those achieved by the canonical inducer. Moreover, by constructing chimeric proteins with swapped N-terminal domains, we created novel regulators with mixed promoter and inducer recognition profiles. As a result, a collection of engineered TFs was generated with an enhanced response to benzoate, 3-methylbenzoate, 2-methylbenzoate, 4-methylbenzoate, salicylic acid, aspirin, and acetylsalicylic acid molecules for eliciting gene expression in E. coli.

KEYWORDS: transcriptional regulation, protein engineering, homology modeling, gene regulatory network, reverse engineering, bacterial expression system

$\mathrm{T}$ ranscriptional regulation plays a central role in the adaptation of cells to changing environmental conditions. In bacteria, this step is mainly regulated by the interaction of RNA polymerase (RNAP) with the promoter region through the use of many sigma factors and by a large number of transcription factors (TFs) that can promote or block RNAP binding or further steps in transcription. ${ }^{1}$ With the growing interest in the engineering of living cells for novel biotechnological and biomedical applications, a special focus has emerged in understanding gene regulation at the molecular level. ${ }^{1-4}$ In this context, many different classes of TFs have been extensively characterized in the molecular detail from bacteria to mammals, and this knowledge has allowed a number of engineering projects, where natural systems can be

Received: April 29, 2019

Published: July 30, 2019 


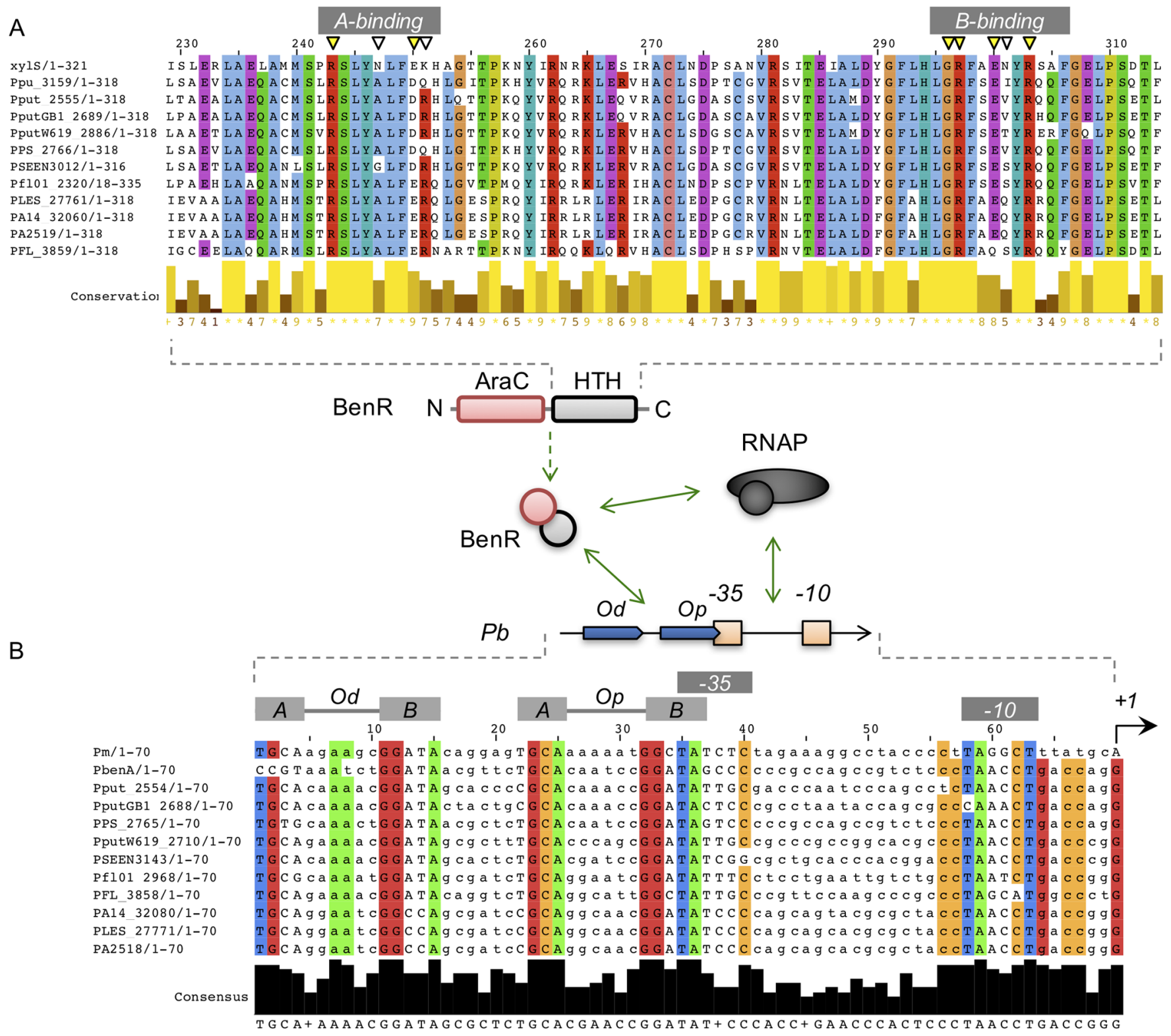

Figure 1. Analysis of BenR homologues and target promoters in Pseudomonas. (A) Analysis of protein conservation between XylS from Pseudomonas putida mt-2 and BenR homologues from strains of P. putida (Ppu 3159, Pput 2555, PputGB1 2689, PputW619 2886, PPS 2765), P. entomophila (PSEEN3143), P. fluorescens (Pfl01_2968, PFL_3858), and P. aeruginosa (PA14_32080, PLES_27771, PA2518). PbanA in the second line indicates the promoter from P. putida KT2440 (Ppu 3159). Only the region relative to the HTH domain is shown. Critical aa's for DNA recognition (labeled as A-binding and B-binding) are marked with inverted triangles, with conserved regions colored in yellow. In the middle, the schematic representation of the BenR interaction with the RNAP and the $\sigma$ factor (necessary for the correct initiation of transcription) and the target promoter shows the two binding sites (Od and $O p$ ) and the $-35 /-10$ boxes at $P b$ and $P m$. (B) Promoter alignment for Pm from $P$. putida mt-2 and for $\mathrm{Pb}$ from several Pseudomonas strains. The two conserved boxes (A and B) from $\mathrm{Od}$ and $\mathrm{Op}$ binding sites are highlighted.

repurposed to display novel behaviors. ${ }^{1,5-9}$ Attempts in this direction are very diverse, and examples include the construction of mutated variants of natural TFs with enhanced or modified performance, ${ }^{10-15}$ the recombination of protein domains to create TFs with completely altered specificity or dynamical behavior, ${ }^{16,17}$ and the mining of novel regulators from genomes or metagenomes. ${ }^{18,19}$ Additionally, the revolution provided by the CRISPR/Cas9 system has also impacted the field of gene regulation, as this system has been repurposed to construct fully synthetic expression systems based on RNA/ DNA interaction. ${ }^{20-22}$

Despite the progress in the engineering of novel expression systems, a critical bottleneck relies on the selection of suitable signal-recognition modules related to the application of interest. In other words, whereas many different TFs are well-characterized as responsive to small molecules (sugars, ions, aromatics, etc.), many times, the application at stake requires systems responsive to unusual compounds. ${ }^{23}$ Therefore, the construction of TF variants with enhanced responsiveness to non-natural ligands has become more appealing. Approaches to accomplish this task range from the use of laborious random mutagenesis followed by selection ${ }^{11,12}$ to the use of computational analysis to guide rational design. ${ }^{24}$ Here we focused on the engineering of novel expression systems responsive to commercially available drugs suitable to in vivo administration to a mammalian animal. Our 


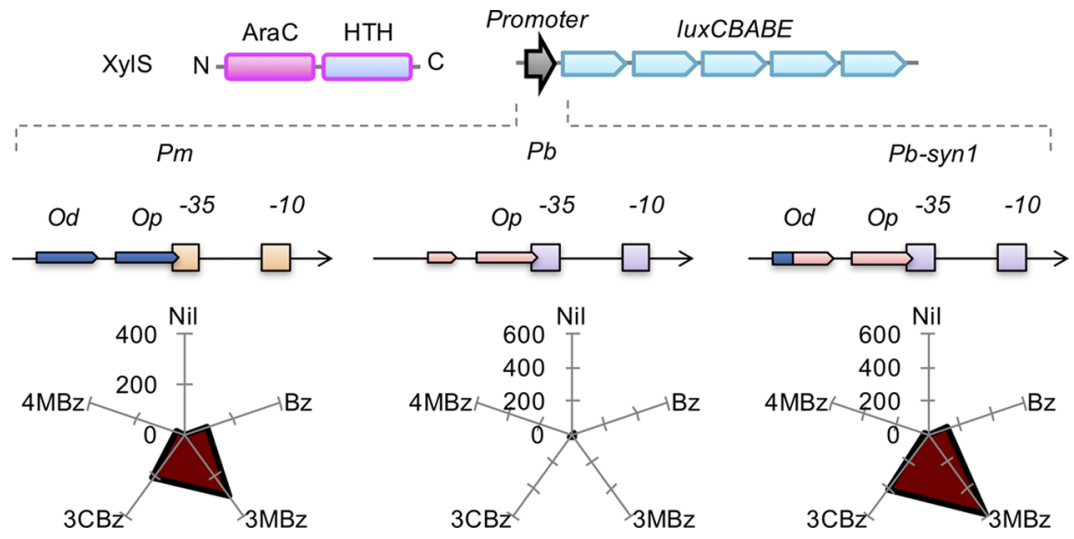

Figure 2. Recognition of $P m$ and $P b$ by XylS. For the analysis, E. coli DH5 $\alpha$ strain was transformed with pSEVA438 (harboring a functional XylS expressed with its native promoter ${ }^{33}$ ) and pSEVA226 (a reporter vector with the luxCDABE operon ${ }^{33}$ ) harboring $P m, P b$, or $P b$-syn1, a variant of $\mathrm{Pb}$ endowed with the A box of $\mathrm{Od}$ from $\mathrm{Pm} .{ }^{27}$ All strains were grown on minimal media to the midexponential phase and then exposed for $3 \mathrm{~h}$ to $100 \mu \mathrm{M}$ benzoate $(\mathrm{Bz}), 3$-methylbenzoate $(3 \mathrm{MBz})$, 3-chlorobenzoate $(3 \mathrm{CBz})$, or 4-methylbenzoate $(4 \mathrm{MBz})$. The graphs represent the fold change of promoter activity relative to the noninduced condition.

particular interest was focused on acetylsalicylic acid (ASA or aspirin), a longstanding, safe and widely used drug. This compound has been applied in synthetic regulatory circuits to deliver lytic proteins to tumors in vivo, representing a promising field for the development of tumor-targeting circuits for clinical applications. ${ }^{25}$ As a starting point, we sought to investigate the molecular mechanisms of signal recognition by two homologous regulators of Pseudomonas putida, namely, BenR and XylS. These two TFs are members of the AraC/XylS family of transcriptional activators ${ }^{26-28}$ that recognize different aromatic compounds with structural similarities to ASA. Yet, whereas both regulators share $\sim 60 \%$ amino acid (aa) identity, BenR is responsive to only benzoate, ${ }^{27}$ whereas XylS can recognize a large number of substituted variants. ${ }^{29}$ Additionally, some crosstalk between these two regulators and their target promoters has been characterized, as XylS can recognize only its target promoter $\mathrm{Pm}$, whereas BenR can efficiently activate its natural target $\mathrm{Pb}$ as well as $\mathrm{Pm} .^{27}$

In this study, we have investigated the molecular mechanisms of signal recognition by these two regulators using computational tools and in vivo validation. By constructing a model for the ligand-binding domain of BenR and performing molecular docking with benzoate and a collection of analogues, we identified a potential binding pocket strongly conserved between these two TFs. Thereby, we used site-directed mutagenesis and the construction of chimeric proteins to validate the identified binding pocket of the protein. Finally, we demonstrated how a single aa position plays a critical and opposite role in the activity of both proteins. Some changes in this position in BenR resulted in the complete loss of protein activity, whereas the same in XylS triggered an enhanced response to benzoate analogues, including ASA. The results presented here thus provide insights into not only the mechanism of signal recognition by members of the AraC/XylS family but also the engineering of a regulatory device responsive to aspirin.

\section{RESULTS}

Analysis of Conserved Elements in BenR and XyIS Close Homologues and Target Promoters. To investigate the molecular mechanisms accounting for the functional differences between BenR and XylS, we analyzed the close homologues of these proteins present in the genomes of some species of Pseudomonas. As represented schematically in Figure 1 , these proteins are TFs formed by two domains, the $\mathrm{N}$ terminal (AraC domain), which is required for ligand recognition, ${ }^{30}$ and the $\mathrm{C}$-terminal domain composed of two helix-turn-helix $(\mathrm{HTH})$ regions required for the recognition of the distal and proximal operators $(O d$ and $O p)$ upstream of the target promoters. ${ }^{27,31}$ It is proposed that two monomers of XylS are required for the activation of the $P m$ promoter, each binding to an operator region and contacting an $\mathrm{A}$ and $\mathrm{B}$ box conserved within this region. A previous study ${ }^{32}$ used alanine scanning mutagenesis to identify four residues in XylS required for the recognition of the A boxes (Arg242, Asn246, Glu249, and Lys250) and five required for the interaction with boxes $B$ (G295, Arg296, Asp299, Asn300 and Arg302). As can be observed in the protein alignment between BenR and XylS homologues, most of these positions are well conserved in the proteins analyzed, with the exception of residues Asn246, Lys250, and Asn 300 (Figure 1A). It is surprising to notice that whereas the change of Asn to Ala at position 246 in XylS reduced the capability of this protein to activate $P m$ by half, $\mathrm{Ala}$ is found to be well-conserved in most BenR proteins analyzed. This indicates that BenR homologues might be less stringent in the interaction at the A box of the target promoter. $^{27}$ In the same direction of this hypothesis, the analysis of $\mathrm{Pm}$ and $\mathrm{Pb}$ promoters from several Pseudomonas strains reveals that most features (A and B boxes, $-35 / 10$ region) are well conserved, except for the $\mathrm{A}$ box of $\mathrm{Pb}$ (the target of the BenR studied here) from Pseudomonas putida KT2440 (Figure 1B). In this sense, to check the effect of the A box in the interaction between XylS and $P m$ and $P b$ promoters, we assayed the promoter activity using a lux reporter system. We used a wild-type $x y l S$ gene expressed from a pSEVA vector $^{33}$ and $P m, P b$, and $P b$-syn 1 (a $P b$ variant with the recomposed A box of the $O d$ region $^{27}$ ). Using this system, we observed that whereas XylS could recognize $P m$ very efficiently, it was not able to induce $\mathrm{Pb}$ activity in response to the inducers tested (Figure 2). However, when a version of $\mathrm{Pb}$ with the reconstituted A box ( $P b$-syn 1$)$ was used, a strong induction of promoter activity was observed in response to the inducers used (Figure 2). ${ }^{27}$ Taken together, these results reinforce the notion that whereas XylS has a critical requirement for complete $\mathrm{A}$ and $\mathrm{B}$ boxes at the $\mathrm{Od}$ and $\mathrm{Op}$ regions, BenR is less stringent for promoter recognition. 


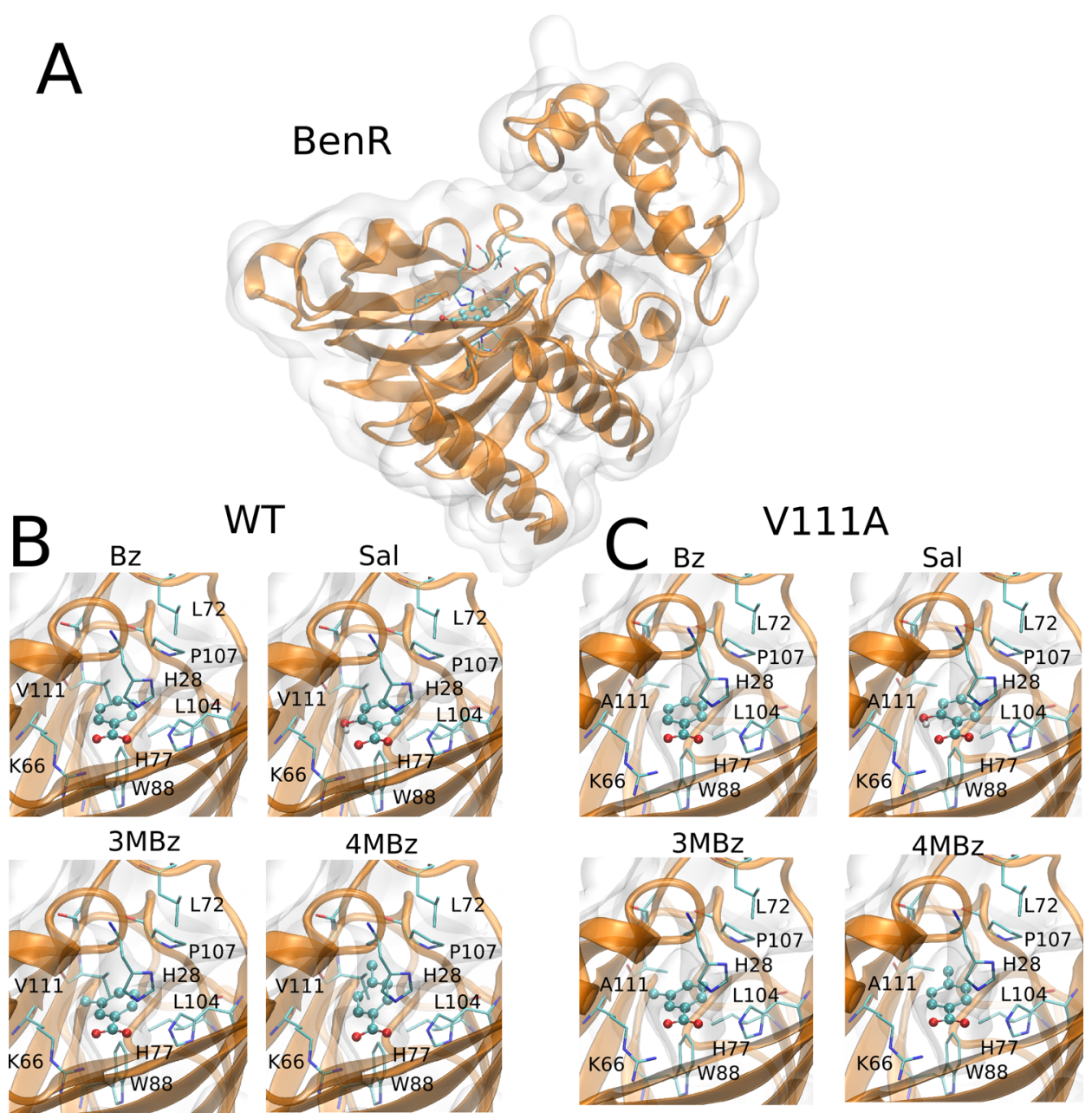

Figure 3. Mapping ligand binding sites in BenR by protein structure prediction and molecular docking. (A) Homology model of wild-type BenR showing the putative binding site of the ligands. (B) Docking of benzoate (Bz), 3-methylbenzoate (3MBz), 4-methylbenzoate (4MBz), and salicylate (Sal) at the wild-type BenR protein, highlighting the critical aa participating in the putative binding site. (C) Docking of BenR-V111A variant showing the putative binding site, as in panel B.

\footnotetext{
Single Amino Acid Position Is Critical for Aromatic Recognition in BenR and XylS. After tracing critical differences in the DNA recognition requirements between BenR and XylS, we decided to investigate aa differences that could explain the divergence in the ligand selectivity between these two TFs. As presented before, BenR has a very narrow inducer selectivity because this TF can only respond to benzoate as an inducer under natural conditions. However, XylS can be activated by a diverse collection of aromatic inducers, such as benzoate and methylated or chlorinated benzoate analogues. ${ }^{29}$ To gain insight into the molecular mechanisms responsible for these differences, we constructed a 3D protein model for the $\mathrm{N}$-terminal region of BenR using homology modeling. The resulting model was subjected to molecular docking using benzoate, 3-methylbenzoate $(3 \mathrm{MBz})$, 4-methylbenzoate $(4 \mathrm{MBz})$, and salicylate (Sal). Using this approach, we obtained a protein structural model (Figure 3A) and identified a potential cavity on the protein surface that accommodates a benzoate molecule (Figure 3B). Additionally, our results suggest that the identified binding pocket binds with less affinity for the benzoate analogues, indicating that the inducer selectivity could be based on size exclusion. By analyzing the model and the predicted binding pocket, we could identify eight aa's (His 28 , Arg 66, Leu 72, His 77, Trp
}

88, Leu 104, Pro 107, and Val 111) that contributed to the surface of the cavity (Figure 3B,C). We then compared these aa's between BenR and XylS, hypothesizing that a change in some of these aa's could explain the difference in ligand specificity between these two regulators. To our surprise, six out eight aa's from the predicted binding pocket were conserved between the two proteins. The differences were at positions 28 and 111, representing histidine (28) and valine (111) in BenR and tyrosine (28) and alanine (111) in XylS. Because alanine has a shorter side chain, we hypothesized that this could lead to a bigger binding pocket in XylS that could better accommodate the methylated or chlorinated benzoate analogues (Figure 3C and Table S3).

The difference in binding energy suggests that mutation of Val111 to Ala increases the affinity of $3 \mathrm{MBz}$ (Table S3). To investigate this possibility, we constructed point mutations in $b e n R$ and $x y l S$ at aa positions 111 and 110 , as we noticed that this last position, while not involved in the binding pocket, was also not conserved between the two regulators (Figure 4A). In addition to the point mutations, we constructed a chimaera between the $\mathrm{N}$-terminal part of XylS and the C-terminal part of BenR and also subjected this TF to mutagenesis. All assays were performed using the cognate promoter for each TF (i.e., $\mathrm{Pb}$ for BenR and $\mathrm{Pm}$ for XylS) controlling a green fluorescent 
A
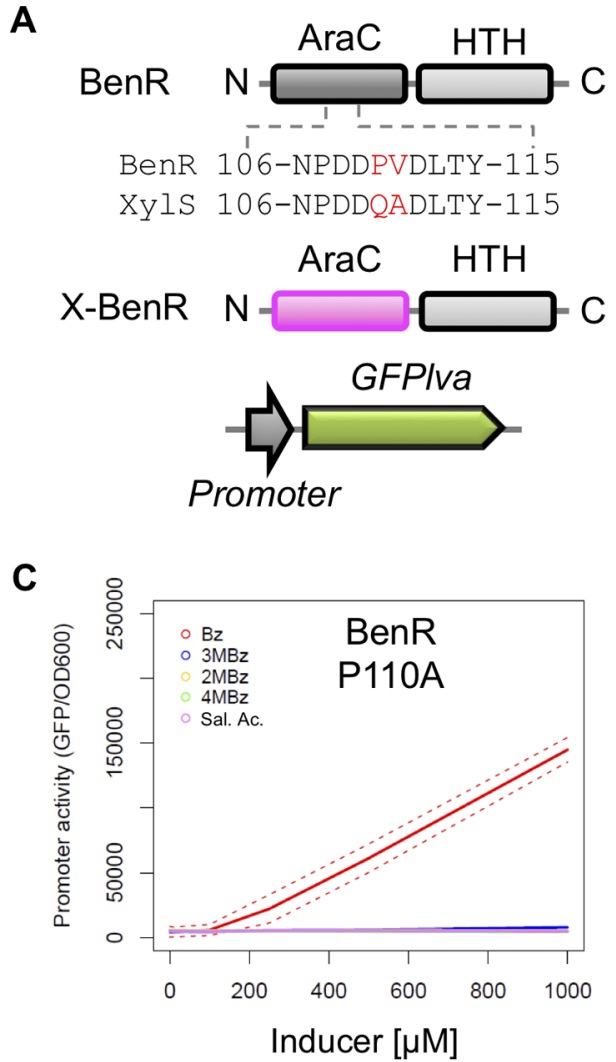

D

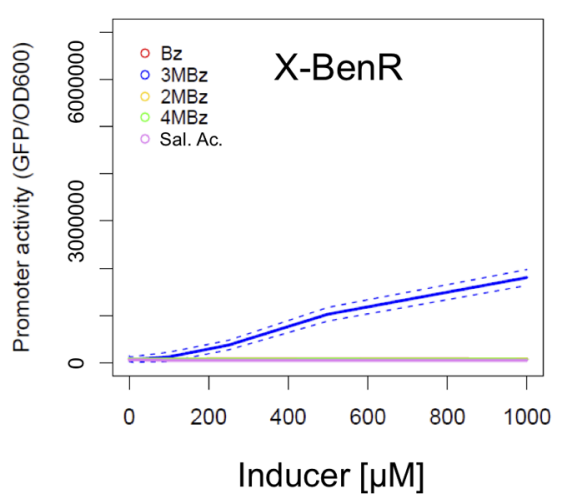

B
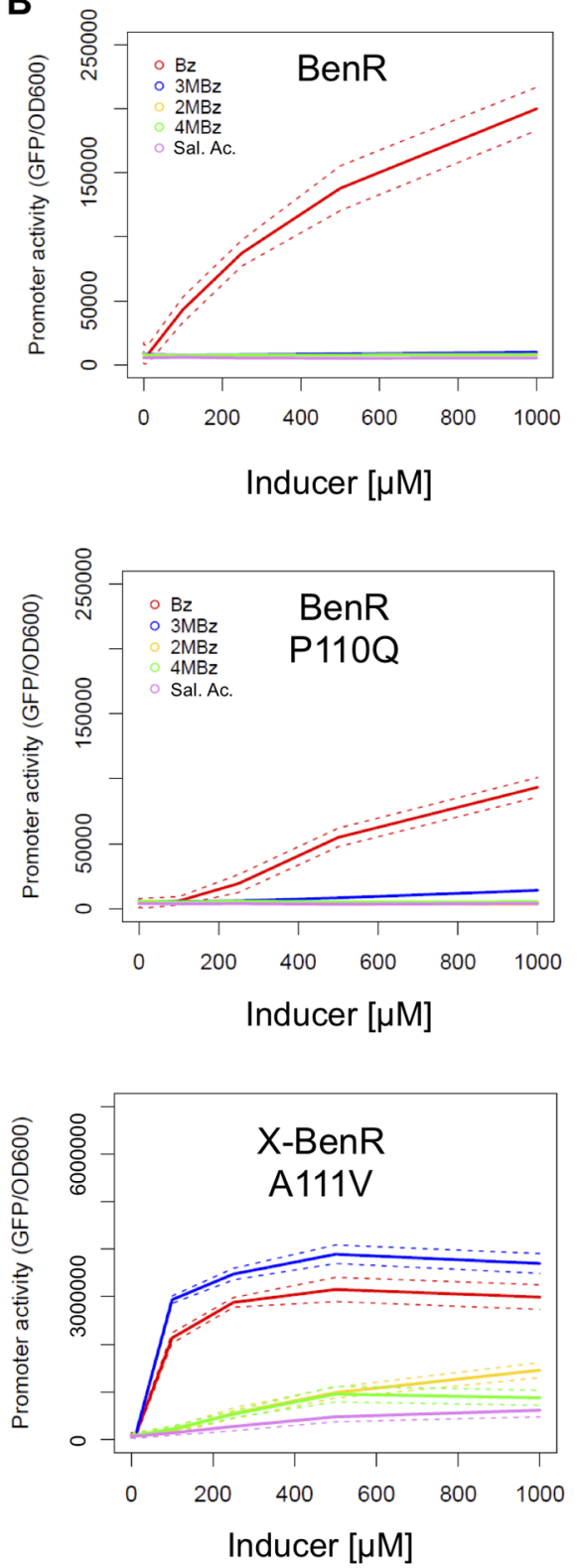
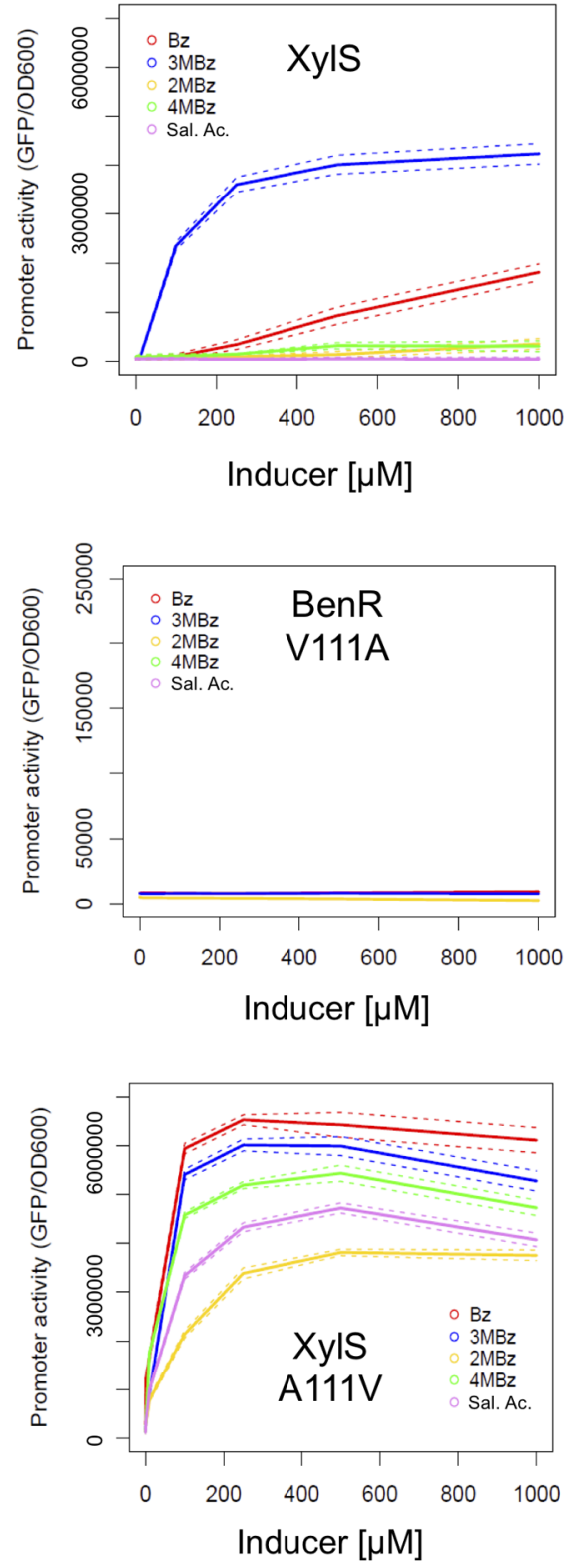

Figure 4. Experimental identification of critical aa's for inducer recognition in BenR and XylS. (A) Schematic representation of BenR and the chimeric protein X-BenR (a fusion between the N-terminal domain of XylS with the C-terminal domain of BenR), showing the nonconserved positions 110 and 111 tested here. All protein variants were tested with a GFPlva reporter under the control of the cognate promoter (i.e., $P b$ for BenR and X-BenR and Pm for XylS). (B) Analysis of the promoter activity of BenR-Pb and XylS-Pm in response to different concentrations of benzoate $(\mathrm{Bz}), 3$-methylbenzoate $(3 \mathrm{MBz})$, 2-methylbenzoate $(2 \mathrm{MBz})$, 4-methylbenzoate $(4 \mathrm{MBz})$, and salicylic acid (Ac Sal). The solid line indicates the average from three independent experiments, whereas the dashed lines represent the lower and higher limits of the standard deviation. (C) Analysis of the promoter activity for BenR mutants at positions 110 (BenR-P110A and BenR-P110Q) and 111 (BenR-V111A). (D) Analysis of the promoter activity for chimeric X-BenR protein and its variant with a mutation in position 111 (X-BenR-A111V) as well as for the mutated version of XylS (XylS-A111V). The promoter activities (panels B-D) reported here were calculated after $5 \mathrm{~h}$ of exposure to the different inducers.

protein (GFP) reporter gene (Figure 4A) to allow investigation at the single-cell level ${ }^{34,35}$ (Figures S3-S5). The promoter activities were calculated after $5 \mathrm{~h}$ of exposure to the different inducers. As can be observed in Figure 4B, wild-type BenR was specific to benzoate at all concentrations tested, whereas wild-type XylS displayed a preferential response to $3 \mathrm{MBz}$, an intermediated response to benzoate, and a lower response to $2 \mathrm{MBz}$ and $4 \mathrm{MBz}$. When we mutated position 110 of BenR from Pro to Ala or Gln (the aa found at this position in XylS), we could observe that the mutants presented the same expression profile as the wild type but with reduced efficacy (Figure 4C). However, when position 111 was changed from $\mathrm{Val}$ to $\mathrm{Ala}$ in BenR, the resulting protein variant did not display any response to the inducers tested. Contrary to the expected, this change (Val 111 to Ala) did not widen the inducer specificity of BenR. By the same token, the construction of BenR mutants with changes at both positions 110 and 111 also resulted in nonfunctional proteins (Figure S1), potentially due to the role of Val111 in signal recognition. Therefore, it is worth noticing that the exchange of a shorter side-chain aa (Ala) for a major side-chain aa (Val) does not necessarily result in a spatial decrease in the aa binding pocket. 
A
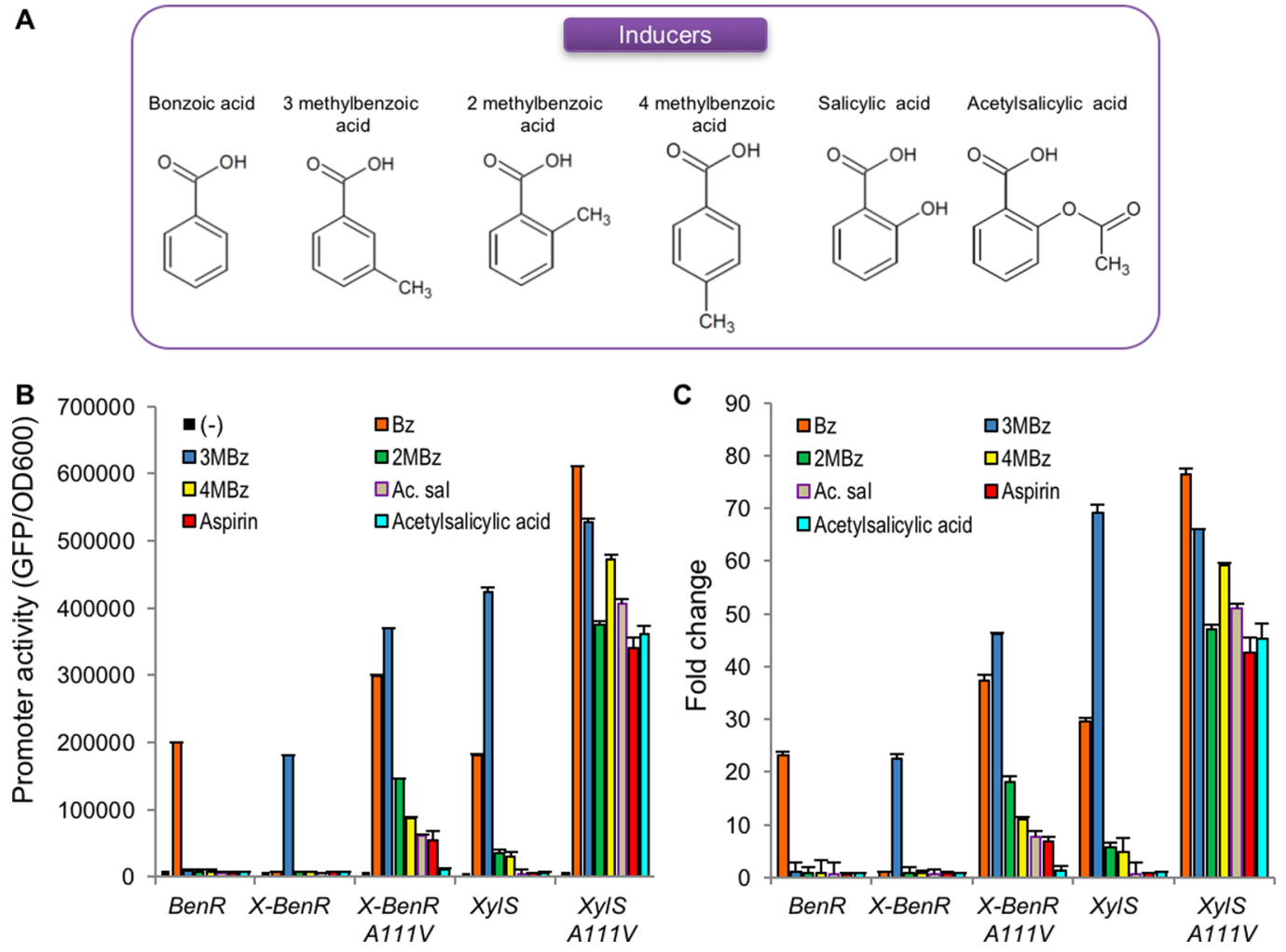

Figure 5. Analysis of transcriptional response to aromatic compounds and aspirin. (A) Schematic representation of the chemical structure of the different inducers tested. (B) Promoter activity of the different proteins reported here after $3 \mathrm{~h}$ of exposure to the different inducers. (All compounds were tested at $1 \mathrm{mM}$.) Aspirin refers to the commercial formulation obtained from a conversional drug store (with concentration adjusted to $100 \mu \mathrm{M}$ ), whereas acetylsalicylic acid specifies the pure compound obtained from Sigma-Aldrich. (C) Fold change calculated for each expression system in response to the different inducers used. Error bars represent the standard deviations from three independent experiments.

Taken together, these results indicate that Val111 is key for inducer recognition by BenR, and it is possible that it is related to the strengthening of its association with the effector binding pocket identified by homology modeling and molecular docking.

The construction of the chimeric protein harboring the $\mathrm{N}$ terminal of XylS (the region responsible for ligand recognition) and the $\mathrm{C}$-terminal of BenR (which recognizes DNA) resulted in the new protein $\mathrm{X}$-BenR that displayed an induction profile similar to that of XylS for the $3 \mathrm{MBz}$ induction but with a reduced efficacy (Figure 4D). However, X-BenR increased its inducer response to $3 \mathrm{MBz}$ at the same level as that which BenR responds to $\mathrm{Bz}$ (Figure 4D and Figure S2), perhaps because $\mathrm{Pm}$ has a higher promoter activity than $\mathrm{Pb}$. To check the role of position 111 in the inducer selectivity of XylS, we constructed point mutations of XylS and X-BenR by changing the alanine at this position for a valine. Unexpectedly, the resulting mutant proteins displayed an enhanced response to the optimal inducer $(3 \mathrm{MBz})$ as well as to the suboptimal inducers benzoate, $2 \mathrm{MBz}, 4 \mathrm{MBz}$, and salicylic acid (Figure 4D). From these results, it appears that the C-terminal of BenR does not allow as much promiscuity as that found in XylS. These results strengthen the notion that the required elements for inducer selectivity are placed in the first 196 aa's of these proteins, ${ }^{36}$ although the effector response is not completely independent of, but is also related to, the C-terminal DNAbinding domain. Finally, attempts to construct a chimeric protein harboring the $\mathrm{N}$-terminal of BenR and the C-terminal of XylS (named B-XylS) resulted in nonfunctional products with no detectable response to benzoate or $3 \mathrm{MBz}$ (Figure S2).
Yet the single-cell analysis of promoter induction by flow cytometry showed that whereas wild-type BenR- and XylSbased expression systems presented clear unimodal patterns (i.e., with a single population of fluorescent cells), the X-BenR chimaera and mutated versions of XylS and X-BenR displayed a wider population distribution that could indicate stable subpopulations (Figures S3-S5). Taken together, these results evidenced a remarkably different role of position 111 between BenR and XylS, which led to the identification of two TF variants with an enhanced response to a wide range of benzoate derivatives.

Transcriptional Factors Responsive to a New Set of Aromatic Compounds and Aspirin. After the inducer recognition profiles of BenR and XylS are characterized, we assay the TF variants for a new set of inductors. Figure 5 represents the overall performances of the TFs in response to a new set of benzoate derivatives (Figure 5A). As shown in Figure 5B, BenR $(P b$-BenR) and X-BenR (X-BenR/Pb) produced the lowest promoter outputs and were exclusively responsive to benzoate (BenR) or $3 \mathrm{MBz}$ (X-BenR). Because these proteins have a BenR C-terminal domain, they can recognize both $\mathrm{Pm}$ and $\mathrm{Pb}$. On the contrary, XylS has an intermediate level of promoter output and a preference for $3 \mathrm{MBz}$, followed by benzoate, and only a minor response to $2 \mathrm{MBz}$ and $4 \mathrm{MBz}$. Yet the mutated version of X-BenR (XBenR-A $111 \mathrm{~V} / \mathrm{Pb}$ ) promoted an overall increased response to the suboptimal inducers of XylS $(\mathrm{XylS} / \mathrm{Pm})$ and also a response to aspirin and ASA. Finally, the mutated version of XylS (XylS-A111V) displays a remarkable gain of response to all benzoate derivatives tested, including aspirin and ASA, with 
promoter outputs similar to those of wild-type XylS induced with its optimal effector $3 \mathrm{MBz}$ (Figure 5B). When fold-change is calculated relative to noninduced conditions, it can be noticed that the maximal induction of the XylS-A111V (XylSA111V/Pm) system ( 76-fold) exceeds that of the wild-type XylS ( $\sim 69$-fold, Figure $5 \mathrm{C}$ ). In this new system, the response to ASA reaches 42 - and 45-fold, respectively, yet because this enhanced response could be the result of the construction of a TF with a promiscuous effector specificity, we tested the response of XylS-A111V to toluene, xylene, phenol, and a number of nonaromatic inducers (L-arabinose, fructose, glucose, isopropyl $\beta$-D-1-thiogalactopyranoside (IPTG), and arsenite; Figure S6A). As can be observed in Figure S6B, the system did not respond to any of these compounds, whereas further tests with vanillin, 4-hydroxybenzoic acid, and benzilic alcohol also show only a minor effect of this last compound on the activity of X-BenR-A111V and XylS-A111V (Figure S6C). Taken together, these data show that benzoate analogues are the preferential inducers of the newly generated systems described here.

Promoter Engineering Further Enhances X-BenRA111V Response to Nonoptimal Inducers. The data presented above demonstrate how changes in the aa sequence of BenR and XylS could drastically change the inducer specificity of these two regulators, yet, in the case of BenR, previous studies by our group have demonstrated that changes in the operator sequence of its target promoter $(\mathrm{Pb})$ could also impact the way this regulator responds to suboptimal inducers. More specifically, because $P b$ is formed by one complete operator sequence (harboring boxes A and B, Figure 1B) plus another incomplete operator (where the A box is missing), the addition of the A box to restore the second binding site makes the $\mathrm{BenR} / \mathrm{Pb}$ system more responsive to the suboptimal inducer $3 \mathrm{MBz} .{ }^{27}$ In this sense, because we noticed a gain of function for the X-BenRA111V chimeric protein constructed here, we decided to investigate if this regulator would have an improved response to the new inducers when activating a mutated version of $\mathrm{Pb}$ harboring two functional operators $(\mathrm{Pb}$ syn1, Figure 6A). As shown in Figure 6B, the newly created XBenR-A $111 \mathrm{~V}$ regulators displayed an increased response to most inducers tested, with a more than two-fold change in promoter activity when induced with $\mathrm{Bz}, 3 \mathrm{MBz}, 2 \mathrm{MBz}$, and $4 \mathrm{MBz}$. These results confirm the previous notion that promoter architecture is an important element controlling the inducer response to suboptimal inducers in BenR regulators and also adds a new modulation level (the promoter itself) for the optimization of biosensors from the XylS family.

\section{DISCUSSION}

The results presented here shed some light on the molecular mechanisms for ligand and promoter recognition of BenR and XylS from $P$. putida. Of particular interest, XylS has been extensively investigated both in the context of the natural regulation of the meta pathways in P. putida mt- $2^{37-39}$ as well as for its applicability as a universal expression system for Gram-negative bacteria. ${ }^{12,40,41}$ Previous attempts have investigated the critical aa for inducer recognition and promoter activation, ${ }^{12,32,42}$ but these studies have not provided a clear molecular proposition on how this protein interacts with its ligands or the promoter. On the contrary, fewer studies have investigated BenR at the molecular level. ${ }^{26,27,43}$ As for the findings presented here, we initially expect that changes in the aa of the identified binding pocket of BenR could adjust the
A
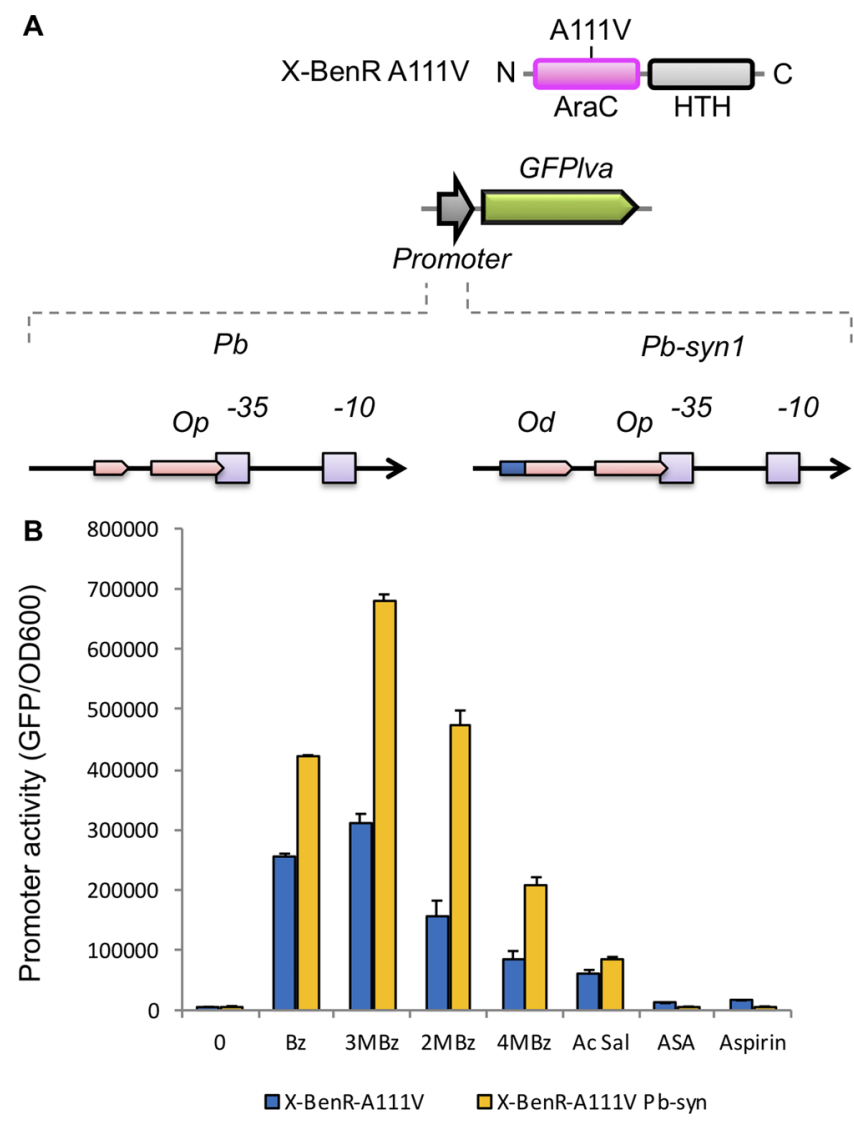

Figure 6. Effect of promoter architecture on the sensitivity of the XBenR A111V regulator. (A) Schematic representation of the assayed system, where a wild-type or a synthetic $\mathrm{Pb}$ promoter ${ }^{27}$ harboring a completed $O p$ binding site has been used to control GFP expression. (B) Analysis of promoter activity for the X-BenR A111V mutant in response to benzoate $(\mathrm{Bz})$, 3-methylbenzoate $(3 \mathrm{MBz})$, 2-methylbenzoate $(2 \mathrm{MBz})$, 4-methylbenzoate $(4 \mathrm{MBz})$, salicylic acid (Ac Sal), acetyl salicylic acid (ASA), and aspirin. All inducers were used at 100 $\mu \mathrm{M}$. Vertical bars are the standard deviations from three independent experiments.

ligand selectivity of the protein, as reported for the $\mathrm{TtgV}$ regulator that can discriminate between molecules with one or two aromatic rings. ${ }^{44,45}$ Yet, contrary to the initial size exclusion model proposed, our experimental validation of the binding site prediction supports a role for position 111 in both BenR and XylS as a key element connecting the binding of the ligand to the changes in domain arrangement of the protein, similarly to the mechanism of activation of AraC of E. coli. ${ }^{46}$ In this sense, the modeling of BenR with both $\mathrm{N}$ - and C-terminal domains suggests that residue 111 is close to the interface between the ligand binding and DNA binding domains (Figures S7, S8, and S10). In this scenario, valine could make critical interactions in BenR that are disrupted when this aa is changed for alanine. In the same way, changing alanine in XylS (or in X-BenR) for valine would allow the establishment of novel interactions that could enhance the performance of the protein, allowing the recognition of novel inducers such as salicylate or ASA. Previous work aiming at the construction of a XylS- $P m$ expression cassette with an increased response to $3 \mathrm{MBz}$ has reported several mutations in both the $\mathrm{N}$ - and $\mathrm{C}$ terminal regions of XylS. Among these mutants, an A111V mutation has been reported before, also based on the 3D modeling of XylS, suggesting that this A111 residue interacts 
Table 1. Strains and Plasmids Used in This Work

\begin{tabular}{|c|c|c|}
\hline strains and plasmids & description & reference \\
\hline \multicolumn{3}{|l|}{ Strains } \\
\hline P. putida KT2440 & P. putida mt-2 derivative & 59 \\
\hline E. coli DH5 $\alpha$ & F- $\varphi 80 \Delta$ lacZ $\Delta$ M15 $\Delta$ (lacZYAA-argF) U169 recA1 endA1 hsdR17 R-M+ supE4 thi gyrA relA & 50 \\
\hline \multicolumn{3}{|c|}{ (2) } \\
\hline pSEVA438 & $\mathrm{Sm} / \mathrm{Sp}^{\mathrm{R}}$, ori $\mathrm{pBBR} 1$; Expression vector harboring the $x y l S-P m$ expression system & 33 \\
\hline pSEVA226 & $\mathrm{Km}^{\mathrm{R}}$, ori $\mathrm{RK} 2$; reporter vector harboring the $l u x C D A B E$ operon & 33 \\
\hline pSEVA226-Pm & $\mathrm{Km}^{\mathrm{R}}$, ori RK2; pSEVA226 with the $P m$ promoter cloned as a $E c o \mathrm{RI} / B a m H I$ fragment & 27 \\
\hline pSEVA226-Pbsyn1 & $\mathrm{Km}^{\mathrm{R}}$, ori RK2; pSEVA226 with the Pbsyn1 promoter cloned as a EcoRI/BamHI fragment & 27 \\
\hline pMR1 & $\mathrm{Cm}^{\mathrm{R}}$, ori $\mathrm{p} 15 \mathrm{a}$; dual mCherry/GFPlva promoter probe vector & 51 \\
\hline pMR1-BenR-Pb & $C m^{\mathrm{R}}$, ori p15a; pMR1 variant with $b e n R-P b$ expression system closed as a $B g l \mathrm{II} / E c o \mathrm{RI}$ fragment & this study \\
\hline pMR1-BenR-V111A & $\mathrm{Cm}^{\mathrm{R}}$, ori $\mathrm{p} 15 \mathrm{a}$; pMR1-BenR-Pb with benR gene mutated at position V111A & this study \\
\hline pMR1-BenR-P110A & $C m^{\mathrm{R}}$, ori $\mathrm{p} 15 \mathrm{a}$; pMR1-BenR-Pb with benR gene mutated at position $\mathrm{P} 110 \mathrm{~A}$ & this study \\
\hline pMR1-BenR-P110Q & $\mathrm{Cm}^{\mathrm{R}}$, ori $\mathrm{p} 15 \mathrm{a}$; pMR1-BenR-Pb with benR gene mutated at position P110Q & this study \\
\hline pMR1-BenR-Q110A111 & $\mathrm{Cm}^{\mathrm{R}}$, ori $\mathrm{p} 15 \mathrm{a}$; pMR1-BenR-Pb with benR gene mutated at positions $\mathrm{P} 110 \mathrm{Q}$ and $\mathrm{V} 111 \mathrm{~A}$ & this study \\
\hline pMR1-X-BenR & $\mathrm{Cm}^{\mathrm{R}}$, ori p15a; pMR1-BenR-Pb with benR with the $\mathrm{N}$-terminal region replaced by that of $x y l S$ & this study \\
\hline pMR1- X-BenR-A111V & $C m^{\mathrm{R}}$, ori p15a; pMR1-X-BenR with chimeric X-benR gene mutated at position A111V & this study \\
\hline pMR1-XylS-Pm & $C m^{\mathrm{R}}$, ori p15a; pMR1 variant with $x y l S-P m$ expression system closed as a BglII/EcoRI fragment & this study \\
\hline pMR1-XylS-Pm-A111V & $C m^{\mathrm{R}}$, ori $\mathrm{p} 15 \mathrm{a}$; pMR1-XylS-Pm with $x y l S$ gene mutated at position A111V & this study \\
\hline pMR1-B-Xyls & $C m^{\mathrm{R}}$, ori $\mathrm{p} 15 \mathrm{a}$; pMR1-XylS-Pm with $x y l S$ with the N-terminal region replaced by that of $b e n R$ & this study \\
\hline
\end{tabular}

with the effector binding pocket. However, in this work, authors performed the A111V mutation together with one or two additional aa positions. ${ }^{12}$ Therefore, the role of position 111 in XylS has never been investigated in isolation. It was interesting to notice that changing the promoter architecture of $\mathrm{Pb}$ allowed the increased responsivity of the chimeric X-BenRA111V to benzoate analogues, yet this strategy was not able to improve the responsivity to ASA or aspirin. This could indicate that the responsivity to these two compounds would require some additional interactions with the TF that are possible only in XylS, and this should be further investigated in the future. Additionally, most of the previously reported mutations affecting the XylS inducer response specificity are located close to the predicted binding pocket identified in this work (Figure S9), increasing the confidence of the computational approach used here.

It is interesting to notice that the mutations affecting the signal specificity of BenR and XylS either completely abolish the protein activity or generate regulators with an enhanced response to a series of ligands. In other words, it was not possible to switch the specificity of the ligand-binding domains from one compound to another. This notion resembles the stem protein model investigated for XylR (another aromatic responsive regulator from $P$. putida $\mathrm{mt}-2$ ), where the selection of mutant proteins responsive to new ligands resulted in variants promiscuous to several aromatic compounds. ${ }^{47}$ It is also important to notice that the computational approach used here predicted the ligand binding pocket site together with the conservation analysis of phylogenetically related protein homologues, which represents a powerful tool to guide the rational design of TF variants. Similar approaches could be applied to other members of the AraC/XylS family of TFs as well as to regulators from different families, aiming at the generation of novel expression systems for inducers of interest. Additionally, recent approaches based on the construction and high-throughput characterization of chimeric proteins have been used to create new benzoate responsive regulators. Yet this approach has generated very modest induction levels for the final engineered proteins (with approximately three-fold changes), whereas the approach used here yielded an induction of about 40 times for the mutated version of XylS. ${ }^{48}$ Whereas $\mathrm{NahR}$, a LysR-type transcriptional regulator, is able to induce gene expression in response to salicylate, ${ }^{10}$ the TFs engineered here represent a new set of tools for the expression of genes of interest in response to salicylate and ASA. Additionally, the expression system based on XylS-A111V displays a $\sim 10$-fold change in response to $10 \mu \mathrm{M}$ of ASA, which is in the same range of the observed sensitivity for the natural ASAresponsive regulator $\mathrm{NahR}$ (which reaches a 20-fold change in response to a similar concentration of the compound ${ }^{10}$ ). These concentrations are in the range of the physiological concentrations of ASA in blood, as this molecules can reach levels as high as $\sim 30 \mu \mathrm{M}$ after $20 \mathrm{~min}$ of administration of the drug. ${ }^{49}$ Yet, whereas the new aspirin-responsive regulator presented here is not specific to this compound, it is reasonable to think that during real applications (i.e., in vivo in a mammalian cell model), systems would not be exposed to benzoate or any of its analogues. Therefore, the lack of exclusive responsivity to aspirin would not be an issue under real case applications. Taken together, these results demonstrate the expansion of the genetic toolbox for the engineering of synthetic circuits inducible to safe drugs.

\section{MATERIALS AND METHODS}

Bacterial Strains and Growth Conditions. The plasmids and bacterial strains used in this study are listed in Table 1. Cloning and assay procedures were performed in E. coli DH5 $\alpha$. All DNA manipulations, including cloning, polymerase chain reaction (PCR), and transformations of $E$. coli, were performed according Sambrook et al. ${ }^{50}$ Bacterial strains were routinely grown in LB media supplemented with $36 \mu \mathrm{g} \mathrm{mL} \mathrm{m}^{-1}$ chloramphenicol or, when necessary, in $\mathrm{M} 9$ minimal media (6.4 $\mathrm{g} \mathrm{L}^{-1} \mathrm{Na}_{2} \mathrm{HPO}_{4} \cdot 7 \mathrm{H}_{2} \mathrm{O}, 1.5 \mathrm{~g} \mathrm{~L}^{-1} \mathrm{KH}_{2} \mathrm{PO}_{4}, 0.25 \mathrm{~g} \mathrm{~L}^{-1}$

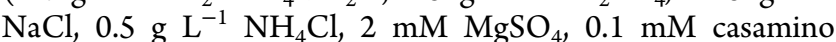
acids, $1 \%$ glycerol) supplemented with chloramphenicol at 36 $\mu \mathrm{g} \mathrm{mL}^{-1}$. Liquid cultures were shaken at $180 \mathrm{rpm}$ at $37^{\circ} \mathrm{C}$ for 
$\sim 16 \mathrm{~h}$. The aromatic compounds used as inducers were all purchased from Sigma-Aldrich. The inducers and their catalogue numbers are benzoic acid (242381), 3-methylbenzoic acid (3117714), 2-methylbenzoic acid (169978), 4methylbenzoic acid (117390), salicylic acid (S5922), ASA (A5376), Bayer aspirin (1000 $\mu \mathrm{M})$ and isopropyl $\beta$-D-1tiogalactopiranosida (IPTG) (I5502), sodium arsenite (S7400), toluene (244511), xylene (214736), phenol (P1037), L-arabinose (A3256), D-(-)-fructose (F0127), and D-(+)-glucose (G8270).

Plasmid Construction. The benR gene and $P b e n R$ and $P b$ promoters were amplified by PCR using specific primers (Table S1) and P. putida KT2440 genomic DNA as the template. The PCR products were digested with specific restriction enzymes (see the underlined sequences in Table S1) and cloned into the pMR1 vector, ${ }^{51}$ yielding the pMR1BenR-Pb (BenR) construct. BenR mutants, pMR1-BenRP110A (BenR-P110A), pMR1-BenR-P110Q (BenR-P110Q), pMR1-BenR-V111A (BenR-V111A), pMR1-BenR-A110A111 (BenR-A110A111), and pMR1-BenR-Q110A111 (BenRQ110A111), were generated by circular polymerase extension cloning (CPEC) site-directed mutagenesis methodology ${ }^{52}$ using the pMR1-BenR-Pb construct as the template and the primers listed in Table S1. (Mutated base pairs are highlighted in bold and underlined.) The $x y l S$ gene and $P s$ and $P m$ promoters were amplified by PCR using pSEVA438 vector as the template, ${ }^{33}$ yielding the pMR1-XylS-Pm (XylS) construct. XylS mutant pMR1-XylS-A111V (XylS-A111V) was constructed by CPEC site-directed mutagenesis using the pMR1-XylS-Pm construct as the template and the primers listed in Table S1. (Mutated base pairs are highlighted in bold and underlined.) Two chimeric transcription factors were constructed. The first construct was generated by directly linking the $\mathrm{N}$-terminal domain of XylS and the C-terminal domain of BenR using, respectively, $P$. putida $\mathrm{mt}-2$ and KT2440 strains as templates. The second construct was generated by linking the $\mathrm{N}$-terminal domain of BenR and the C-terminal domain of XylS using the pMR1-BenR- $P b$ and the pMR1-XylS- $P m$ as templates. All fragments were amplified by PCR. In the first construct, the PbenR promoter was cloned upstream the chimaera, and the $P b$ promoter was cloned upstream the GFPlva reporter gene, yielding the pMR1-XBenR (X-BenR). The chimaera mutant pMR1-X-BenR-A111V (X-BenR-A111V) was constructed using the vector pMR1-XBenR as the template. In the second construct, the Ps and Pm promoters were cloned upstream the chimaera and the GFPlva reporter gene, respectively, generating the pMR1-B-XylS (BXylS). All PCR amplifications were performed using Phusion high-fidelity DNA polymerase (Thermo Fisher Scientific). All resulting constructs were sequenced using dideosyterminal methods to confirm the correct assembly prior to the fluorescence assays. The aa sequences of the final construct generated here are represented in Table S2.

GFP Fluorescence Assay and Data Processing. To measure the activity of all constructions performed in this work, plasmids were transformed into E. coli DH5 $\alpha$. Freshly plated single colonies were grown in M9 minimal media supplemented with suitable antibiotics. The cultures $(10 \mu \mathrm{L})$ were then assayed in a 96-well microplates with $170 \mu \mathrm{L}$ of M9 minimal media and $20 \mu \mathrm{L}$ of the different compounds tested. When required, benzoic acid $(\mathrm{Bz}), 3$-methylbenzoic acid $(3 \mathrm{MBz}), 2$-methylbenzoic acid $(2 \mathrm{MBz})$, 4-methylbenzoic acid $(4 \mathrm{MBz})$, salicylic acid $(0-1000 \mu \mathrm{M})$, ASA, Bayer aspirin
$(1000 \mu \mathrm{M})$ and IPTG, sodium arsenite, toluene, xylene, phenol, L-arabinose, fructose, and glucose $(100 \mu \mathrm{M})$ were used. Cell growth and GFP fluorescence were quantified using a Victor X3 plate reader (PerkinElmer). The responsiveness of regulators was calculated as arbitrary units using the ratio between fluorescence levels and the optical density at $600 \mathrm{~nm}$ (reported as $\mathrm{GFP} / \mathrm{OD}_{600}$ ) or the luminescence by optical density at $600 \mathrm{~nm}$ after background correction. As a control, all assays were performed without the addition of compounds (inducers) as the threshold background signal during calculations. Fluorescence and absorbance measurements were taken at $30 \mathrm{~min}$ intervals up to $8 \mathrm{~h}$ at $37^{\circ} \mathrm{C}$. All experiments were performed in technical and biological triplicates. Raw data were processed using ad hoc $\mathrm{R}$ script (https://www.r-project.org/).

Flow Cytometry Analysis. High-throughput single-cell analysis of the bacteria carrying the BenR, XylS, XBenR, XylS mutant, or XBenR mutant systems was run as follows. First, we selected single colonies of the transformed strain (E. coli $\mathrm{DH} 5 \alpha$ ) and cultivated it overnight in $\mathrm{M} 9$ minimal medium (containing $6.4 \mathrm{~g} / \mathrm{L} \mathrm{Na} \mathrm{HPO}_{4} \cdot 7 \mathrm{H}_{2} \mathrm{O}, 1.5 \mathrm{~g} / \mathrm{L} \mathrm{KH}_{2} \mathrm{PO}_{4}, 0.25$ $\mathrm{g} / \mathrm{L} \mathrm{NaCl}$, and $0.5 \mathrm{~g} / \mathrm{L} \mathrm{NH} 4 \mathrm{Cl}$ ) supplemented with $2 \mathrm{mM}$ $\mathrm{MgSO}_{4}, 0.1 \mathrm{mM} \mathrm{CaCl} 2,0.1 \mathrm{mM}$ casamino acids, chloramphenicol $(36 \mu \mathrm{g} / \mathrm{mL})$, and $1 \%$ glycerol as the sole carbon source (supplemented M9) at $37{ }^{\circ} \mathrm{C}$ and $180 \mathrm{rpm}$. Next, overnight grown cells were diluted to $1: 10$ in fresh supplemented M9 and were grown for $3 \mathrm{~h}$ at $37{ }^{\circ} \mathrm{C}$ and 180 $\mathrm{rpm}$. At this point, the cultures were induced with different concentrations $(0,10,100,250,500$, and $1000 \mu \mathrm{M})$ of the inducers. The BenR system was induced with benzoate, XylS was induced with benzoate and 3-metilbenzoate, X-BenR was induced with 3-metilbenzoate, and XylS mutant and X-BenR mutant were induced with benzoate, 3-metil-benzoate, salicylic acid, and acetyl-salicylic acid. After $3 \mathrm{~h}$ of induction, the cultures were stored in ice and immediately analyzed for GFP fluorescence using the Millipore Guava EasyCyte mini flow cytometer (Millipore). The results were analyzed by $\mathrm{R}$ scripts using the flowCore and flowViz packages available on Bioconductor (https://bioconductor.org/).

3D Structure Model Construction and Docking Analysis. The 3D models presented here were generated by SWISS-MODEL server (https://swissmodel.expasy.org/) using the best homologue for each protein. For the visualization of the models, PyMol (https://pymol.org/) and Chimaera (https://www.cgl.ucsf.edu/chimera/) were used. To predict the potential binding site for the aromatic ligands, Swiss-Docking (https://www.swissdock.ch/) and Docking Server (https://www.dockingserver.com/web) were used. Additionally, Jalview (http://www.jalview.org/) was used for the visualization of protein and DNA alignments generated by T-coffee (http://tcoffee.crg.cat/apps/tcoffee/all.html). From the generated 3D models using SwissModel, ${ }^{53}$ models were first inspected visually for histidine protonation and Asn and Gln positioning. Models were further refined by minimizing their structure with the AMBER FF14SB ${ }^{54}$ force field using AMBER. $^{55}$

Molecular Docking. The energy maps were computed inside the grid, with a grid size of $26 \times 30 \times 40$. Dockings were carried out using the LGA/LS algorithm implemented on Autodock $4^{56}$ (version 4.2.6, with a maximum of 27000 generations or 2500000 energy evaluations). Fifty independent runs were performed, and the resulting poses were clustered according to the ligand heavy-atom rmsd using a 
cutoff of $2 \AA$, thus defining a result. 3D structures of the ligands were generated using OpenBabel ${ }^{57}$ and manually inspected. Images were created with VMD. ${ }^{58}$

\section{ASSOCIATED CONTENT}

\section{S Supporting Information}

The Supporting Information is available free of charge on the ACS Publications website at DOI: 10.1021/acssynbio.9b00191.

Protein sequences reported here and Figures $\mathrm{S} 1-\mathrm{S} 10$ and Tables S1-S3 (PDF)

\section{AUTHOR INFORMATION}

\section{Corresponding Author}

*Tel: +55 163602 3107. Fax: +55 163633 6840. E-mail: silvarochar@usp.br.

\section{ORCID}

Lucas Defelipe: 0000-0001-7859-7300

Víctor de Lorenzo: 0000-0002-6041-2731

Rafael Silva-Rocha: 0000-0001-6319-631X

\section{Notes}

The authors declare no competing financial interest.

\section{ACKNOWLEDGMENTS}

We thank the lab members for insightful discussion on this work. We thank Gabriel Lencione Lovate for help with acquiring some chemicals used in this work. R.S.-R. and M.E.G. were supported by Young Research Awards, grant nos. 2012/22921-8 and 2015/04309-1, São Paulo Research Foundation (FAPESP). L.M.O.M., A.S.-M., L.M.-S., and L.F.A. were supported by FAPESP Ph.D. Fellowships (grant nos. 2016/19179-9, 2016/06323-4, 2017/17924-1, and 2018/ 04810-0).

\section{REFERENCES}

(1) Browning, D. F., and Busby, S. J. W. (2016) Local and Global Regulation of Transcription Initiation in Bacteria. Nat. Rev. Microbiol. $14,638-650$.

(2) Galán-Vásquez, E., Sánchez-Osorio, I., and Martínez-Antonio, A. (2016) Transcription Factors Exhibit Differential Conservation in Bacteria with Reduced Genomes. PLoS One 11 (1), e0146901.

(3) Gama-Castro, S., Salgado, H., Santos-Zavaleta, A., LedezmaTejeida, D., Muñiz-Rascado, L., García-Sotelo, J. S., AlquiciraHernández, K., Martínez-Flores, I., Pannier, L., Castro-Mondragón, J. A., Medina-Rivera, A., Solano-Lira, H., Bonavides-Martínez, C., Pérez-Rueda, E., Alquicira-Hernández, S., Porrón-Sotelo, L., LópezFuentes, A., Hernández-Koutoucheva, A., Del Moral-Chávez, V., Rinaldi, F., and Collado-Vides, J. (2016) RegulonDB Version 9.0: High-Level Integration of Gene Regulation, Coexpression, Motif Clustering and Beyond. Nucleic Acids Res. 44, D133-D143.

(4) Steinacher, A., Bates, D. G., Akman, O. E., and Soyer, O. S. (2016) Nonlinear Dynamics in Gene Regulation Promote Robustness and Evolvability of Gene Expression Levels. PLoS One 11 (4), e0153295.

(5) Baumstark, R., Hänzelmann, S., Tsuru, S., Schaerli, Y., Francesconi, M., Mancuso, F. M., Castelo, R., and Isalan, M. (2015) The Propagation of Perturbations in Rewired Bacterial Gene Networks. Nat. Commun. 6, 10105.

(6) Mannan, A. A., Liu, D., Zhang, F., and Oyarzun, D. A. (2017) Fundamental Design Principles for Transcription-Factor-Based Metabolite Biosensors. ACS Synth. Biol. 6 (10), 1851-1859.

(7) Lee, J. W., Gyorgy, A., Cameron, D. E., Pyenson, N., Choi, K. R., Way, J. C., Silver, P. A., Del Vecchio, D., and Collins, J. J. (2016) Creating Single-Copy Genetic Circuits. Mol. Cell 63 (2), 329-336.
(8) Nielsen, A. a K., Der, B. S., Shin, J., Vaidyanathan, P., Paralanov, V., Strychalski, E. a, Ross, D., Densmore, D., and Voigt, C. a. (2016) Genetic Circuit Design Automation. Science 352 (6281), aac7341.

(9) Unkles, S. E., Valiante, V., Mattern, D. J., and Brakhage, A. A. (2014) Synthetic Biology Tools for Bioprospecting of Natural Products in Eukaryotes. Chem. Biol. 21 (4), 502-508.

(10) Shin, H. J. (2010) Development of Highly-Sensitive Microbial Biosensors by Mutation of the NahR Regulatory Gene. J. Biotechnol. 150 (2), 246-250.

(11) Garmendia, J., de las Heras, A., Galvao, T. C., and de Lorenzo, V. (2008) Tracing Explosives in Soil with Transcriptional Regulators of Pseudomonas Putida Evolved for Responding to Nitrotoluenes. Microb. Biotechnol. 1 (3), 236-246.

(12) Vee Aune, T. E., Bakke, I., Drablos, F., Lale, R., Brautaset, T., and Valla, S. (2010) Directed Evolution of the Transcription Factor XylS for Development of Improved Expression Systems. Microb. Biotechnol. 3 (1), 38-47.

(13) Bates, D. M., Popescu, C. V., Khoroshilova, N., Vogt, K., Beinert, H., Munck, E., and Kiley, P. J. (2000) Substitution of Leucine 28 with Histidine in the Escherichia Coli Transcription Factor FNR Results in Increased Stability of the [4Fe-4S](2+) Cluster to Oxygen. J. Biol. Chem. 275 (9), 6234-6240.

(14) Chen, J. X., Steel, H., Wu, Y. H., Wang, Y., Xu, J., Rampley, C. P. N., Thompson, I. P., Papachristodoulou, A., and Huang, W. E. (2019) Development of Aspirininducible Biosensors in Escherichia Coli and SimCells. Appl. Environ. Microbiol. 85, No. e02959-18.

(15) Meyer, A. J., Segall-Shapiro, T. H., Glassey, E., Zhang, J., and Voigt, C. A. (2019) Escherichia Coli "Marionette" Strains with 12 Highly Optimized Small-Molecule Sensors. Nat. Chem. Biol. 15, 196.

(16) Shis, D. L., Hussain, F., Meinhardt, S., Swint-Kruse, L., and Bennett, M. R. (2014) Modular, Multi-Input Transcriptional Logic Gating with Orthogonal LacI/GalR Family Chimeras. ACS Synth. Biol. 3 (9), 645-651.

(17) Younger, A. K., Dalvie, N. C., Rottinghaus, A. G., and Leonard, J. N. (2017) Engineering Modular Biosensors to Confer MetaboliteResponsive Regulation of Transcription. ACS Synth. Biol. 6 (2), 311325

(18) Stanton, B. C., Nielsen, A. A., Tamsir, A., Clancy, K., Peterson, T., and Voigt, C. A. (2014) Genomic Mining of Prokaryotic Repressors for Orthogonal Logic Gates. Nat. Chem. Biol. 10 (2), 99-105.

(19) Libis, V., Delepine, B., and Faulon, J. L. (2016) Sensing New Chemicals with Bacterial Transcription Factors. Curr. Opin. Microbiol. 33, 105-112.

(20) Bikard, D., Jiang, W., Samai, P., Hochschild, A., Zhang, F., and Marraffini, L. A. (2013) Programmable Repression and Activation of Bacterial Gene Expression Using an Engineered CRISPR-Cas System. Nucleic Acids Res. 41 (15), 7429-7437.

(21) Bikard, D., and Marraffini, L. A. (2013) Control of Gene Expression by CRISPR-Cas Systems. F1000Prime Rep. 5, 47.

(22) Qi, L. S., Larson, M. H., Gilbert, L. A., Doudna, J. A., Weissman, J. S., Arkin, A. P., and Lim, W. A. (2013) Repurposing CRISPR as an RNA-Guided Platform for Sequence-Specific Control of Gene Expression. Cell 152 (5), 1173-1183.

(23) Libis, V., Delepine, B., and Faulon, J. L. (2016) Expanding Biosensing Abilities through Computer-Aided Design of Metabolic Pathways. ACS Synth. Biol. 5 (10), 1076-1085.

(24) de los Santos, E. L., Meyerowitz, J. T., Mayo, S. L., and Murray, R. M. (2016) Engineering Transcriptional Regulator Effector Specificity Using Computational Design and In Vitro Rapid Prototyping: Developing a Vanillin Sensor. ACS Synth. Biol. 5 (4), 287-295.

(25) Royo, J. L., Becker, P. D., Camacho, E. M., Cebolla, A., Link, C. Santero, E., and Guzman, C. A. (2007) In Vivo Gene Regulation in Salmonella Spp. by a Salicylate-Dependent Control Circuit. Nat. Methods 4 (11), 937-942.

(26) Perez-Pantoja, D., Kim, J., Silva-Rocha, R., and de Lorenzo, V. (2015) The Differential Response of the Pben Promoter of 
Pseudomonas Putida Mt-2 to BenR and XylS Prevents Metabolic Conflicts in m-Xylene Biodegradation. Environ. Microbiol. 17, 64.

(27) Silva-Rocha, R., and de Lorenzo, V. (2012) Broadening the Signal Specificity of Prokaryotic Promoters by Modifying CisRegulatory Elements Associated with a Single Transcription Factor. Mol. BioSyst. 8 (7), 1950-1957.

(28) Cowles, C. E., Nichols, N. N., and Harwood, C. S. (2000) BenR, a XylS Homologue, Regulates Three Different Pathways of Aromatic Acid Degradation in Pseudomonas Putida. J. Bacteriol. 182 (22), 6339-6346.

(29) Xue, H., Shi, H., Yu, Z., He, S., Liu, S., Hou, Y., Pan, X., Wang, H., Zheng, P., Cui, C., Viets, H., Liang, J., Zhang, Y., Chen, S., Zhang, H. M., and Ouyang, Q. (2014) Design, Construction, and Characterization of a Set of Biosensors for Aromatic Compounds. ACS Synth. Biol. 3 (12), 1011-1014.

(30) Tobes, R., and Ramos, J. L. (2002) AraC-XylS Database: A Family of Positive Transcriptional Regulators in Bacteria. Nucleic Acids Res. 30 (1), 318-321.

(31) Kessler, B., de Lorenzo, V., and Timmis, K. N. (1993) Identification of a Cis-Acting Sequence within the Pm Promoter of the TOL Plasmid Which Confers XylS-Mediated Responsiveness to Substituted Benzoates. J. Mol. Biol. 230 (3), 699-703.

(32) Domínguez-Cuevas, P., Marín, P., Marqués, S., and Ramos, J. L. (2008) XylS-Pm Promoter Interactions through Two Helix-TurnHelix Motifs: Identifying XylS Residues Important for DNA Binding and Activation. J. Mol. Biol. 375 (1), 59-69.

(33) Silva-Rocha, R., Martínez-García, E., Calles, B., Chavarría, M., Arce-Rodríguez, A., de las Heras, A., Páez-Espino, A. D., DuranteRodríguez, G., Kim, J., Nikel, P. I., Platero, R., and de Lorenzo, V. (2013) The Standard European Vector Architecture (SEVA): A Coherent Platform for the Analysis and Deployment of Complex Prokaryotic Phenotypes. Nucleic Acids Res. 41 (D1), D666-D675.

(34) Silva-Rocha, R., and de Lorenzo, V. (2012) Stochasticity of TOL Plasmid Catabolic Promoters Sets a Bimodal Expression Regime in Pseudomonas Putida Mt-2 Exposed to m-Xylene. Mol. Microbiol. 86, 199.

(35) Silva-Rocha, R., and de Lorenzo, V. (2012) A GFP-LacZ Bicistronic Reporter System for Promoter Analysis in Environmental Gram-Negative Bacteria. PLoS One 7 (4), e34675.

(36) Michan, C., Zhou, L., Gallegos, M. T., Timmis, K. N., and Ramos, J. L. (1992) Identification of Critical Amino-Terminal Regions of Xy1S. The Positive Regulator Encoded by the TOL Plasmid. J. Biol. Chem. 267 (32), 22897-22901.

(37) Moreno, R., Fonseca, P., and Rojo, F. (2010) The Crc Global Regulator Inhibits the Pseudomonas Putida PWW0 Toluene/Xylene Assimilation Pathway by Repressing the Translation of Regulatory and Structural Genes. J. Biol. Chem. 285 (32), 24412-24419.

(38) Gonzalez-Perez, M. M., Ramos, J. L., and Marques, S. (2004) Cellular XylS Levels Are a Function of Transcription of XylS from Two Independent Promoters and the Differential Efficiency of Translation of the Two MRNAs. J. Bacteriol. 186 (6), 1898-1901.

(39) Marques, S., Manzanera, M., Gonzalez-Perez, M. M., Gallegos, M. T., and Ramos, J. L. (1999) The XylS-Dependent Pm Promoter Is Transcribed in Vivo by RNA Polymerase with Sigma 32 or Sigma 38 Depending on the Growth Phase. Mol. Microbiol. 31 (4), 1105-1113.

(40) Blatny, J. M., Brautaset, T., Winther-Larsen, H. C., Karunakaran, P., and Valla, S. (1997) Improved Broad-Host-Range RK2 Vectors Useful for High and Low Regulated Gene Expression Levels in Gram-Negative Bacteria. Plasmid 38 (1), 35-51.

(41) Blatny, J. M., Brautaset, T., Winther-Larsen, H. C., Haugan, K., and Valla, S. (1997) Construction and Use of a Versatile Set of BroadHost-Range Cloning and Expression Vectors Based on the RK2 Replicon. Appl. Environ. Microbiol. 63 (2), 370-379.

(42) Dominguez-Cuevas, P., Marin, P., Busby, S., Ramos, J. L., and Marques, S. (2008) Roles of Effectors in XylS-Dependent Transcription Activation: Intramolecular Domain Derepression and DNA Binding. J. Bacteriol. 190 (9), 3118-3128.

(43) Moreno, R., and Rojo, F. (2008) The Target for the Pseudomonas Putida Crc Global Regulator in the Benzoate
Degradation Pathway Is the BenR Transcriptional Regulator. J. Bacteriol. 190 (5), 1539-1545.

(44) Guazzaroni, M. E., Gallegos, M. T., Ramos, J. L., and Krell, T. (2007) Different Modes of Binding of Mono- and Biaromatic Effectors to the Transcriptional Regulator TTGV: Role in Differential Derepression from Its Cognate Operator. J. Biol. Chem. 282 (22), 16308-16316.

(45) Guazzaroni, M. E., Krell, T., Felipe, A., Ruiz, R., Meng, C., Zhang, X., Gallegos, M. T., and Ramos, J. L. (2005) The Multidrug Efflux Regulator TtgV Recognizes a Wide Range of Structurally Different Effectors in Solution and Complexed with Target DNA: Evidence from Isothermal Titration Calorimetry. J. Biol. Chem. 280 (21), 20887-20893.

(46) Schleif, R. (2010) AraC Protein, Regulation of the l-Arabinose Operon in Escherichia Coli, and the Light Switch Mechanism of AraC Action. FEMS Microbiol. Rev. 34 (5), 779-796.

(47) Galvao, T. C., Mencia, M., and de Lorenzo, V. (2007) Emergence of Novel Functions in Transcriptional Regulators by Regression to Stem Protein Types. Mol. Microbiol. 65 (4), 907-919.

(48) Juárez, J. F., Lecube-Azpeitia, B., Brown, S. L., Johnston, C. D., and Church, G. M. (2018) Biosensor Libraries Harness Large Classes of Binding Domains for Construction of Allosteric Transcriptional Regulators. Nat. Commun. 9, 3101.

(49) Cotty, V. F., Sterbenz, F. J., Mueller, F., Melman, K., Ederma, H., Skerpac, J., Hunter, D., and Lehr, M. (1977) Augmentation of Human Blood Acetylsalicylate Concentrations by the Simultaneous Administration of Acetaminophen with Aspirin. Toxicol. Appl. Pharmacol. 41 (1), 7-13.

(50) Sambrook, J., Fritsch, E. F., and Maniatis, T. (1989) Molecular Cloning: A Laboratory Manual, Cold Spring Harbor, New York.

(51) Guazzaroni, M.-E., and Silva-Rocha, R. (2014) Expanding the Logic of Bacterial Promoters Using Engineered Overlapping Operators for Global Regulators. ACS Synth. Biol. 3, 666-675.

(52) Quan, J., and Tian, J. (2011) Circular Polymerase Extension Cloning for High-Throughput Cloning of Complex and Combinatorial DNA Libraries. Nat. Protoc. 6 (2), 242-251.

(53) Biasini, M., Bienert, S., Waterhouse, A., Arnold, K., Studer, G., Schmidt, T., Kiefer, F., Cassarino, T. G., Bertoni, M., Bordoli, L., and Schwede, T. (2014) SWISS-MODEL: Modelling Protein Tertiary and Quaternary Structure Using Evolutionary Information. Nucleic Acids Res. 42, W252.

(54) Maier, J. A., Martinez, C., Kasavajhala, K., Wickstrom, L., Hauser, K. E., and Simmerling, C. (2015) Ff14SB: Improving the Accuracy of Protein Side Chain and Backbone Parameters from Ff99SB. J. Chem. Theory Comput. 11, 3696.

(55) Case, D. A., Betz, R. M., Cerutti, D. S., Cheatham, T. E., Darden, T. A., Duke, R. E., Giese, T. J., Gohlke, H., Goetz, A. W., Homeyer, N., Izadi, S., Janowski, P., Kaus, J., Kovalenko, A., Lee, T. S., LeGrand, S., Li, P., Lin, C., Luchko, T., Luo, R., Madej, B., Mermelstein, D., Merz, K. M., Monard, G., Nguyen, H., Nguyen, H. T., Omelyan, I., Onufriev, A., Roe, D. R., Roitberg, A., Sagui, C., Simmerling, C. L., Botello-Smith, W. M., Swails, J., Walker, R. C., Wang, J., Wolf, R. M., Wu, X., Xiao, L., and Kollman, P. A. (2018) AMBER 2018; University of California, San Francisco, CA.

(56) Morris, G. M., Huey, R., Lindstrom, W., Sanner, M. F., Belew, R. K., Goodsell, D. S., and Olson, A. J. (2009) Software News and Updates AutoDock4 and AutoDockTools4: Automated Docking with Selective Receptor Flexibility. J. Comput. Chem. 30, 2785.

(57) O'Boyle, N. M., Banck, M., James, C. A., Morley, C., Vandermeersch, T., and Hutchison, G. R. (2011) Open Babel: An Open Chemical Toolbox. J. Cheminf. 3, 33.

(58) Humphrey, W., Dalke, A., and Schulten, K. (1996) VMD: Visual Molecular Dynamics. J. Mol. Graphics 14, 33.

(59) Bagdasarian, M., Lurz, R., Ruckert, B., Franklin, F. C., Bagdasarian, M. M., Frey, J., and Timmis, K. N. (1981) SpecificPurpose Plasmid Cloning Vectors. II. Broad Host Range, High Copy Number, RSF1010-Derived Vectors, and a Host-Vector System for Gene Cloning in Pseudomonas. Gene 16 (1-3), 237-247. 


\section{CHAPTER IV}

\section{PredicTF: a tool to predict bacterial transcription factors in complex microbial communities}

This chapter was submmited as:

MONTEIRO, Lummy Maria Oliveira; SARAIVA, João; TOSCAN, Rodolfo Brizola; STADLER, Peter; SILVA-ROCHA, Rafael; da ROCHA, Ulisses Nunes. PredicTF: a tool to predict bacterial transcription factors in complex microbial communities. 

microbial communities.

3

4 Lummy Maria Oliveira Monteiro ${ }^{1,2,3}$, Joao Saraiva ${ }^{1}$, Rodolfo Brizola Toscan ${ }^{1}$, Peter F Stadler $^{2}$, Rafael Silva-Rocha ${ }^{3}$, Ulisses Nunes da Rocha ${ }^{1 *}$

6

$7 \quad{ }^{1}$ Helmholtz Center for Environmental Research (UFZ), Leipzig, Germany

$8 \quad{ }^{2}$ Universität Leipzig (UL), Leipzig, Germany

$9 \quad{ }^{3}$ Ribeirão Preto Medical School (FMRP), University of São Paulo (USP), Ribeirão Preto, Brazil 10

*Correspondence: Ulisses Nunes da Rocha, ulisses.rocha@ufz.de

13

14 Authors' email addresses:

15 Lummy Monteiro - lummymaria@gmail.com

16 João Saraiva - joao.saraiva@ufz.de

17 Rodolfo Brizola Toscan - rodolfo.toscan@ufz.de

18 Peter F. Stadler - studla@bioinf.uni-leipzig.de

19 Rafael Silva-Rocha - silvarochar@usp.br

20 Ulisses Nunes da Rocha - ulisses.rocha@ufz.de 


\section{Abstract}

28 Background: Transcription Factors (TFs) are proteins controlling the rate of genetic

29 information and regulating cellular gene expression. A better understanding of TFs in a

30 bacterial community context may open novel revenues for exploring gene regulation in 31 ecosystems where bacteria play a key role. Here we describe PredicTF, the first platform 32 supporting the prediction and classification of novel bacterial TF not only in single 33 species but also in complex microbial communities.

34 Results: We created our TF database (BacTFDB) by merging data from CollectTF and

35 UniProt. The TF sequences from these two databases were merged and manually curated generating a robust bacterial TF database with $11.961 \mathrm{TFs}$ sequences distributed in $99 \mathrm{TF}$ families. BacTFDB was used to train a deep learning model to predict novel TFs and their families. Five model organisms were used to test the performance and the accuracy of PredicTF. PredicTF was able to identify 27 to $60 \%$ of the known TFs with an accuracy of 73 to $91 \%$ in our five model organisms. We further evaluated PredicTF using a twostep approach. First, we tested PredictTF's ability to predict TFs for the genome of an environmental isolate of $P$. aeruginosa PAO1 followed by the mapping of these TFs in the transcriptomic data for three clinical isolates. We were able to map 69 of the 199 predicted TFs to the transcriptomes. This result demonstrates the potential of PredicTF to map and compare TFs profiles under different environmental conditions. In the second evaluation step, PredicTF was used to predict TFs in a metagenome recovered from a community performing anaerobic ammonium oxidation (anammox) in a bioreactor. A total of 792 TFs were predicted in this community. These 792 TFs were mapped in 11

49 metatranscriptomes of reference from the same bioreactor where the metagenome was

50 collected allowing the comparison of profiles of regulators expressed in different 51 environmental situations. 
52 Conclusion: PredicTF provides the first tool to profile TFs in yet-to be cultured bacteria

53 and it opens the potential to evaluate regulatory networks in complex microbial

54 communities. PredicTF is a flexible, open source pipeline able to predict and annotate

55 TFs in genomes and metagenomes. PredicTF is available at

56 https://github.com/mdsufz/PredicTF.

58 Keywords: Gene regulation, Transcription factors, Deep Learning, Transcription factor database, Microbial Communities

60

\section{Background}

The functional potential of microbial communities can be determined by the genetic content of its constituent members. However, genetic content alone does not

64 guarantee that a given function or enzymatic reaction will be performed [1]. In this scenario, Transcription Factor proteins (TFs) play a central and critical role in gene regulation. These proteins are responsible for optimizing proteins and structural RNAs and the subsequent levels of metabolites and other properties, ensuring the survival and adaptation of organisms to the most diverse types of stress and environmental changes

69 [2]. The activity of bacterial TFs is modulated by environmental signals (e.g. changes in 70 the oxygen condition, temperature, $\mathrm{pH}$ or the lack of a specific substrate) [3].

71 Additionally, for many promoters, combinations of transcription factors work together to 72 integrate different signals [2,4]. TFs can also work with other DNA-binding proteins 73 whose primary role is to sculpt the bacterial folded chromosome [2,5]. Knowledge of the

74 TFs profile expressed by an organism is the first step to better understand the regulatory network that controls protein expression in an organism or a community. 
Since TFs may determine when and which genes are expressed, profiling TFs can

help understand the regulation of gene expression and to build regulatory networks in complex microbial communities. Further, defining which factors control gene expression may offer insights into the mechanisms controlling ecosystem processes and even interactions between species of a microbial community. However, current TF databases are focused on single or small groups of genomes. These databases are largely manually curated based on literature evidence and pairwise sequence comparison of genomes from model organisms. Examples of these databases include RegulonDB for Escherichia coli K-12 [6], DBTBS for Bacillus subtilis [7], FlyBase for Drosophila [8], and FTFD for fungal species [9]. DBD [10], is a database generated from the prediction of TFs from 150 sequenced genomes from across the tree of life. Unfortunately, DBD has has not been updated for more than 9 years.

One of the major goals in the manipulation of microbiomes for ecological and biotechnological applications is to control the outcome of their functions [11]. As TFs are key to potentially control which genes are expressed, one of the best ways to study and understand gene regulation in a microbiome may be to profile its TFs. To date, no platform supports prediction and classification of novel bacterial TF from 'omics data recovered from microbial communities.

Deep Learning approaches have been used to predict DNA sequence affinities [12] and to identify TF-binding sites in humans [13]. Although deep learning has been used in gene regulation, it has never been used to predict bacterial TFs. Further, the need for a user-friendly tool for prediction of TFs that could assist in gene regulation analysis motivated the development of PredicTF. PredicTF is a deep learning tool used to predict and identify TFs from full protein-length sequences. Further, we constructed a robust 
100 database for bacterial transcriptional factors (BacTFDB) that was used to train our Deep

101 Learning model.

102

103 Implementation

104 PredictTF is a command line software for prediction of novel transcription factors

105 from genomic and metagenomic data. We created a bacterial transcription factor database

106 (BacTFDB) by merging and manually curating TFs present in CollectTF [14] and the

107 Universal Protein Resource (UniProt) [15]. CollectTF provides well described and

108 characterized, in vivo validated, TFs while UniProt is a comprehensive resource for

109 protein sequence and annotation data. We used BacTFDB to train a deep learning model

110 to predict new TFs and their families in genomes and metagenomes. Five model

111 organisms (Escherichia coli, Bacillus subtillis, Pseudomonas fluorescens, Azotobacter

112 vinelandii and Caulobacter crescentus) were used to test the performance and accuracy

113 of PredicTF. We used the same approach to predict TFs from a clinical isolate ( $P$.

114 aeruginosa PAO1) and a metagenome sample isolated from an anaerobic ammonium

115 oxidation community. We also determined if the predicted TFs were expressed in

116 transcriptomes (isolate) and metatranscriptomes (microbial community), respectively

117 (Fig. 1).

118

119 BacTFDB - Bacterial Transcription Factor Data Base

120 To create a novel Bacterial Transcription Factor Data Base (BacTFDB), we

121 collected data from two publicly available databases. Initially, we chose to collect data

122 from CollecTF [14], a well described and characterized database. Since CollecTF does

123 not provide an application programming interface (API) for bulk download, we developed

124 a Python code (version 2.7) using the Beautiful Soup 4.4.0 library to recover the data 
125 from CollecTF. With this strategy we listed 390 TF experimentally validated amino acid 126 sequences distributed over $44 \mathrm{TF}$ families. The script can be found at 127 https://github.com/mdsufz/PredicTF.

128 Additionally, we retrieved $\mathrm{TF}$ amino acid sequences from UniProt using

129 UniProt's API. We downloaded sequences of interest by adding a filter with the key

130 words (Transcription factor, transcriptional factor, regulator, transcriptional repressor, 131 transcriptional activator, transcriptional regulator). After, we filtered for Reviewed

132 (Swiss-Prot) - Manually annotated sequences that belonged to the bacteria taxonomy. The 133 UniProt API was accessed on $8^{\text {th }}$ September-2019 and a total of $21.581 \mathrm{TF}$ amino acid 134 sequences, with applied filters, were collected. We merged the data collected from 135 CollecTF and UniProt databases which resulted in a total of 21.971 TFs. Next, we 136 removed redundant TF entries and TF sequences lacking a TF family since PredicTF was 137 designed to also assign TF family. Finally, a manual inspection was performed to remove 138 case sensitive and presence of characters associated to the database header. The first 139 version of BacTFDB contains a total of 11.691 unique TF sequences. A summary of the 140 information contained in BacTFDB can be found in the supplementary data (Additional 141 file 1: Fig. S1). To evaluate PredicTF in model organisms we created 5 subsets of 142 BacTFDB. The description of these subsets can be found in the supplementary data 143 (Additional file 2: Table S1).

\section{Mapping Transcription Factors using PredictTF}

146 We used a deep learning approach similar to that found in DeepARG [16].

147 Supervised machine learning models are usually divided into characterization, training, 148 and prediction units. Briefly, our approach uses the concept of dissimilarity-based 149 classification [17] where sequences are represented and featured by their identity 
150 distances to known genes. In PredicTF, sequences were represented and featured by their

151 identity distances to known TFs families. The BacTFDB was used to train and test the

152 deep learning model (https://github.com/mdsufz/PredicTF) and the latter validated in

153 model organisms. Next, PredicTF was used to predict novel TFs from full protein-length

154 sequences in genomes and in one metagenome. After prediction, the data was mapped in

155 transcriptomes and metatranscriptomes from samples where the genetic potential was 156 determined.

157 Using PredicTF, we trained five different models - one for each model organism

158 (Additional file 3: Table S2). For each model, the TFs affiliated with the respective model 159 organism were removed prior to training to avoid overfitting. PredicTF-no-coli was 160 trained to predict TFs in E. coli, PredicTF-no-subtilis was trained to predict TFs in $B$. 161 subtilis, PredicTF-no-crescentus was trained to predict TFs in C. crescentus, PredicTF162 no-fluorescens was trained to predict TFs in P. fluorescens and PredicTF-no-vinelandii 163 was trained to predict TFs in A. vinelandii.

\section{Performance and accuracy calculation}

We evaluated PredicTF by calculating accuracy and performance. Performance

167 can be deemed to be the fulfillment of a task. In PredicTF case, performance is how good

168 TF predictions are. Using model organisms (see later in the session Prediction of

169 Transcription Factors in model organisms), performance was calculated by quantifying

170 the number of TFs that PredicTF was able to predict divided by number of TFs already

171 described and annotated for our model organisms (Equation 1). Accuracy indicates how

172 correct the predictions performed by PredicTF are. Also using data of model organism,

173 accuracy was determined by calculating the number of TFs correctly predicted divided

174 by the total number of TFs predicted by PredicTF. We divided accuracy in two categories. 
175 In the first accuracy category, we determined accuracy against experimentally validated

176 TFs (Equation 2). In the second accuracy category, we determined accuracy against TFs

177 without experimental validation (Equation 3); i.e., putative TFs. The performance,

178 accuracy, and accuracy for putative TFs were calculated as follows:

179

$180 \quad$ Equation 1

$$
\text { Performance }(\%)=\frac{\text { Predicted } T F S * 100}{\text { Annotated } T F S}
$$

182

183 where, Performance (\%) is calculated by the ratio of the total number of TFs predicted

184 by PredicTF (Predicted TFs) to the total number of proteins annotated as TFs in NCBI

185 (Annotated TFs) multiplied by 100.

186

187 Equation 2

188

$$
\operatorname{Accuracy}(\%)=\frac{\text { TFs predicted correctly } * 100}{\text { TFs predicted }}
$$

189

190 where, Accuracy (\%) is determined by the ratio of the total number of TFs predicted by

191 PredicTF in agreement with NCBI annotation (TFs predicted correctly) to the total

192 number of TFs predicted by PredicTF (TFs predicted) multiplied by 100.

193

194 Equation 3

195

$$
\text { Accuracy for putative } T F S(\%)=\frac{\text { putative } T F \text { s predicted correctly } * 100}{\text { putative TFs predicted }}
$$


197 where, Accuracy for putative TFs (\%) is determined by the total number of putative TFs 198 predicted correctly divided by putative TFs predicted multiplied by 100; Putative TFS

199 predicted correctly is the total number of putative TFs predicted correctly by PredicTF in 200 agreement with NCBI annotation; and, Putative TFs predicted is the total number of 201 putative TFs predicted by PredicTF.

\section{Prediction of Transcription Factors in model organisms}

We selected bacterial species that have been widely studied as model organisms.

Some bacterial species became model organisms for TF studies because they are easy to maintain and grow in a laboratory setting and to manipulate in pure culture experiments.

207 Five complete genomes from model organisms (E. coli, B. subtillis, P. fluorescens, A. vinelandii and C. crescentus) were downloaded directly from NCBI. The strains details and accession number (RefSeq) for all selected organisms are listed in the supplementary data (Additional file 3: Table S2). By evaluating PredicTF using model organisms

211 (Additional file 2: Table S1) we extrapolated performance and accuracy of our deep learn

212 model. Since known TFs for each organism were removed from each the training dataset, we eliminate the possibility of mapping TFs already known and annotated for each of the different species. Performance, accuracy and accuracy for putative TFs of PredicTF for these five model organisms were calculated using Equations 1, 2 and 3.

\section{Prediction of Transcription Factors in a clinical isolate}

We demonstrated the use of PredicTF in a previously sequenced $P$. aeruginosa

219 (PAO1) genome, a clinical isolate publicly available in NCBI (accession number NC_002516.2). P. aeruginosa PAO1 was selected because its genome has been sequenced and because of the availability of transcriptomes from three clinical mutants 
222 of PAO1 (Y71, Y82, and Y89) grown in the presence and absence of an antibiotic 223 cocktail. The transcriptomes of $P$. aeruginosa PAO1 mutants $\mathrm{Y} 71$, Y82, and Y89 are 224 available in NCBI (Bioproject identifier PRJNA479711) [18]. These clinical $P$. 225 aeruginosa PAO1 mutants were isolated from the sputa of three different pneumonia 226 patients. Transcriptomes of $P$. aeruginosa PAO1 wild type and its mutants cultured in 227 two different conditions (LB medium and LB medium in presence of antibiotic cocktail) have been previously described [18]. We used this data to determine the TF profile in these $P$. aeruginosa PAO1 mutants grown in two different conditions.

PredicTF was first used to predict TFs in the P. aeruginosa PAO1 genome. Next, the predicted TFs were mapped to the transcriptomes of the $P$. aeruginosa PAO1 mutants Y71, Y82 and Y89 (see later). Further description of the mapping of the transcriptomes to the genomes is available at https://github.com/mdsufz/PredicTF. The PredicTF model used in this step was trained with the full database BacTFDB. The performance and accuracy were calculated using Equations 1 and 2, respectively. All accession numbers used in this work are listed in the supplementary data (Additional file 3: Table S2).

\section{Prediction of Transcription Factors in Complex Microbial Communities}

To test PredicTF in a complex microbial community, we used an anaerobic ammonium oxidizing (anammox) microbial community from an anammox membrane bioreactor metagenome (LAC_MetaG_1) (data publicly available at NCBI bioproject via accession number PRJNA511011) [19]. We removed short and low-quality reads using

243 Trim Galore - v0.0.4 dev according developer's instructions [20]. Over 50 million reads

244 survived this step and were assembled using the de novo assembler metaSPADES -

245 v3.12.0 [21]. The assembly was translated from nucleotide to amino acid sequences, 
considering all possible translation frames, using emboss transeq [22]. The translated assembly was then used as input for the prediction of transcription factors using PredicTF.

248 The region from each predicted TF was extracted. These putative TFs were later used in 249 the mapping TFs to metatranscriptomes.

We checked if the putative TFs predicted in the metagenomes were transcribed by checking if the metatranscriptomic libraries were mapping to those regions. The metatranscriptomic and metagenomic libraries used in this step belonged to the same bioreactor. These metatranscriptomes are publicly available at the European Nucleotide Archive under the accession numbers SRR7091385, SRR7523233, SRR7523244, SRR7523245, SRR7091400, SRR7091401, SRR7091381, SRR7091402, SRR7091406, SRR7523243, SRR7523246. These 11 metatranscriptomes were used to demonstrate the effectiveness of the pipeline and to indicate the potential of PredicTF to profile transcription factors in complex microbial communities. All accession numbers used in this work are listed in the supplementary data (Additional file 3: Table S2).

\section{Mapping transcription factors to transcriptomes and metatranscriptomes}

Each transcriptomic and metatranscriptomic library was quality controlled by removing short and low-quality reads using Trim Galore - v0.0.4 dev [20]. The 7 transcriptomic libraries for the $P$. aeruginosa PAO1 wild type and mutants showed at least 26 million paired-end reads after quality checking. The 11 metatranscriptomic libraries yielded over 50 million reads per library after quality check. After, the remaining

267 transcriptomic and metatranscriptomic reads were mapped to their respective assembled 268 genome or metagenome using Bowtie2 - v2.3.0 [23]. The number of reads mapped, and the regions covered was extracted using SAMTools - v1.9 [24] and python 2.7. The regions of the genome or metagenome assembly covered by transcriptomic or 
271 metatranscriptomic reads were then crossed-referenced with the regions of their 272 respective assembly which PredicTF assigned as putative TFs creating a TF profile for 273 each transcript and metatranscriptome. A detailed description on the mapping of RNA274 seq data to their respective genome or metagenome assembly can be found at the

275 PredicTF github (https://github.com/mdsufz/PredicTF).

276

277 Results and Discussion

278 Database

279 BacTFDB is a robust and versatile bacterial TF database, it contains 11.691 TFs 280 amino acid sequences spanning $1049 \mathrm{TF}$ families and 720 different bacterial species. Fig. 2812 shows the database distribution based on TF families and regulatory elements (Fig. 2A) 282 and the distribution based on bacterial species (Fig. 2B). Although BacTFDB is composed 283 by 11.961 TFs elements from 1049 different families and 720 organism's species, Fig. 2 284 shows TFs families and organisms' species that accumulate at least more than 50 sequences. We will update BacTFDB annually by adding novel entries deposited in UniProt and CollecTF. BacTFDB was used in PredicTF's deep learning model training.

287 This model was later used to predict new TFs and their families in genomes and 288 metagenomes.

\section{Performance and Accuracy}

The performance and accuracy of PredicTF were evaluated through the prediction

292 of TFs in five model organisms (E. coli, B. subtillis, P. fluorescens, A. vinelandii and C.

293 crescentus). For each model organism a different PredicTF model was trained to predict 294 TFs from full protein-length sequences (described in the implementation section). After 

organisms and the accuracy for experimentally validated TFs ranged from $73.91 \%$ and genomes of E. coli and B. subtillis with accuracies $85.71 \%$ and $100 \%$, respectively (Table A.vinelandii (Table 1). TFs predicted by PredicTF for each organism, sorted by TF family, are shown in Fig. 3. For all organisms tested the most predicted TF family was LysR followed by OmpR/PhoB. The degree of accuracy obtained by PredicTF suggests that the deep learning strategy used is promising for the prediction of TFs in genomic or improved by expanding the number and diversity of sequences present in BacTFDB. As BacTFDB will be update yearly, we expect an improvement in TF identification of with every update.

Table 1. PredicTF performance, accuracy for experimentally validated Transcription 313 Factors (Accuracy EV) and accuracy for putative Transcription Factors (Accuracy PU) in 314 genomes of model organisms.

\begin{tabular}{cccc}
\hline Organism & Performance $^{\mathbf{a}}$ & Accuracy EV $^{\mathbf{b}}$ & Accuracy PU $^{\mathbf{c}}$ \\
\hline E. coli $\boldsymbol{k 1 2}$ & $35.40 \%$ & $88.51 \%$ & $85.71 \%$ \\
B. subtillis & $27.23 \%$ & $73.91 \%$ & $100 \%$ \\
C. crescentus & $38.04 \%$ & $83.93 \%$ & - \\
P. fluorescens & $51.19 \%$ & $91.43 \%$ & - \\
A. vinelandii & $60.53 \%$ & $90.40 \%$ & -
\end{tabular}

${ }^{a}$ Performance was calculated by the ratio of the total number of TFs predicted by PredicTF (Predicted TFs) to the total number of proteins annotated as TFs in NCBI (Annotated TFs) multiplied by 100 ;

${ }^{\mathrm{b}}$ Accuracy EV was determined by the ratio of the total number of TFs predicted by PredicTF in agreement with NCBI annotation (TFs predicted correctly) to the total number of TFs predicted by PredicTF (TFs predicted) multiplied by 100;

${ }^{c}$ Accuracy TU was determined by the total number of putative TFs predicted correctly divided by putative TFs predicted multiplied by 100; Putative TFs predicted correctly is the total number of putative TFs predicted correctly by PredicTF in agreement with NCBI annotation; and, Putative TFs predicted is the total number of putative TFs predicted by PredicTF;

${ }^{\mathrm{d}}$ Currently there are no putative annotated TFs described in the genome of $C$. crescentus, $P$. fluorescens and $A$.vinelandii 
PredicTF was used to predict TFs on the genome of $P$. aeruginosa PAO1 and these TFs were mapped in transcriptomes from the same isolate [18]. PredicTF predicted a total of 199 TFs in the P. aeruginosa PAO1 genome shown in Additional file 4: Fig. S2A by a family's distribution graphic. These 199 TFs were mapped in the transcriptomic data of a reference of $P$. aeruginosa PAO1. Initially, the mapping was done in the transcriptome of $P$. aeruginosa PAO1 cultured in LB media. Using this strategy, we were able to map 69 of the 199 predicted TFs to the transcriptomes under the experimental conditions carried out by Hwang \& Yoon, 2019 (Additional file 4: Fig. S2B) [18]. Next, the mappings were done for another three clinical mutants of P. aeruginosa PAO1 (Y82, Y71, Y89) cultured in LB media (absence of an antibiotic cocktail) (Additional file 5: Fig. S3A, S3C and S3F). The TFs family's distribution for each P. aeruginosa PAO1 mutant cultured in presence of antibiotic cocktail is shown in the supplementary data (Additional file 5: Fig. S3B, S3D and S3F). These results demonstrate the potential of PredicTF in mapping regulatory elements in bacterial genomes and the use of this tool to map and compare TFs profiles after under different environmental conditions.

Mining and Predicting TFs in a Metagenome and Metatranscriptome using PredicTF

PredicTF was used to profile putative TFs in one metagenome recovered from an anaerobic ammonium oxidation community [19] followed by the mapping of the predicted TFs in metatranscriptomes recovered from the same community

347 (metatranscriptomes accession numbers can be found in Additional file 3: Table S2). A total of 792 TFs (Fig. 4A) were predicted in the LAC_MetaG_1, an anaerobic ammonium 
349 oxidizing microbial community from an anammox membrane bioreactor [19]. These 792

350 TFs are distributed across $27 \mathrm{TF}$ families (Fig. 4A) and are related to the regulation of

351 functions such as the oxygen limitation response and late symbiotic functions

352 (NarL/FixJ), phosphate regulon response (OmpR/PhoB), transcriptional activator for

353 nitrogen-regulated promoters (NtrC/DctD) and ferric uptake regulation (Fur). Next, the

354792 TFs were mapped in 11 metatranscriptomes collected in different dates from the same

355 bioreactor where the metagenome was recovered (Additional file 6: Table S3, Fig. 4B).

356 Clustering analysis demonstrated the presence of five different groups of TFs families

357 based on the number of transcription factor families expressed in each library (Fig. 4B).

358 It is interesting to note that the two most abundant clusters in the heatmap are directly

359 related to the oxygen limitation caused by the anaerobic ammonium oxidizing cultivation.

360 In a bioreactor where oxygen is limited, an increase in the amount of nitrogen and

361 phosphate is expected. The presence of these elements (Nitrogen and Phosphate) diverts

362 the metabolism of the microbial community towards the production of regulators (TFs)

363 that will help to maintain community stability. Clustering analyzes can be helpful to

364 demonstrate the similarity between metatranscriptomic libraries based on the occurrence

365 of TFs. This strategy can be useful to compare the profiles of TFs expressed in different

366 environmental situations (comparing libraries with different metadata) creating patterns

367 of TFs expression. Exploration of TF profiling in microbial communities (metagenomes

368 or metatranscriptomes) will allow the exploration of regulation within complex microbial

369 communities. Further, The recovery of metagenome assembled genomes is becoming

370 standard in metagenomics studies [25-27]. The use of PredicTF together with the

371 recovery of metagenome assembled genomes will allow the exploration of species-

372 specific molecular mechanisms involved in the regulation of different ecosystem

373 processes. 


\section{Conclusions}

A better understanding of TFs in a bacterial community context open revenues for

376 the exploration of gene regulation in ecosystems where bacteria play a key role. Our deep

377 learning strategy was based on a novel and robust TF bacterial database (BacTFDB) with

378 over 11 thousand TFs and their respective families. BacTFDB is a unique resource for

379 the exploration of TFs and it provided the data to train a model within PredicTF capable

380 of predicting novel TFs from genomes and metagenomes. PredicTF is the first pipeline

381 designed to predict and annotate TFs in complex microbial communities. The prediction

382 of TFs can provide information for those aiming to study and understand bacterial

383 communities within a context of gene regulation. We also demonstrated that PredicTF

384 can be used to predict novel TFs in metagenomes and metatrascriptomes creating the

385 potential profile for regulatory elements in complex microbial communities.

386 PredicTF is a flexible open source pipeline able to predict and annotate TFs in

387 genomes and metagenomes and can be found at https://github.com/mdsufz/PredicTF.

Ethics approval and consent to participate

$390 \quad$ Not applicable

Consent for publication

393 Not applicable 
400 LMOM were supported by FAPESP PhD (award \# 2016/19179-9) and FAPESP Research

401 Internship Scholarship Abroad (award \# 2018/21133-2). RSR was supported by FAPESP

402 (award \# 2019/15675-0). JS and UNR were supported by the Helmholtz Young 403 Investigator grant VH-NG-1248 Micro 'Big Data'.

404

405

Authors' contributions

406

LMOM, JS, PFS, RSR, and UNR developed the concept of PredicTF. LMOM, JS, UNR developed the PredicTF workflow. LMOM, JS, and UNR performed the benchmarks. LMOM provided information and data for the creation BacTFDB dataset. RBT and UNR perfformed the metagenome and metatranscriptome analysis. LMOM and UNR wrote the manuscript. All authors read and approved the manuscript.

411

\section{Availability of data and materials}

413 Genomes of the model organisms used in the Tool Validation step are available at the

414 National Center for Biotechnology Information (https://www.ncbi.nlm.nih.gov/) under

415 the accession numbers NC_000913.3, NC_000964.3, NC_011916.1, NC_021149.1, and

416 NC_016830. The datasets supporting the Prediction of Transcription Factors in a clinical

417 isolate of this article are available at National Center for Biotechnology Information

418 (https://www.ncbi.nlm.nih.gov/) under the accession number NC_002516.2 (genome)

419 and study accession PRJNA479711 (transcriptomes). The datasets used for the Prediction

420 of Transcription Factors in Complex Microbial Communities of this study are available 421 at National Center for Biotechnology Information (https:/www.ncbi.nlm.nih.gov/) under 422 the study accession PRJNA511011. The respective data sets of metatranscriptomes used 423 are available at National Center for Biotechnology Information 
424 (https://www.ncbi.nlm.nih.gov/) under the SRA numbers SRR7091385, SRR7523233,

425 SRR7523244, SRR7523245, SRR7091400, SRR7091401, SRR7091381, SRR7091402,

426 SRR7091406, SRR7523243, SRR7523246 and the Joint Genome Institute

427 (https://jgi.doe.gov/) under the Gold Analysis Project identifiers Gp0267156,

428 Gp0267150, Gp0267154, Gp0267155, Gp0267157, Gp0267158, Gp026715, Gp0267159,

429 Gp0267152, Gp0267153, Gp0267160. All analysis, results and scripts used to generate

430 figures are available at https://github.com/mdsufz/PredicTF.

431

432 Competing of interests

433 Not applicable

434

435 Availability and requirements

436 Project name: PredicTF

437 Project home page: https://github.com/mdsufz/PredicTF

438 Operating system: Linux64

439 Programming languages: Python 2.7

440 Other requirements: DIAMOND [28]; Nolearn Lasagne deep learning library [29];

441 Sklearn machine learning routines (https://scikit-learn.org/stable/) [30]; Theano

442 (http://deeplearning.net/software/theano/) $\quad$ [31]. Trim Galore $\quad$ - v0.0.4 dev

443 (https://www.bioinformatics.babraham.ac.uk/projects/trim galore/) [20]. MetaSPADES

444 - v3.12.0 (https://github.com/ablab/spades\#meta) [21]. Emboss transeq

445 (http://www.bioinformatics.nl/cgi-bin/emboss/transeq) [22]. Bowtie2 - v2.3.0

446 (https://sourceforge.net/projects/bowtie-bio/) [23]. $\quad$ SAMTools $\quad-\quad$ v1.9

447 (http://github.com/samtools/) [24].

448 
$450 \quad$ List of Abbreviations

451 Transcription Factors (TFs)

452 Bacterial Transcription Factor Data Base (BacTFDB)

453 Transcription factor binding sites (TFBSs)

454 anaerobic ammonium oxidizing (anammox)

455

456

457

458

459

460

461

462

463

464

465

466

467

468

469

470

471

472

473 
475 Figure legends:

$476 \quad$ Fig. 1

477

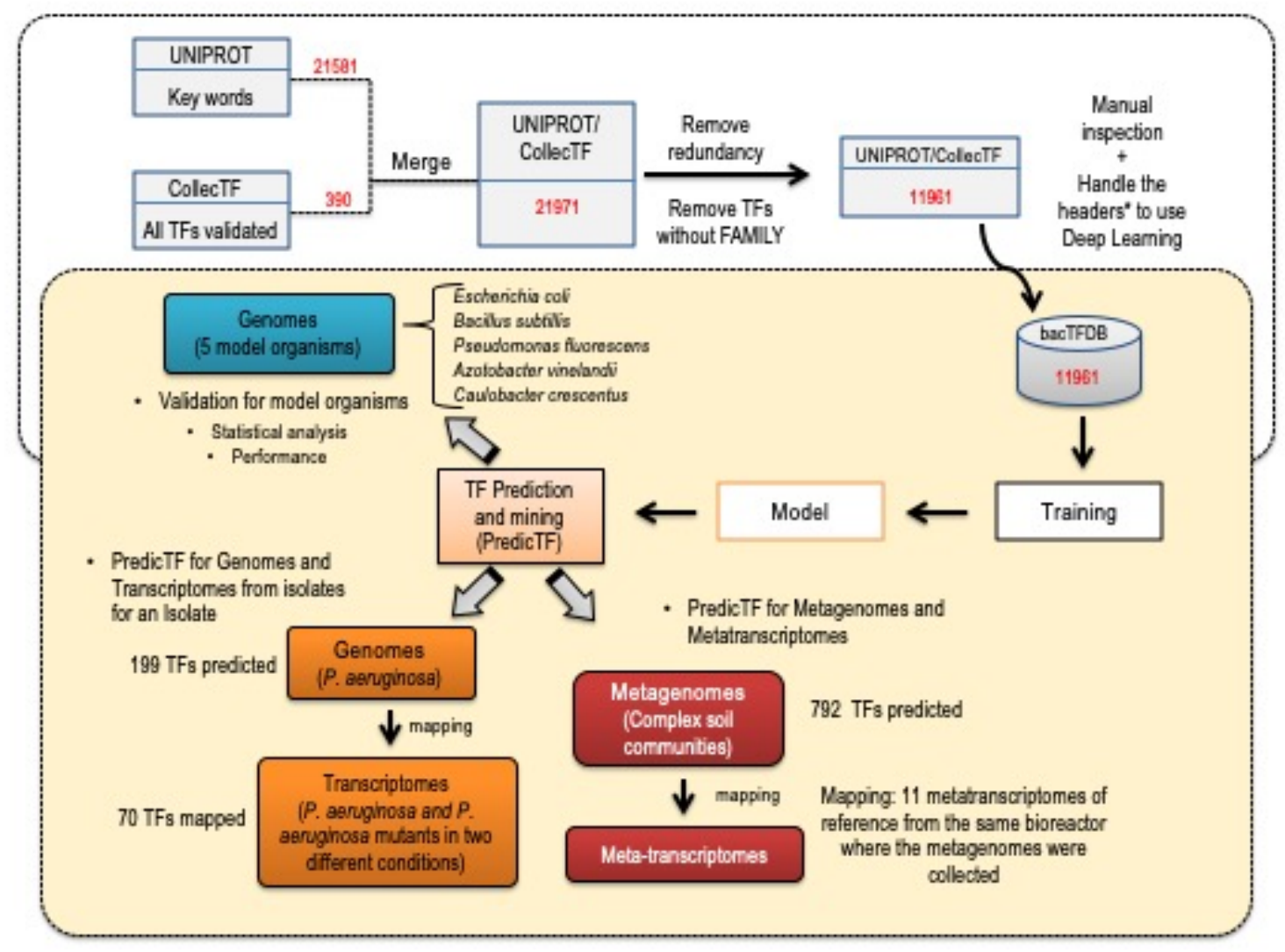

478 PredicTF workflow and testing. We collected publicly available data on TFs from two

479 different databases: CollecTF and UNIPROT. After removing redundancies and filtering

480 TFs well characterized, this data (BacTFDB) was used to train a deep learning model to

481 predict new TFs and their families. Five model organisms (Escherichia coli, Bacillus

482 subtillis, Pseudomonas fluorescens, Azotobacter vinelandii and Caulobacter crescentus)

483 were used to test the accuracy of PredicTF. Later, we used the same approach to predict

484 TFs from an insolate ( $P$. aeruginosa) and mapped TFs predicted in transcriptomics data

485 (P. aeruginosa and mutants in two experimental conditions). Finally, we used our tool to

486 predict TF for complex communities (metagenome) and mapped these TFs in their

487 respective meta-transcriptomes. 
489 Fig. 2

490

491

A

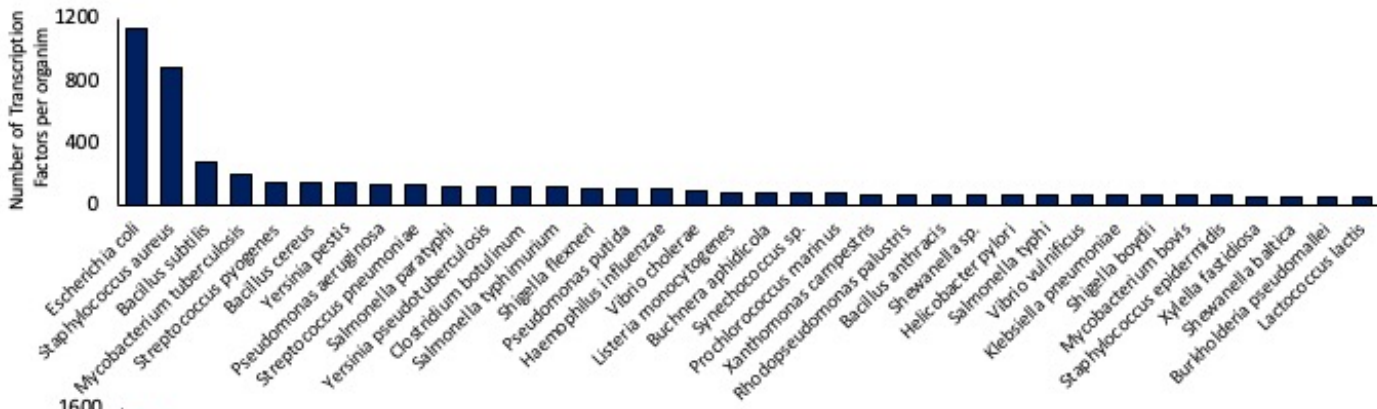

B

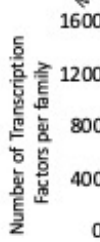
600 0 0 1

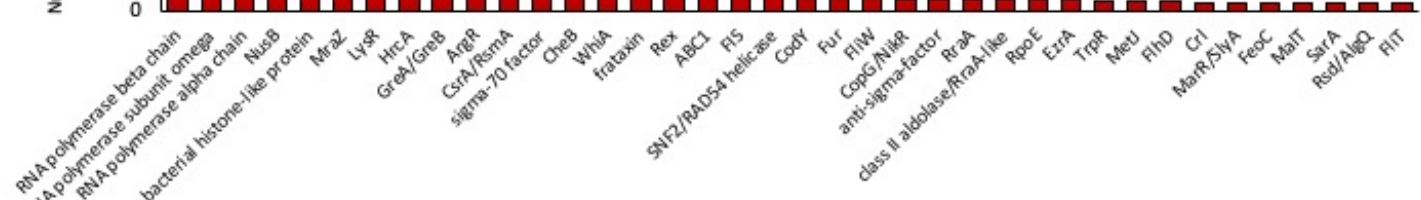

492

Database composition: Transcription Factor Database (BacTFDB) distribution. A)

493

Database distribution based on the TFs and

B) Regulatory Elements families and

494

Organisms species. In these graphics only families with up to 50 sequences and only

495 organisms that contributed with more than 50 sequences are shown.

496

497

498

499

500

501

502

503

504 
$506 \quad$ Fig. 3

507
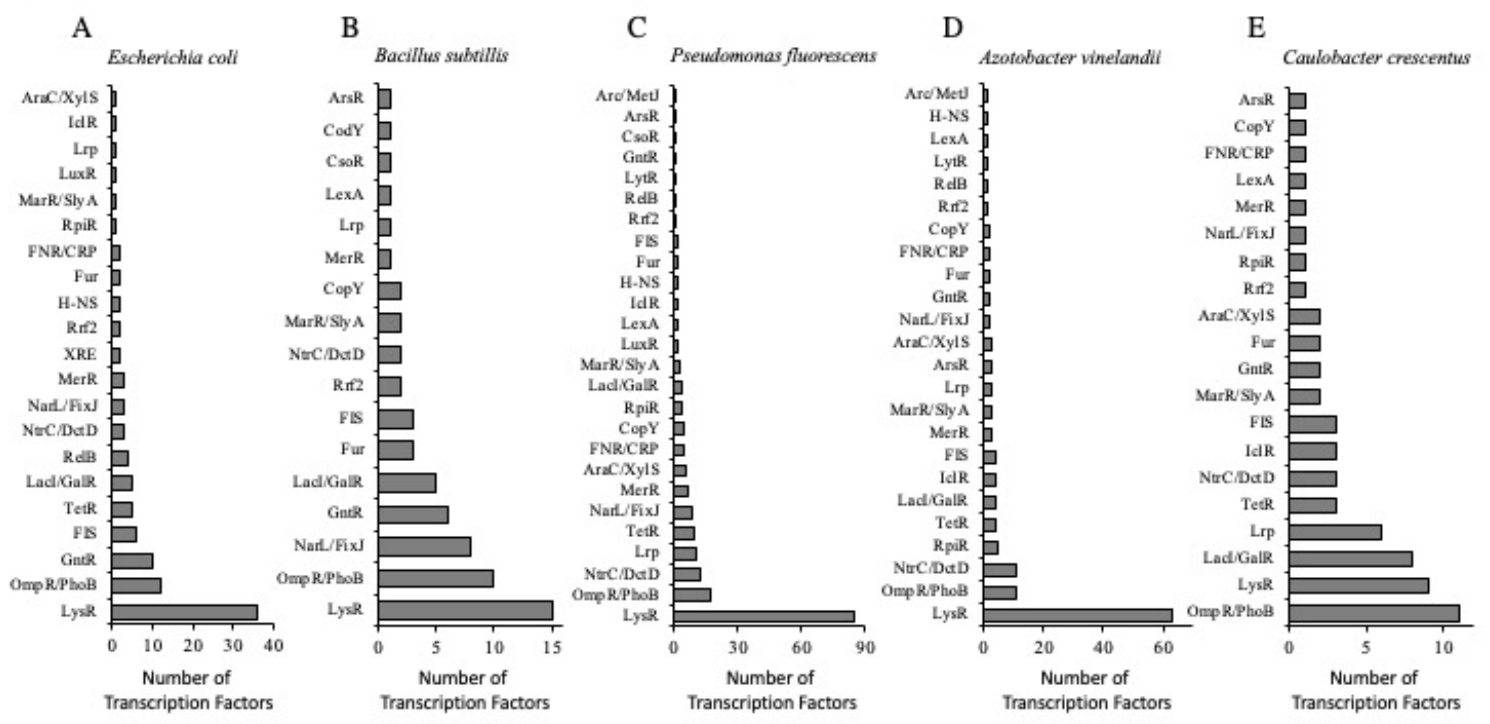

508 Prediction of TFs by PredicTF for genomes of model organisms. Prediction of TFs or

5095 model organisms sorted by family. A) Escherichia coli B) Bacillus subtillis

510 Caulobacter crescentus D) Pseudomonas fluorescens E) Azotobacter vinelandii 
$524 \quad$ Fig. 4

525
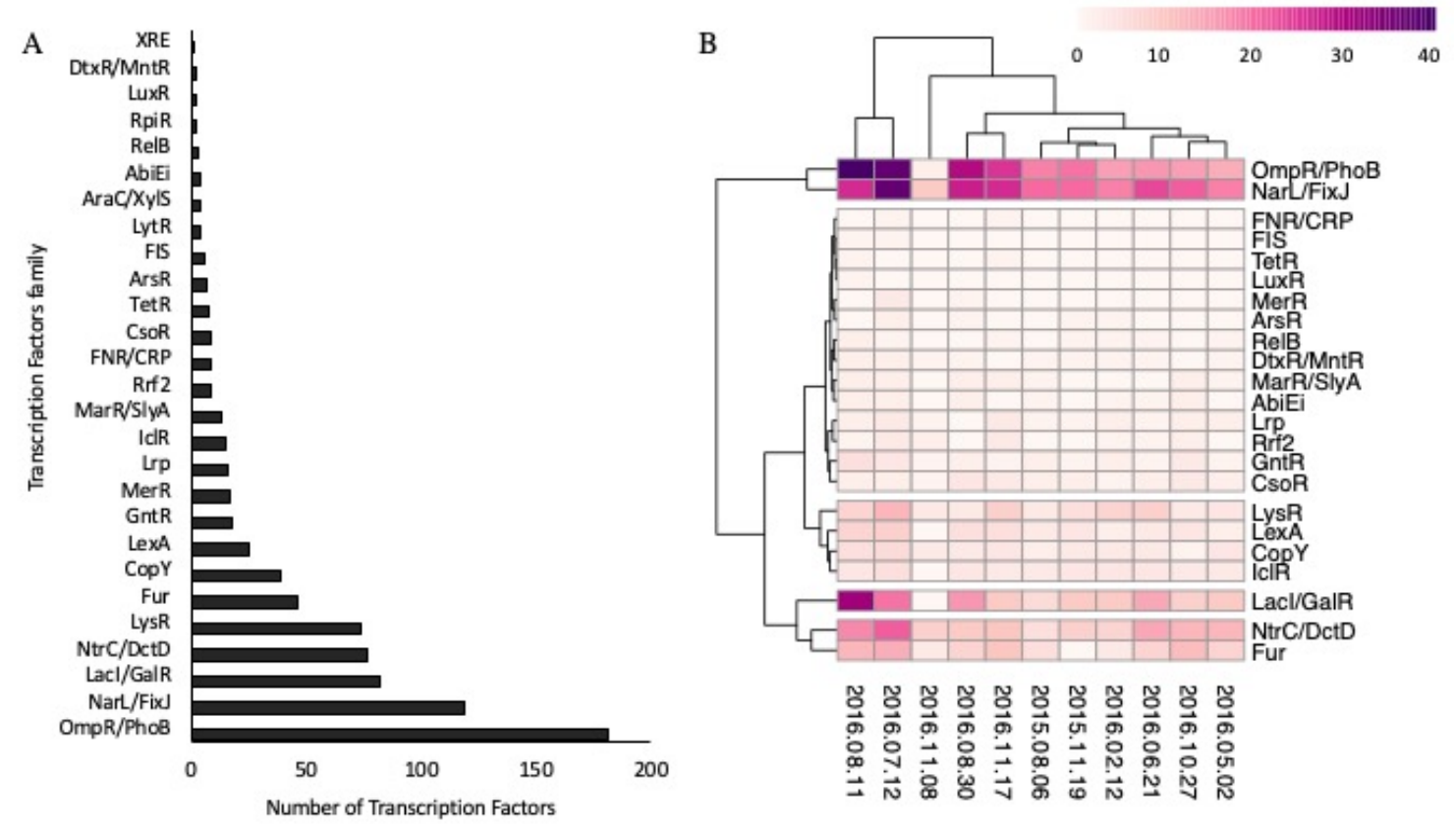

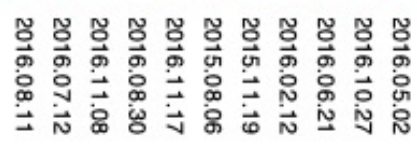

526 Recovery of novel Transcription Factors in one metagenome and eleven

527 metatranscriptomes. A) PredicTF predicted 792 TFs were predicted in one anaerobic

528 ammonium oxidizing microbial communities from anammox membrane bioreactor

529 (LAC_MetaG_1) and were grouped by family. B) Using 792 TFs predicted in one

530 metagenome, we mapped these TFs for 11 metatranscriptomes of reference from the same

531 bioreactor where the metagenome was recovered.

532

533

534

535

536

537

538 
$540 \quad$ Additional files

$541 \quad$ Additional file 1: Fig. S1

542 Bacterial Transcription Factor Data Base (BacTFDB) were created from from two 543 publicly available databases. We collect $390 \mathrm{TFs}$ from CollecTF and 21.581 from UniProt 544 (accessed 8-Sep-2019) accumulating 21.581 Transcription Factor (TF) amino acid sequences. We merged the data from CollecTF and UniProt databases resulting in a total of 21.971 TFs amino acid. We removed redundant TF entries and since PredicTF was

547 designed to also assign TF family, TF sequences lacking a TF family were removed.

548 Finally, a manual inspection was performed to remove misleading of spelling, case

549 sensitive and presence of characters associate to the database header. The final database 550 (BacTFDB) contains a total of $11.691 \mathrm{TF}$ unique sequences.

Additional file 2: Table S1

553 Description of the bacterial transcriptional factors database (BacTFDB) subsets used to train models to predict Trancription Factors in model organisms

Additional file 3: Table S2

557 Accession number for 5 model organisms, Pseudomonas aeruginosa PAO1 genome and 558 transcriptomes and Complex Microbial Communities used to validate and test PredicTF.

$560 \quad$ Additional file 4: Fig. S2

561 Transcription factor (TF) families predicted for Pseudomonas aeruginosa PAO1 genome 562 (accession number NC_002516.2) [18] using PredicTF and their mapping to $P$. 563 aeruginosa PAO1 growing in LB medium. A) A total of 199 TFs distributed in 25 TF 
564 families were predicted in the $P$. aeruginosa PAO1 genome. B) These 199 TFs were 565 mapped in the transcriptomic data of a reference of $P$. aeruginosa PAO1 (Bioproject 566 identifier PRJNA479711) [18]. Initially, the mapping was done in the transcriptome of $P$.

567 aeruginosa PAO1 cultured in LB media. Using this strategy, we were able to map 69 of 568 the 199 predicted TFs to the transcriptome.

569

$570 \quad$ Additional file 5: Fig. S3

571 Transcription Factor (TF) family profiles in three Pseudomonas aeruginosa PAO1 572 mutants. After the prediction of Transcription Factors (TFs) using P. aeruginosa PAO1 573 genome, we mapped transcriptomes from three $P$. aeruginosa PAO1 mutants (Y82, Y71, 574 Y89) cultured in LB media (A, C and F). After, the mapping was done for each $P$. 575 aeruginosa PAO1 mutant cultured in presence of antibiotic cocktail (B, D and E). $P$. aeruginosa PAO1 mutant Y82 (A, B); P. aeruginosa PAO1 mutant Y71 (C, D); P. aeruginosa PAO1 mutant Y89 (E, F).

578

$579 \quad$ Additional file 6: Table S3

580 Number of Transcription Factors (TFs) per TF family mapped to each of the 11

581 metatranscriptomes of reference from the same bioreactor where the metagenome 582 (accession number PRJNA511011, NCBI) used to predict the putative TFs was collected. 583 The different metatranscriptomes are represented by their European Nucleotide Archive 584 accession numbers. 


\section{References}

591 1. Liu J, Meng Z, Liu - Xiaoyue, Zhang X-H. Microbial assembly, interaction, 592 functioning, activity and diversification: a review derived from community compositional 593 data. Mar Life Sci Technol [Internet]. 2019 [cited 2020 Jul 20];1:112-28. Available from: 594 https://doi.org/10.1007/s42995-019-00004-3

595 2. Browning DF, Busby SJW. The regulation of bacterial transcription initiation. Nat Rev 596 Microbiol [Internet]. 2004;2:57-65. Available from: 597 http://www.ncbi.nlm.nih.gov/pubmed/15035009

598 3. Browning DF, Butala M, Busby SJW. Bacterial Transcription Factors: Regulation by 599 Pick “N” Mix. J. Mol. Biol. Academic Press; 2019. p. 4067-77.

600 4. Browning DF, Busby SJW. Local and global regulation of transcription initiation in 601 bacteria. Nat Rev Microbiol [Internet]. Nature Publishing Group; 2016;14:638-50. 602 Available from: http://www.nature.com/doifinder/10.1038/nrmicro.2016.103

603 5. Browning DF, Grainger DC, Busby SJ. Effects of nucleoid-associated proteins on 604 bacterial chromosome structure and gene expression. Curr Opin Microbiol. 2010;13:77360580.

606 6. Gama-Castro S, Salgado H, Santos-Zavaleta A, Ledezma-Tejeida D, Muñiz-Rascado 607 L, García-Sotelo JS, et al. RegulonDB version 9.0: high-level integration of gene 608 regulation, coexpression, motif clustering and beyond. Nucleic Acids Res. 609 2016;44:D133-43.

610 7. Sierro N, Makita Y, De hoon M, Nakai K. DBTBS: A database of transcriptional 611 regulation in Bacillus subtilis containing upstream intergenic conservation information. 612 Nucleic Acids Res [Internet]. 2008 [cited 2020 Jun 15];36. Available from: 613 https://academic.oup.com/nar/article-abstract/36/suppl_1/D93/2507686

614 8. Consortium F. FlyBase: a Drosophila database. Flybase Consortium. Nucleic Acids 615 Res [Internet]. 1998 [cited 2020 Jun 15];26:85-8. Available from: http://astorg.u616 strasbg.fr:7081/

617 9. Park J, Park J, Jang S, Kim S, Kong S, Choi J, et al. FTFD: An informatics pipeline 618 supporting phylogenomic analysis of fungal transcription factors. Bioinformatics. $619 \quad 2008 ; 24: 1024-5$.

620 10. Kummerfeld SK. DBD: a transcription factor prediction database. Nucleic Acids Res 621 [Internet]. 2006 [cited 2020 Jun 15];34:D74-81. Available from: 622 https://academic.oup.com/nar/article-abstract/34/suppl_1/D74/1133788

623 11. Widder S, Allen RJ, Pfeiffer T, Curtis TP, Wiuf C, Sloan WT, et al. Challenges in 624 microbial ecology: Building predictive understanding of community function and 625 dynamics [Internet]. ISME J. Springer Nature; 2016 [cited 2020 Jul 20]. p. 2557-68. 626 Available from: www.nature.com/ismej 
627 12. Alipanahi B, Delong A, Weirauch MT, Frey BJ. Predicting the sequence specificities 628 of DNA- and RNA-binding proteins by deep learning. Nat Biotechnol [Internet]. 2015 629 [cited 2020 Jun 15];33:831-8. Available from: http://tools.genes.toronto.edu/

630 13. Pan X, Shen H Bin. RNA-protein binding motifs mining with a new hybrid deep 631 learning based cross-domain knowledge integration approach. BMC Bioinformatics. 632 BioMed Central Ltd.; 2017;18.

633 14. Kiliç S, White ER, Sagitova DM, Cornish JP, Erill I. CollecTF: A database of 634 experimentally validated transcription factor-binding sites in Bacteria. Nucleic Acids Res 635 [Internet]. 2014 [cited 2020 Jun 15];42. Available from: 636 https://academic.oup.com/nar/article-abstract/42/D1/D156/1051934

637 15. UniProt Consortium T. UniProt: the universal protein knowledgebase. Nucleic Acids 638 Res [Internet]. 2018 [cited 2020 Jul 20];46:2699-2699. Available from: 639 https://academic.oup.com/nar/article-abstract/32/suppl_1/D115/2505378

640 16. Arango-Argoty G, Garner E, Pruden A, Heath LS, Vikesland P, Zhang L. DeepARG: 641 A deep learning approach for predicting antibiotic resistance genes from metagenomic 642 data. Microbiome. BioMed Central Ltd.; 2018;6.

643 17. Sørensen L, Loog M, Lo P, Ashraf H, Dirksen A, Duin RPW, et al. Image 644 dissimilarity-based quantification of lung disease from CT. Lect Notes Comput Sci 645 (including Subser Lect Notes Artif Intell Lect Notes Bioinformatics). 2010. p. 37-44.

646 18. Hwang W, Yoon SS. Virulence Characteristics and an Action Mode of Antibiotic 647 Resistance in Multidrug-Resistant Pseudomonas aeruginosa. Sci Rep [Internet]. 2019 648 [cited 2020 Jun 15];9. Available from: https:/www.nature.com/articles/s41598-018$649 \quad 37422-9$

650 19. Keren R, Lawrence JE, Zhuang W, Jenkins D, Banfield JF, Alvarez-Cohen L, et al. 651 Increased replication of dissimilatory nitrate-reducing bacteria leads to decreased 652 anammox bioreactor performance. Microbiome. BioMed Central Ltd.; 2020;8.

653 20. Krueger F. Babraham Bioinformatics - Trim Galore! [Internet]. Version 0.5.0. 2018 654 [cited 2020 Jul 29]. Available from: 655 https://www.bioinformatics.babraham.ac.uk/projects/trim_galore/

656 21. Nurk S, Meleshko D, Korobeynikov A, Pevzner PA. MetaSPAdes: A new versatile 657 metagenomic assembler. Genome Res [Internet]. 2017 [cited 2020 Jul 29];27:824-34. 658 Available from: http://www.genome.org/cgi/doi/10.1101/gr.213959.116.

659 22. Madeira F, Park YM, Lee J, Buso N, Gur T, Madhusoodanan N, et al. The EMBL660 EBI search and sequence analysis tools APIs in 2019. Nucleic Acids Res [Internet]. 2019 661 [cited $2020 \mathrm{Jul} 29] ; 47:$ W636-41. Available from: https://academic.oup.com/nar/article$662 \mathrm{abstract} / 47 / \mathrm{W} 1 / \mathrm{W} 636 / 5446251$

663 23. Langmead B, Salzberg SL. Fast gapped-read alignment with Bowtie 2. Nat Methods 664 [Internet]. 2012 [cited 2020 Jul 29];9:357-9. Available from: http://bowtie665 bio.sourceforge.net/bowtie2/index.shtml. 
666 24. Li H, Handsaker B, Wysoker A, Fennell T, Ruan J, Homer N, et al. The Sequence 667 Alignment/Map format and SAMtools. Bioinformatics [Internet]. 2009 [cited $2020 \mathrm{Jul}$ 668 29];25:2078-9. Available from: https://academic.oup.com/bioinformatics/article669 abstract/25/16/2078/204688

670 25. Parks DH, Rinke C, Chuvochina M, Chaumeil PA, Woodcroft BJ, Evans PN, et al. 671 Recovery of nearly 8,000 metagenome-assembled genomes substantially expands the tree 672 of life. Nat Microbiol [Internet]. 2017 [cited 2020 Jul 29];2:1533-42. Available from: 673 https://www.nature.com/articles/s41564-017-0012-7/

674 26. Pasolli E, Asnicar F, Manara S, Zolfo M, Karcher N, Armanini F, et al. Extensive 675 Unexplored Human Microbiome Diversity Revealed by Over 150,000 Genomes from 676 Metagenomes Spanning Age, Geography, and Lifestyle. Cell [Internet]. 2019 [cited 2020 677 Jul 29];176:649-662.e20. Available from: $678 \mathrm{https}: / / \mathrm{www} . \mathrm{sciencedirect.com/science/article/pii/S0092867419300017}$

679 27. Tully BJ, Graham ED, Heidelberg JF. The reconstruction of 2,631 draft metagenome680 assembled genomes from the global oceans. Sci Data [Internet]. 2018 [cited 2020 Jul 681 29];5. Available from: https://www.nature.com/articles/sdata2017203

682 28. Buchfink B, Xie C, Huson DH. Fast and sensitive protein alignment using 683 DIAMOND. Nat. Methods. Nature Publishing Group; 2014. p. 59-60.

684 29. van Merriënboer B, Bahdanau D, Dumoulin V, Serdyuk D, Warde-Farley D, 685 Chorowski J, et al. Blocks and Fuel: Frameworks for deep learning. arxiv.org [Internet]. 6862015 [cited 2020 Jun 15]; Available from: https://arxiv.org/abs/1506.00619

687 30. Pedregosa FABIANPEDREGOSA F, Michel V, Grisel OLIVIERGRISEL O, Blondel 688 M, Prettenhofer P, Weiss R, et al. Scikit-learn: Machine Learning in Python Gaël 689 Varoquaux Bertrand Thirion Vincent Dubourg Alexandre Passos PEDREGOSA, 690 VAROQUAUX, GRAMFORT ET AL. Matthieu Perrot [Internet]. J. Mach. Learn. Res. 691 2011. Available from: http://scikit-learn.sourceforge.net.

692 31. The Theano Development Team, Al-Rfou R, Alain G, Almahairi A, Angermueller C, 693 Bahdanau D, et al. Theano: A Python framework for fast computation of mathematical 694 expressions. 2016 [cited 2020 Jun 15]; Available from: 695 https://groups.google.com/group/theano-dev/ 
IV. GENERAL CONCLUSIONS 
- In charpters I and II we demonstrate the existence of emergent properties in complex synthetic promoters in E. coli, which could be extrapolated to naturally occurring regulatory systems and would significantly impact the engineering of synthetic biological circuits in bacteria. Additionally, our results demonstrated in a systematic way that the arrangement and number of these cis-regulatory elements are crucial for the final expression dynamics of the target promoters. Taken together, these data presented here demonstrate how small changes in the architecture of bacterial promoters could result in drastic changes in the final regulatory logic of the system, with important implications for the understanding of natural complex promoters in bacteria and their engineering for novel applications. Our findings also present a comprehensive strategy for fine-tuning gene circuits to perform optimally in a given context (e.g., engineering of synthetic promoters) as well as provide insights for the understanding of natural complex promoters controlled by global regulators.

- In charpter III a collection of engineered transcription factors was generated with enhanced response to a well characterized and largely innocuous molecule with a potential for eliciting heterologous expression of bacterial genes in animal carriers. These results demonstrate the expansion of the genetic toolbox for the engineering of synthetic circuits inducible by safe chemical compounds.

- In charpter IV we provide a deep learning strategy based on a novel and robust TF bacterial database (BacTFDB). BacTFDB is a unique resource for the exploration of TFs and it provides the data to train a model within PredicTF capable of predicting novel TFs from genomes and metagenomes. PredicTF is the first pipeline designed to predict and annotate TFs in complex microbial communities. We also demonstrated that PredicTF can be used to 
predict novel TFs in metagenomes and metatrascriptomes creating the potential profile for regulatory elements in complex microbial communities. 


\section{ADDITIONAL INFORMATION}




\section{Articles published in journals (related to this thisis)}

- MONTEIRO, Lummy Maria Oliveira; ARRUDA, Leticia Magalhaes; SILVA-ROCHA, Rafael. Emergent properties in complex synthetic bacterial promoters. ACS synthetic biology, v. 7, n. 2, p. 602-612, 2018.

https://doi.org/10.1021/acssynbio.7b00344

- MONTEIRO, Lummy Maria Oliveira; SANCHES-MEDEIROS, Ananda; WESTMANN, Caua Antunes; \& SILVA-ROCHA, Rafael. Modulating Fis and IHF binding specificity, crosstalk and regulatory logic through the engineering of complex promoters. bioRxiv, p. 614396, 2019. https://doi.org/10.1101/614396

- MONTEIRO, Lummy Maria Oliveira; ARRUDA, Letícia Magalhaes; SANCHES-MEDEIROS, Ananda; MARTINS-SANTANA, Leonardo; ALVES, Luana de Fátima; DEFELIPE, Lucas; TURJANSKI, Adrian Gustavo; GUAZZARONI, María-Eugenia \& SILVA-ROCHA, Rafael. Reverse engineering of an aspirin-responsive transcriptional regulator in Escherichia coli. ACS synthetic biology, v. 8, n. 8, p. 1890-1900, 2019.

https://doi.org/10.1021/acssynbio.9b00191

\section{Submitted}

- MONTEIRO, Lummy Maria Oliveira; SARAIVA, João; TOSCAN, Rodolfo Brizola; STADLER, Peter; SILVA-ROCHA, Rafael; da ROCHA, Ulisses Nunes. PredicTF: a tool to predict bacterial transcription factors in complex microbial communities. (Submitted)

\section{Articles published in journals (Not related to this thesis)}

- SANCHES-MEDEIROS, Ananda; MONTEIRO, Lummy Maria Oliveira; SILVA-ROCHA, Rafael. Calibrating transcriptional activity using constitutive synthetic promoters in mutants for global regulators in Escherichia coli. International journal of genomics, v. 2018, 2018. https://doi.org/10.1155/2018/9235605

- ARRUDA, Letícia Magalhaes; MONTEIRO, Lummy Maria Oliveira; SILVA-ROCHA, Rafael. The Chromobacterium violaceum ArsR arsenite repressor exerts tighter control on its cognate promoter than the Escherichia coli system. Frontiers in microbiology, v. 7, p. 1851, 2016. https://doi.org/10.3389/fmicb.2016.01851

- NORA, Luísa Czamanski, WESTMANN, Caua Antunes, MARTINS-SANTANA, Leonardo; ALVES, Luana de Fátima; MONTEIRO, Lummy Maria Oliveira; GUAZZARONI, Maria Eugenia; SILVA-ROCHA, Rafael. The art of vector engineering: towards the construction of next-generation genetic tools. Microbial biotechnology, v. 12, n. 1, p. 125-147, 2019.

https://doi.org/10.1111/1751-7915.13318 


\section{Submitted}

- TLÁSKAL, Vojtěch; BRABCOVÁ, Vendula; VĚTROVSKÝ, Tomáš; JOMURA, Mayuko; LÓPEZ-MONDÉJAR, Rubén; MONTEIRO, Lummy Maria Oliveira; SARAIVA, João Pedro; HUMAN, Zander Rainier; CAJTHAML, Tomáš; DA ROCHA, Ulisses Nunes; BALDRIAN, Petr. Cross-domain cooperation between bacteria and fungi mediates wood decomposition. (Submitted) 


\section{ATTACHMENTS}




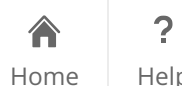

Help

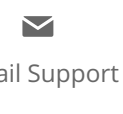

은

Sign in $\stackrel{+}{2}$

Create Account

\begin{tabular}{|c|c|}
\hline \multirow{6}{*}{ स. ACSPublications } & Emergent Properties in Complex Synthetic Bacterial Promoters \\
\hline & $\begin{array}{l}\text { Author: } \\
\text { Lummy Maria Oliveira Monteiro, Letícia Magalhães Arruda, Rafael Silva-Rocha }\end{array}$ \\
\hline & Publication: ACS Synthetic Biology \\
\hline & Publisher: American Chemical Society \\
\hline & Date: Feb 1, 2018 \\
\hline & Copyright @ 2018, American Chemical Society \\
\hline
\end{tabular}

\section{PERMISSION/LICENSE IS GRANTED FOR YOUR ORDER AT NO CHARGE}

This type of permission/license, instead of the standard Terms \& Conditions, is sent to you because no fee is being charged for your order. Please note the following:

- Permission is granted for your request in both print and electronic formats, and translations.

- If figures and/or tables were requested, they may be adapted or used in part.

- Please print this page for your records and send a copy of it to your publisher/graduate school.

- Appropriate credit for the requested material should be given as follows: "Reprinted (adapted) with permission from (COMPLETE REFERENCE CITATION). Copyright (YEAR) American Chemical Society." Insert appropriate information in place of the capitalized words.

- One-time permission is granted only for the use specified in your request. No additional uses are granted (such as derivative works or other editions). For any other uses, please submit a new request.

BACK

(c) 2020 Copyright - All Rights Reserved | Copyright Clearance Center, Inc. | Privacy statement | Terms and Conditions Comments? We would like to hear from you. E-mail us at customercare@copyright.com 
ก?

Home
$?$ $\checkmark$

Email Support
2

Sign in

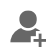

Create Account

\begin{tabular}{|l} 
Reverse Engineering of an Aspirin-Responsive Transcriptional \\
Regulator in Escherichia coli \\
Author: \\
Lummy Maria Oliveira Monteiro, Letícia Magalhães Arruda, Ananda Sanches- \\
ACSPublications \\
Mest Trusted. Most cited. Most Read. \\
Publication: ACS Synthetic Biology \\
Publisher: American Chemical Society \\
Date: Aug 1, 2019 \\
Copyright $\odot$ 2019, American Chemical Society \\
\end{tabular}

\section{PERMISSION/LICENSE IS GRANTED FOR YOUR ORDER AT NO CHARGE}

This type of permission/license, instead of the standard Terms \& Conditions, is sent to you because no fee is being charged for your order. Please note the following:

- Permission is granted for your request in both print and electronic formats, and translations.

- If figures and/or tables were requested, they may be adapted or used in part.

- Please print this page for your records and send a copy of it to your publisher/graduate school.

- Appropriate credit for the requested material should be given as follows: "Reprinted (adapted) with permission from (COMPLETE REFERENCE CITATION). Copyright (YEAR) American Chemical Society." Insert appropriate information in place of the capitalized words.

- One-time permission is granted only for the use specified in your request. No additional uses are granted (such as derivative works or other editions). For any other uses, please submit a new request. 


\section{REFERENCES}


Andrianantoandro, E., Basu, S., Karig, D. K., and Weiss, R. (2006). Synthetic biology: New engineering rules for an emerging discipline. Mol. Syst. Biol. 2. doi:10.1038/msb4100073.

Barnard, A., Wolfe, A., and Busby, S. (2004). Regulation at complex bacterial promoters: How bacteria use different promoter organizations to produce different regulatory outcomes. Curr. Opin. Microbiol. 7, 102-108. doi:10.1016/j.mib.2004.02.011.

Barne, S. L., Belliveau, N. M., Ireland, W. T., Kinney, J. B., and Phillips, R. (2019). Mapping DNA sequence to transcription factor binding energy in vivo. PLoS Comput. Biol. 15. doi:10.1371/journal.pcbi.1006226.

Benner, S. A., and Sismour, A. M. (2005). Synthetic biology. Nat. Rev. Genet. 6, 533-543. doi:10.1038/nrg1637.

Bintu, L., Buchler, N. E., Garcia, H. G., Gerland, U., Hwa, T., Kondev, J., et al. (2005a). Transcriptional regulation by the numbers: Applications. Curr. Opin. Genet. Dev. 15, 125135. doi:10.1016/j.gde.2005.02.006.

Bintu, L., Buchler, N. E., Garcia, H. G., Gerland, U., Hwa, T., Kondev, J., et al. (2005b). Transcriptional regulation by the numbers: models. Curr. Opin. Genet. Dev. 15, 116-124. doi:10.1016/j.gde.2005.02.007.

Brown, N. L., Stoyanov, J. V., Kidd, S. P., and Hobman, J. L. (2003). The MerR family of transcriptional regulators. FEMS Microbiol. Rev. 27, 145-163. doi:10.1016/S01686445(03)00051-2.

Browning, D. F., and Busby, S. J. W. (2004). The regulation of bacterial transcription initiation. Nat. Rev. Microbiol. 2, 57-65. doi:10.1038/nrmicro787.

Browning, D. F., and Busby, S. J. W. (2016). Local and global regulation of transcription initiation in bacteria. Nat. Rev. Microbiol. 14, 638-650. doi:10.1038/nrmicro.2016.103.

Browning, D. F., Butala, M., and Busby, S. J. W. (2019). Bacterial Transcription Factors: Regulation by Pick “N” Mix. J. Mol. Biol. 431, 4067-4077. doi:10.1016/j.jmb.2019.04.011.

Busby, S., and Ebright, R. H. (1994). Promoter structure, promoter recognition, and transcription activation in prokaryotes. Cell 79, 743-746. doi:10.1016/0092-8674(94)90063-9.

Cameron, D. E., Bashor, C. J., and Collins, J. J. (2014). A brief history of synthetic biology. Nat. Rev. Microbiol. 12, 381-390. doi:10.1038/nrmicro3239.

Carbonell, P., Currin, A., Jervis, A. J., Rattray, N. J. W., Swainston, N., Yan, C., et al. (2016). Bioinformatics for the synthetic biology of natural products: Integrating across the DesignBuild-Test cycle. Nat. Prod. Rep. 33, 925-932. doi:10.1039/c6np00018e.

Cases, I., De Lorenzo, V., and Ouzounis, C. A. (2003). Transcription regulation and environmental adaptation in bacteria. Trends Microbiol. 11, 248-253. doi:10.1016/S0966842X(03)00103-3.

Chen, Y., Ho, J. M. L., Shis, D. L., Gupta, C., Long, J., Wagner, D. S., et al. (2018). Tuning the dynamic range of bacterial promoters regulated by ligand-inducible transcription factors. Nat. Commun. 9, 1-8. doi:10.1038/s41467-017-02473-5.

Deplazes-Zemp, A. (2012). The Conception of Life in Synthetic Biology. Sci. Eng. Ethics 18, 757774. doi:10.1007/s11948-011-9269-z.

Elowitz, M., and Lim, W. A. (2010). Build life to understand it. Nature 468, 889-890. doi:10.1038/468889a.

Gama-Castro, S., Salgado, H., Santos-Zavaleta, A., Ledezma-Tejeida, D., Muñiz-Rascado, L., 
García-Sotelo, J. S., et al. (2016). RegulonDB version 9.0: high-level integration of gene regulation, coexpression, motif clustering and beyond. Nucleic Acids Res. 44, D133-D143. doi:10.1093/nar/gkv1156.

Hunziker, A., Tuboly, C., Horváth, P., Krishna, S., and Semsey, S. (2010). Genetic flexibility of regulatory networks. Proc. Natl. Acad. Sci. U. S. A. 107, 12998-3003. doi:10.1073/pnas.0915003107.

Huo, Y. X., Zhang, Y. T., Xiao, Y., Zhang, X., Buck, M., Kolb, A., et al. (2009). IHF-binding sites inhibit DNA loop formation and transcription initiation. Nucleic Acids Res. 37, 3878-3886. doi:10.1093/nar/gkp258.

Hyeon, J. E., Shin, S. K., and Han, S. O. (2016a). Design of nanoscale enzyme complexes based on various scaffolding materials for biomass conversion and immobilization. Biotechnol. J. 11, 1386-1396. doi:10.1002/biot.201600039.

Hyeon, J. E., Shin, S. K., and Han, S. O. (2016b). Design of nanoscale enzyme complexes based on various scaffolding materials for biomass conversion and immobilization. Biotechnol. J. 11, 1386-1396. doi:10.1002/biot.201600039.

Ishihama, A. (2010). Prokaryotic genome regulation: Multifactor promoters, multitarget regulators and hierarchic networks. FEMS Microbiol. Rev. 34, 628-645. doi:10.1111/j.15746976.2010.00227.x.

Khalil, A. S., and Collins, J. J. (2010). Synthetic biology: Applications come of age. Nat. Rev. Genet. 11, 367-379. doi:10.1038/nrg2775.

Konstantinidis, K. T., and Tiedje, J. M. (2004). Trends between gene content and genome size in prokaryotic species with larger genomes. Available at: www.pnas.orgcgidoi10.1073pnas.0308653100 [Accessed August 18, 2020].

Koonin, E. V., and Wolf, Y. I. (2008). Genomics of bacteria and archaea: The emerging dynamic view of the prokaryotic world. Nucleic Acids Res. 36, 6688-6719. doi:10.1093/nar/gkn668.

Lawrence, J. (1999). Selfish operons: The evolutionary impact of gene clustering in prokaryotes and eukaryotes. Curr. Opin. Genet. Dev. 9, 642-648. doi:10.1016/S0959-437X(99)00025-8.

Lee, D. J., Minchin, S. D., and Busby, S. J. W. (2012). Activating Transcription in Bacteria. Annu. Rev. Microbiol. 66, 125-152. doi:10.1146/annurev-micro-092611-150012.

Liu, H., and Chen, Q. (2016). Computational protein design for given backbone: Recent progresses in general method-related aspects. Curr. Opin. Struct. Biol. 39, 89-95. doi:10.1016/j.sbi.2016.06.013.

Liu, J., Meng, Z., Liu, · Xiaoyue, and Zhang, X.-H. (2019). Microbial assembly, interaction, functioning, activity and diversification: a review derived from community compositional data. Mar. Life Sci. Technol. 1, 112-128. doi:10.1007/s42995-019-00004-3.

Martínez-Antonio, A., Collado-Vides, J., Balleza, E., López-Bojorquez, L. N., Martínez-Antonio, A., Resendis-Antonio, O., et al. (2003). Identifying global regulators in transcriptional regulatory networks in bacteria. Curr. Opin. Microbiol. 33, 482-489. doi:10.1016/j.mib.2003.09.002.

Monteiro, L. M. O., Arruda, L. M., Sanches-Medeiros, A., Martins-Santana, L., Alves, L. D. F., Defelipe, L., et al. (2019). Reverse Engineering of an Aspirin-Responsive Transcriptional Regulator in Escherichia coli. ACS Synth. Biol. doi:10.1021/acssynbio.9b00191.

Monteiro, L. M. O., Arruda, L. M., and Silva-Rocha, R. (2018). Emergent Properties in Complex Synthetic Bacterial Promoters. ACS Synth. Biol. 7, 602-612. 
doi:10.1021/acssynbio.7b00344.

Monteiro, L. M. O., Sanches-Medeiros, A., Westmann, C. A., and Silva-Rocha, R. (2020). Unraveling the Complex Interplay of Fis and IHF Through Synthetic Promoter Engineering. Front. Bioeng. Biotechnol. 8. doi:10.3389/fbioe.2020.00510.

Noda, S., Shirai, T., Oyama, S., and Kondo, A. (2016). Metabolic design of a platform Escherichia coli strain producing various chorismate derivatives. Metab. Eng. 33, 119-129. doi:10.1016/j.ymben.2015.11.007.

Sambrook, J., Fritsch, E., and Maniatis, T. (1989). Molecular cloning: a laboratory manual. Available at: https://www.cabdirect.org/cabdirect/abstract/19901616061 [Accessed April 2, 2020].

Sanches-Medeiros, A., Monteiro, L. M. O., and Silva-Rocha, R. (2018). Calibrating transcriptional activity using constitutive synthetic promoters in mutants for global regulators in Escherichia coli. Int. J. Genomics 2018. doi:10.1155/2018/9235605.

Shimada, T., Fujita, N., Yamamoto, K., and Ishihama, A. (2011a). Novel roles of camp receptor protein (CRP) in regulation of transport and metabolism of carbon sources. PLoS One 6. doi:10.1371/journal.pone.0020081.

Shimada, T., Yamamoto, K., and Ishihama, A. (2011b). Novel Members of the Cra Regulon Involved in Carbon Metabolism in Escherichia coli †. J. Bacteriol. 193, 649-659. doi:10.1128/JB.01214-10.

Silva-Rocha, R., and De Lorenzo, V. (2010). Noise and robustness in prokaryotic regulatory networks. Annu. Rev. Microbiol. 64, 257-275. doi:10.1146/annurev.micro.091208.073229.

Silva-Rocha, R., and De Lorenzo, V. (2011). Implementing an OR-NOT (ORN) logic gate with components of the SOS regulatory network of Escherichia coli. Mol. Biosyst. 7, 2389-2396. doi:10.1039/c1mb05094j.

Singleton, P. (2009). Dictionary of DNA and Genome Technology. John Wiley \& Sons, Ltd doi:10.1002/9780470689127.

Siu, Y., Fenno, J., Lindle, J. M., and Dunlop, M. J. (2017). Design and Selection of a Synthetic Feedback Loop for Optimizing Biofuel Tolerance. ACS Publ. 7, 16-23. doi:10.1021/acssynbio.7b00260.

Tamsir, A., Tabor, J. J., and Voigt, C. A. (2011). Robust multicellular computing using genetically encoded NOR gates and chemical "wires". Nature 469, 212-5. doi:10.1038/nature09565.

Wang, B., Kitney, R. I., Joly, N., and Buck, M. (2011). Engineering modular and orthogonal genetic logic gates for robust digital-like synthetic biology. Nat. Commun. 2, 1-9. doi:10.1038/ncomms1516.

Wang, J., Cao, H., Zhang, J. Z. H., and Qi, Y. (2018). Computational Protein Design with Deep Learning Neural Networks. Sci. Rep. 8. doi:10.1038/s41598-018-24760-x.

Way, J. C., Collins, J. J., Keasling, J. D., and Silver, P. A. (2014). Integrating biological redesign: Where synthetic biology came from and where it needs to go. Cell 157, 151-161. doi:10.1016/j.cell.2014.02.039.

Widder, S., Allen, R. J., Pfeiffer, T., Curtis, T. P., Wiuf, C., Sloan, W. T., et al. (2016). Challenges in microbial ecology: Building predictive understanding of community function and dynamics. ISME J. 10, 2557-2568. doi:10.1038/ismej.2016.45.

Yang, Y., Darbari, V. C., Zhang, N., Lu, D., Glyde, R., Wang, Y. P., et al. (2015). Structures of the RNA polymerase- $\sigma 54$ reveal new and conserved regulatory strategies. Science (80-. ). 349, 
882-885. doi:10.1126/science.aab1478.

Zhang, F., and Voytas, D. F. (2018). Synthetic genomes engineered by SCRaMbLEing. Sci. China Life Sci. 61, 975-977. doi:10.1007/s11427-018-9325-1.

Zhang, W., Mitchell, L. A., Bader, J. S., and Boeke, J. D. (2020). Synthetic Genomes. Annu. Rev. Biochem. 89, 77-101. doi:10.1146/annurev-biochem-013118-110704. 